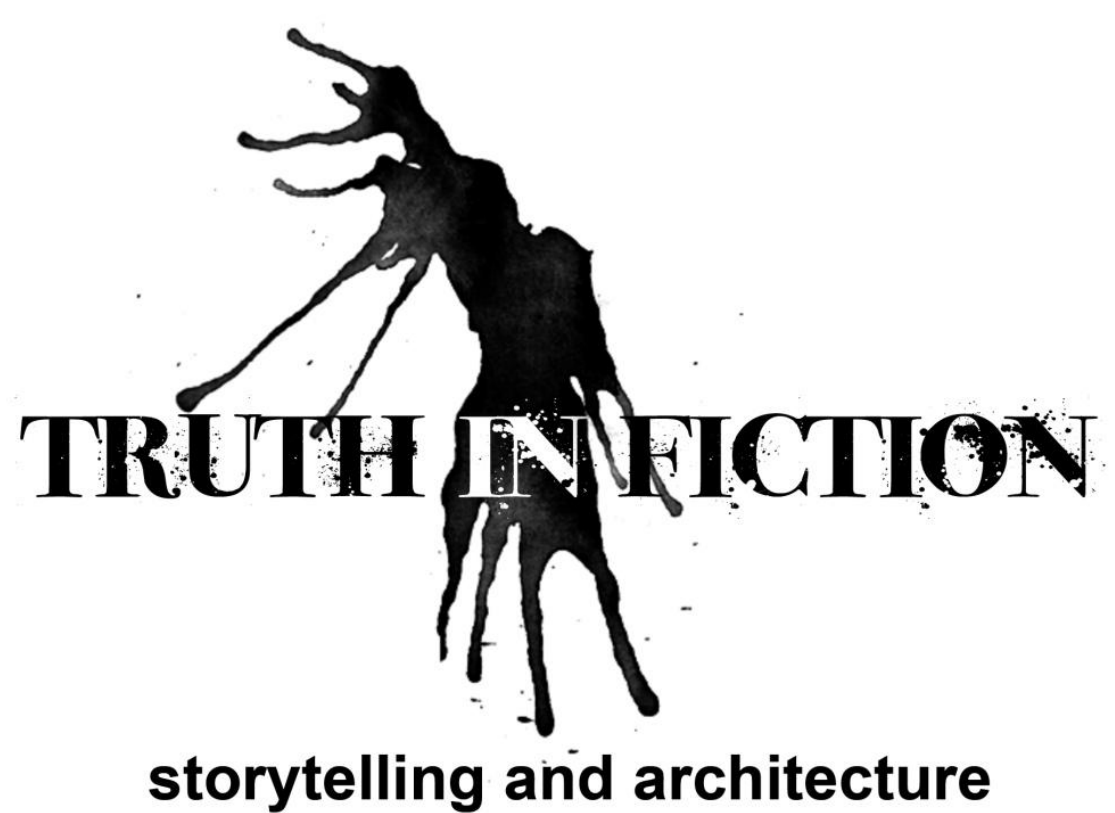

Submitted in partial fulfilment of the Master of Architecture (Professional)

Victoria University of Wellington, School of Architecture. 



\section{ABSTRACT}

Current discourse on architectural narrative suggests that a series of events or impressions of space can be 'read' through a sequencing of spaces and views within a building. It is presumed that a building is read in the same way as a sequence of shots in a film. In this model, architects set up a narrative which is played out through a careful construction of viewpoints and events. In practice this can lead to the manipulation of spatial experience at the sacrifice of individual interpretation, as maintaining the narrative compromises spatial experience. This stems from the fundamental difference between how we experience architecture as opposed to more traditional narratives in printed or pictorial media. The experience of space is not a linear one, nor is it bound by a strict timeline which follows from cause to effect. Unlike a novel, where the author has complete control over the pacing and focus of each scene, the architect cannot rely on others to interpret his exact intentions, or on his architecture remaining true to a single narrative over time.

This research is about storytelling in architecture. Specifically, how we might better use narratives to play to the strengths of our medium. From examining current practices in publicly establishing narratives, to investigating the work of John Hejduk, this work examines how architectural narratives have been constructed in the past, and whether this has been successful. Using an analysis of three works of fiction: The Library of Babel by Jorge Luis Borges, The Castle by Franz Kafka and The House of Leaves by Mark Z Danielewski; I analyse the various uses of the architectural metaphor in fiction and how these fictional spaces have been used as characters within their individual narratives.

I use design to develop a process which takes a basic house plan and applies a non-linear narrative to it. This narrative is not concerned with a single interpretation. This process creates spaces imbued with the stories of the novels studied, and of my role as designer. Yet they may also be reinterpreted again by a new viewer to give a kind of immortality to the story. The architecture continually adapts itself to new experiences and understandings.

Finally, I argue that we do have the ability to use storytelling within architecture to enrich our spaces without resorting to the manipulation of the user. If we return to the cyclic and layered model of storytelling, as opposed to the linear structure of narrative, then our buildings will not only tell our stories more clearly, but also for longer as they appeal to the changing fashions, experiences and applied narratives of the people who use them, remaining relevant to the world of experience. 


\section{ACKNOWIEDGEMENTS}

I would like to thank:

my supervisor, Dr Peter Wood, for his support, encouragement and advice throughout the year.

the academic staff and support networks at Victoria University Faculty of

Architecture for the opportunity and necessary assistance to carry out this

research.

Kellie Kernohan and Elizabeth Devine for their assistance in editing the final document.

my family, friends and cohort for all their support and encouragement.

Thank you for all your help,

Lee. 


\title{
TABIE OF CONTENTS
}

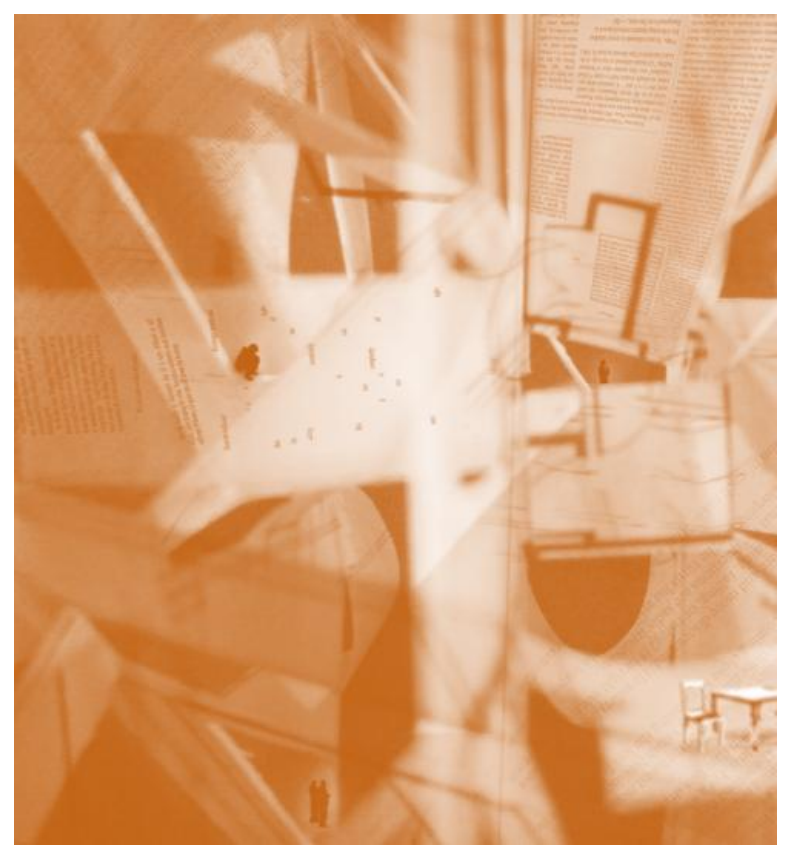

\author{
i Abstract \\ ii \\ iii

\section{Acknowledgements} \\ Table of Contents \\ Table of Figures \\ Introduction

\section{Chapter One: Storytelling} \\ Storytelling and Narrative \\ Theory of Mind \\ The Author, the Context and the Audience \\ Author \\ Context \\ Audience \\ Architectural Context \\ Show not Tell: A Lesson for Architects
}

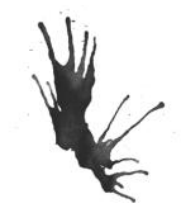




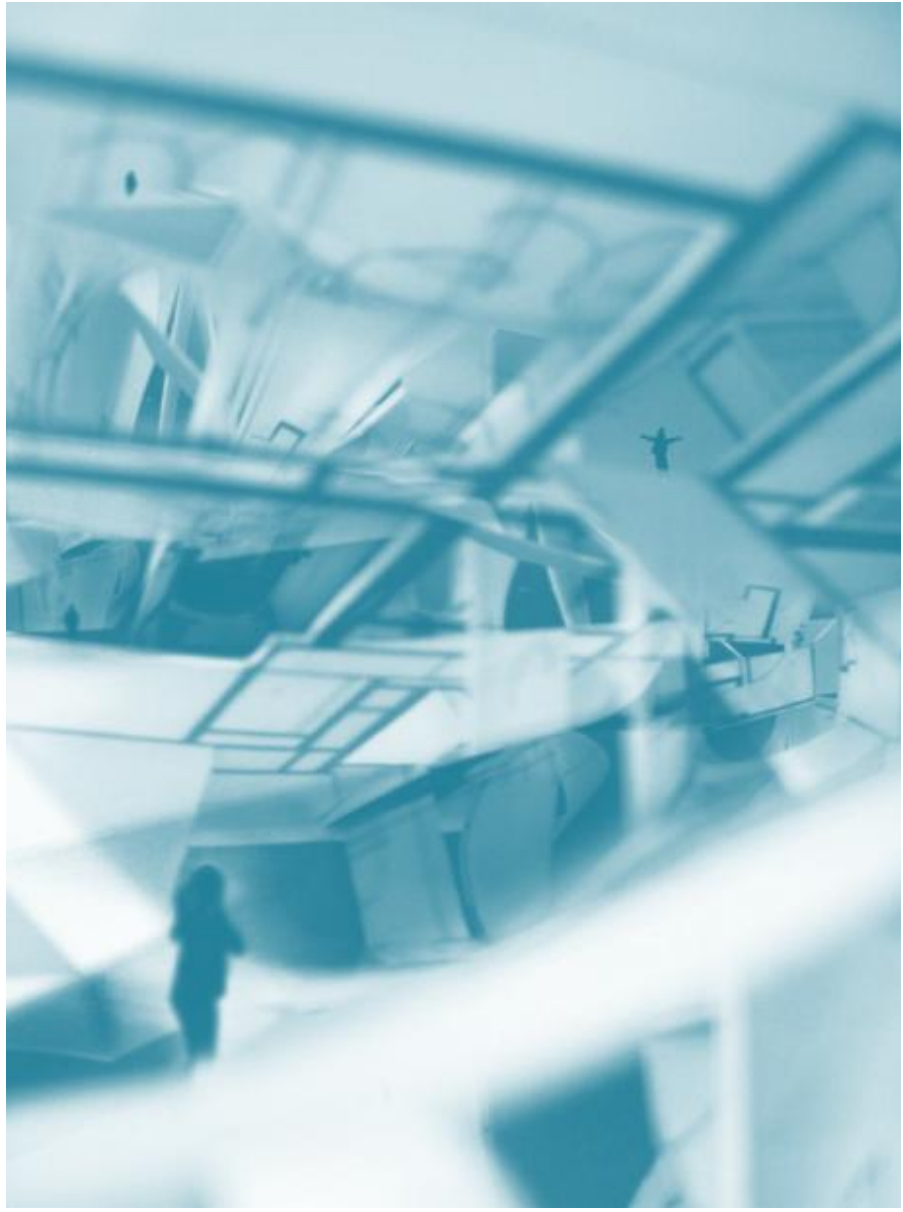

John Hejduk: Constructing a Story

Conclusion

\section{Chapter Two: Story Constructions}

The Library and the Tower

The Perpetual Castle

Labyrinths of the Domestic

Conclusion

\section{Chapter Three: Interpretation}

Ink Blot Experiments

Conclusion

\section{Chapter Four: Floor Plans and Thresholds}

The House

The Plan

Threshold Models

Application of Narrative 


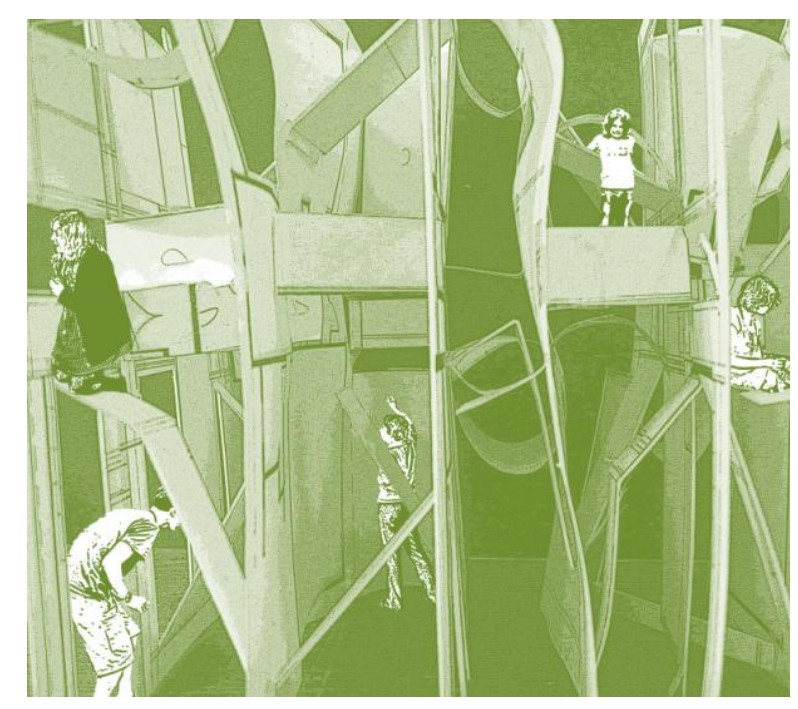

The Library and the Tower

The Perpetual Castle

Labyrinths of the Domestic

Thames House Revisited

Discussion and Critique

\section{Conclusion}

71

Bibliography 


\section{TABIE OF FIGURES}

Figure 1: "Berlin 1983" John Hejduk, Mask of Medusa, p195

Figure 2: "The House of the Suicide" John Hejduk, The Lancaster/Hanover Masque, p64.

Figure 3: "Haute galerie circulaire" Erik Desmazieres, (c)2007 Artists Rights Society (ARS), New York/ADAGP, Paris.

Figure 4: $\underline{\text { The Castle, }}$ cover from the Penguin edition.

Figure 5: Pages from House of leaves, pg 133-4 and pg 440-1, showing use of formatting to create labyrinth.

Figure 6: Created ink blots.

Figure 7: Initial experiments with ink blots.

Figure 8: Application of narrative through line widths.

Figure 9: Drawing along the spine of the ink blot reveals process of interpretation.

Figure 10: Ink blot model made from butter paper.

Figure 11: Colin Thompson, How To Live Forever. London: Random House, 1996.

Figure 12: Views of Threshold sketch model.

Figure 13: "Thames" House, G J Gardner New Zealand.

Figure 14: Symmetrical reconstruction of the plan

Figure 15: Plan with lines taken beyond their natural end points. 
Figure 16: Threshold map 1

Figure 17: Threshold map 2

Figure 18: Set of four plan interpretations

Figure 19: Some Images of the threshold models

Figure 20: The Mirror Model

Figure 21: The hard/soft Model

Figure 22: Side views of the hard/soft model

Figure 23: Early scale ideas

Figure 24: The Grid

Figure 25: The Wall

Figure 26: Tesselation

Figure 27: Mobius Strip 1

Figure 28: Mobius Strip 2

Figure 29: Isolation

Figure 30: Barrier

Figure 31: Overlay 1

Figure 32: Overlay 2

Figure 33: Thames House outside of context

Figure 34: Thames House revisited

Figure 35: Formal presentation 26/10/2010

Figure 36: Process of Interpretation 


\section{INTRODUCTION}

\section{"The universe is made of stories, not of atoms."}

\section{- Muriel Rukeyser, The Speed of Darkness}

It is the prerogative of creative endeavour to express personal 'truth', some deeper understanding of the world we find ourselves in. Architecture represents a coupling of creative and practical concerns which sets it apart from other arts. Considering the impact architecture has on our lives, its very practicality must lie in its ability to support the creative and intellectual needs of human existence as much as it supports physical requirements of shelter. Architecture is an expression of this existence; it is imbued with the stories of its time, its site, its architect and its occupants.

Much of the discourse on architectural narrative implies a series of events or impressions of space that can be 'read' through the sequence of experiencing a building. In practice this can lead to a manipulation of the user as the architect attempts sequence spaces through a careful construction of viewpoints and events. This causes a manipulation of spatial experience and the loss of individual interpretation. Perhaps it is for this reason that the discussion of narratives in architecture has fallen out of fashion; or perhaps it is the current preoccupation with sustainability and by extension the environment and spaces which answer to physical and functional problems. The latter approach often falls short in addressing issues of intellectual and creative stimulation. A building is more than a constructed environment for the corporeal and should respond to more than just the needs of the body; it must stimulate the mind as well as the senses to be truly sustainable.

Easing the paths of communication by forging relationships which allow the spread and expansion of ideas is how storytelling accelerates cultural development. Storytelling is the link from the worlds inside our heads to the worlds inside others' heads. In the act of bringing architecture from this internal world into reality, what we are actually doing is telling a story of who we are and what matters to us. There is opportunity for storytelling in architecture to assist in the accessibility of the design for this intellectual need. The better use of narrative is desirable as potentially one of the most accessible ways for the average user to become involved in enjoyment of the design intent, much like how 
authors use architectural metaphor within written narratives to convey deeper political, social or religious themes.

The current understanding of sequenced narrative does not relate to the amalgamated processes which constitute the experience of a space. Therefore the aim of this research is to develop our understanding of how narrative can be applied to architecture in a non-linear way, so as to encourage new interpretations of the stories embodied in our buildings. This will be achieved by discussing storytelling as a process via which a work can be enriched, through the reinterpretation of the audience.

First, a distinction is made between the story and the narrative. Where the former relates to the concept or purpose of the work, the latter describes the structure imposed upon a particular interpretation of that story. This distinction leads into a discussion of storytelling and its usefulness as a tool for communication. The most important element in this process is the ability of the audience to provide their own interpretation of the work, so that it might accumulate new meaning over time.

By adopting the storytelling maxim of 'show, don't tell' in architectural representation, a certain level of audience interpretation can be encouraged in the understanding of the work. More emphasis is placed on a concept when the audience is allowed to come to a personal understanding of it, and the conceptual framework of the story can be seen as having an individual meaning for each person who encounters it. The investigation of storytelling techniques from the architecture of John Hejduk, and the architecture of fiction narratives, reveals different methods of encouraging this kind of interpretation. Hejduk's Masque projects use a combination of text and images which are read in combination with each other to reveal the characters of his stories. The three fictional narratives discussed (The Library of Babel, The Castle, and House of Leaves) make use of the labyrinth archetype to drive the action within the story, exploring the effect of endlessness in interpretation.

The design component of this research involves working on new ways to encourage interpretation both in the design process and through the representation of the object. Through working with abstract images of ink blots, a process of interpretation is developed and then applied to an architectural object. It is the aim of the experiments to achieve a non-linear understanding of narrative and also to explore the possibilities for interpretation within architectural representational media. The process of design eventually leads to conclusions on the nature and necessity of storytelling in architecture. 
It is my belief that through a better understanding of narrative as it applies to architectural experience we not only improve the new architecture that we create, but also our experience of existing spaces. The ability of a work of architecture to remain relevant is only enabled through its acceptance of new interpretations, much like how a story will remain within the collective consciousness so long as it is reinterpreted through new applications of narrative. The current use of narrative as a sequencing tool does not reflect the way we experience architecture. It is used to manipulate experience, rather than allowing new interpretations to occur. Two questions are posed by this research. How can we encourage storytelling without resorting to the linear application of narrative? How can we direct narrative without sacrificing the opportunity for users to form their own interpretations of the story?

The design process, which is revealed through the experiments, addresses these questions through layering new interpretations of architectural representation. When this cycle of storytelling is used in the creation of new designs, the result is a non-linear narrative within the architecture which is open to continuous interpretation from the perspective of the occupant. The designs generated from this process represent a different understanding of how narrative might be reinterpreted through architecture.

${ }^{1}$ Muriel Rukeyser, The Speed of Darkness (New York: Random House, 1968). 


\section{CHAPTER ONE: STORYTEI ING}

In this chapter, I define exactly what I mean by 'storytelling', and explain how it is important to our roles as architects and designers. The objective is to put the research into the context of architectural practice. To begin we must first understand why storytelling is important to us. By looking at the reasons behind storytelling, I will argue that it is a fundamental form of communication which can give clarity, autonomy and meaning to architecture.

\section{Storytelling and Narrative}

Storytelling is one of the oldest practices of civilisation. The early oral traditions of the art can be found in all cultures ${ }^{1}$. Over time it has evolved into new forms: theatre, written narratives and pictorial media such as art and film. The aim of the practice has always been the same: to recount some history or to explain some past or abstract concept ${ }^{2}$.

As the art of storytelling moved away from the oral tradition and into more widely distributed media (particularly the written word), the stories being told began to take on a more stable and isolated identity ${ }^{3}$. This identity was born of the more permanent applications of the various new media as opposed to the cyclic nature of the oral art. It imposed stylistic structures over the old stories and tied them to a setting and a time, denying them the opportunity to change with retelling ${ }^{4}$.

This is where we can separate storytelling from the sequencing of events within a narrative structure, and the story from a particular application of narrative. As an example, consider William Shakespeare's Romeo and Juliet. The narrative structure of the play is determined by the theatre conventions of the time ${ }^{5}$, and the characters are specific to a particular time and place. The story however is something much older ${ }^{6}$. The basic plotline is one which has been told many times throughout the centuries. Shakespeare even seems to know that his audience will already be aware of the outcome of a story concerning star crossed lovers ${ }^{7}$, as the tragic ending is mentioned within the first few lines. In the retelling, the story gains new meaning and reinforces its immortality as an idea. ${ }^{8}$ The particular narrative of Shakespeare is the structure used to communicate that idea for a specific setting. The narrative is the structuring of a story, edited for a certain telling according to the whim of 
the author ${ }^{9}$. What this implies is that although the application of the narrative might change with each retelling, the essential purpose of the story is always the same.

\section{Theory of Mind}

When discussing what actions constitute storytelling, it becomes apparent from the sheer volume of stories and ways in which to tell them that making stories is a fundamental process of the human $\operatorname{mind}^{10}$. When the constant sequencing of events in human experience is considered, the entirety of what we understand as existence is one grand story which is recorded by the necessity to communicate efficiently and remotely ${ }^{11}$. Our unique ability as human beings to be able to contemplate the abstract leaves us with the problem of having to articulate concepts which cannot be sensed immediately and finding ways of ordering our complex thoughts ${ }^{12}$.

Advanced theory of mind in humans - that is, the ability of an individual to impute mental states to himself and others ${ }^{13}-$ is expressed through storytelling as it gives us the ability to rationalise, explain, wonder and deceive. When we can imagine that others have states of mind similar to our own, then we open ourselves to all kinds of possibilities, not least of all a passion for creating ${ }^{14}$. Christopher Alexander, in The Timeless way of Building, writes of the desire to create:

"It is a fundamental human instinct, as much a part of our desire as the desire for children. It is, quite simply, the desire to make a part of nature, to complete a world which is already made of mountains, streams, snowdrops, and stones, with something made by us, as much a part of nature, and a part of our immediate surroundings." ${ }^{115}$

This desire to create stories is an innate part of us, from our earliest pretending ${ }^{16}$ to our adult fantasies. By fostering our theory of mind, appealing to our creative desires, and allowing us a way of representing abstract thought, storytelling is one of the keys to man's accelerated development. This is in evidence when one considers how culture has expanded with the invention of the printing press, which made stories and the knowledge contained within them easier to distribute, and more recently still, with the advent of television, mass media and the internet ${ }^{17}$.

Yet the idea of storytelling, though it is a cornerstone of society and human communication, has been thrown under a negative light by modern culture; at its best this attitude manifests itself as the 
whimsical notion that stories are something exclusive to children and childhood ${ }^{18}$. Even forty years ago, Walter Benjamin noted that the 'experiences' which were the principle material of the storyteller had "fallen in value" ${ }^{\text {, }}$, and in some ways, this is true: in this information age we are indeed slaves to cold facts and figures, to information without hyperbole, just as Benjamin lamented ${ }^{20}$. But Benjamin was not completely correct. There is still a natural and instinctive part of us that understands how much more richness there is in our lives when we tell stories and speak in more transcendental quantities $^{21}$. This is clear in our informal conversations. We communicate during our day to day lives, not with numbers and details but with approximation, generalisation and exaggeration; glossing over the facts and emphasising the abstract heart of our inner thought processes. The British educationalist Harold Rosen writes that stories "come to life"22 in normal conversation such as this.

"We might be disposed to take stories much more seriously if we perceived them first and foremost as a product of the predisposition of the human mind to narratize experience and to transform it into findings which as social beings we may share and compare with those of others. ${ }^{23}$

Storytelling is natural and ever-present in our relations with others. However this definition does not tie the story to any particular medium and certainly not exclusively to the oral tradition, unlike in Benjamin's definition. It shows that everything we do when relating to others and when representing our inner experience can be considered 'storytelling,24. Perhaps, if Benjamin had taken this view, his essay The Storyteller might have had a less pessimistic take on the future of mankind's ability to tell stories.

"Less and less frequently do we encounter people with the ability to tell a tale properly. More and more often there is embarrassment all around when the wish to hear a story is expressed. It is as if something that seemed inalienable to us, the securest among our possessions, we taken from us: the ability to exchange experiences." ${ }^{25}$

Benjamin is concerned with the decline of craftsmanship in storytelling, in particular the craftsmanship involved in the early oral traditions of the art ${ }^{26}$. He could not have predicted the effect that modern storytelling media such as television and the internet have had on storytelling, nor the sudden explosion of places to share stories and people to share them with ${ }^{27}$. The more open our channels of communication, the more opportunities exist for the sharing of stories; meaning that the figure of the storyteller seen in Benjamin's writing is very much at large today, so long as we take care to separate narrative and story into their respective roles. 


\section{The Author, the Context, and the Audience}

On reading the work of Benjamin and Rosen, it becomes apparent that there are three influences which come together to create the product of the 'story'.

\section{Author:}

Benjamin's storyteller is a craftsman, and his impression is left on the stories he tells "...the way the handprints of the potter cling to the clay vessel. ${ }^{28}$ This is the first element of the story, the role of the author. Something of the creator lives on in his creations. Whether the experience being related is our own, or someone else's, or even wholly imagined on our part, it will be coloured by our own understanding. In turn, the one who receives the story will have his experience of it coloured by the storyteller.

\section{Context:}

As Rosen puts it, "The composer of a story is not a completely free agent." ${ }^{29}$ Although he might invent entire new worlds and impossible realities, the storyteller is still bound to work within the language of the medium he finds himself in, and the expectations of the environment in which he lives. The stories of his culture will affect him and what he is able to produce ${ }^{30}$. Anyone who strives to tell a story will inevitably draw upon the material that has come before, making comparisons, allegories and sometimes outright allusions to prior works; all the time building on the human store of knowledge and the collective unconscious. This is part of the endless nature of the story.

\section{Audience:}

The third party concerned in the ultimate impression of the story is the one to whom the story is being told $^{31}$. It is their interpretation of the author's intent which will ultimately determine the success of the story. Success in this sense does not, necessarily, equate to the author getting across his intended message. The success of the story lies in its ability to be interpreted and understood, so that it might take on a personal meaning for the reader ${ }^{32}$. Benjamin writes that this interpretative task is what separates the story from mere information "... the psychological connection of the events is not forced on the reader. It is left up to him to interpret things the way he understands them, and thus the narrative achieves an amplitude that information lacks." ${ }^{33}$

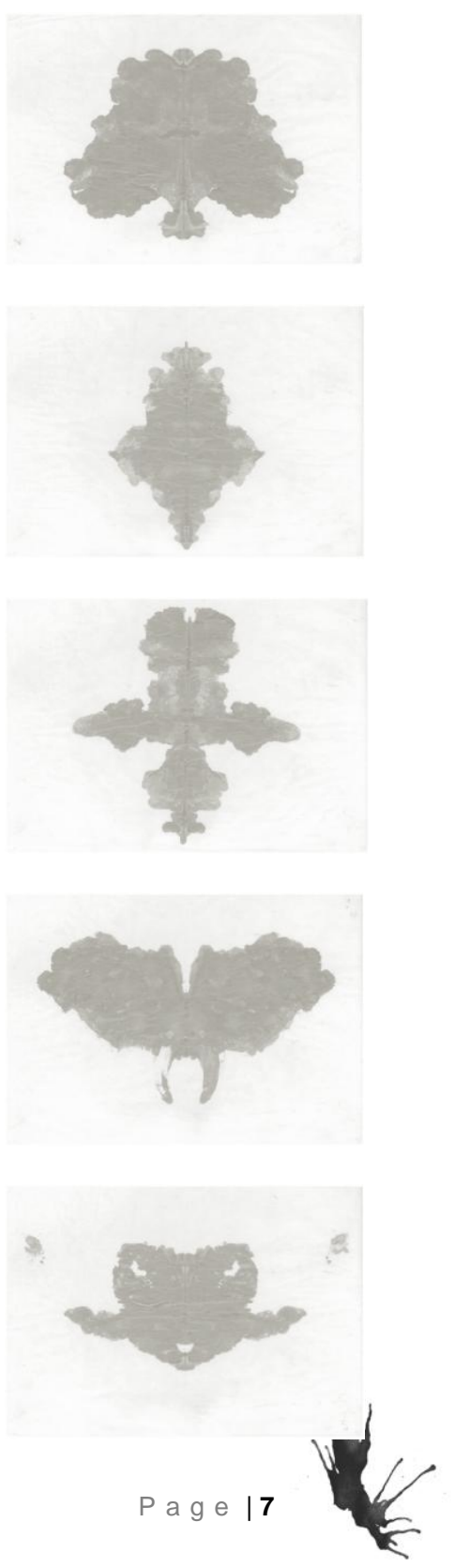


It is this inclusion of the autonomous reader which allows stories to gather more meaning over time, as they are passed from one person to the next. The one who hears the story told by Benjamin's Storyteller becomes the next storyteller, and the story is changed by its retelling ${ }^{34}$. Although Benjamin speaks only of the oral traditions of European storytellers it can be appreciated that all stories, no matter how they are told, will ultimately become cyclic in this way. Stories are constantly being recycled ${ }^{35}$. This can be seen clearly in the popularity of the fairy tale, understood by Benjamin as "the first tutor of mankind" ${ }^{\prime 36}$, which has seen itself being told and told again, even used to tell new stories which are not related to the original premise. Fairy tales are the backbone of many stories, which have been able to grow and evolve as our ability to understand them does. The story is immortal in its continually changing state, so long as it can be read by someone else and repeated.

The relationships between these three influences dictate how well the audience might be able to discern some purpose or meaning in the tale. The story, writes Benjamin, "...contains, openly or covertly, something useful. ${ }^{37}$ His storyteller provides "counsel" for the listener. Meaning is woven into the fabric of the tale, but those meanings need not be moral rules for mankind. There only needs to be some truth relevant to the author, to the context of the environment, or to the reader for a story to gather usefulness for that particular party ${ }^{38}$.

The purpose of all stories is truth, even if they are invented out of whole cloth. Benjamin's cycle of storytelling, the constant layering of meaning through retelling, is not so much to reveal the "perfect narrative" ${ }^{39}$ as he puts it, but a constant universal thought experiment ${ }^{40}$ to discover the 'perfect truth'. Perhaps it is possible to utilise this revealing process in order to uncover a truth within architecture.

\section{Architectural Context}

Lily Chi in her essay on narration in John Hejduk's masques, writes that "... human action is the common concern of both plots and architects.. ${ }^{41}$ Since making the distinction between narrative and story, the statement takes on a new meaning. I felt it was necessary to expand the scope of the architect's concern, because while human action may be the concern of the plot, what lies behind that action is the concern of the story. The human condition is to live inside a mind constantly exploring and pushing boundaries to figure out the big questions of its own existence, and using stories as a 'thought experiment' helps us in this quest ${ }^{42}$. This human condition must be the concern of architects, whose role is to support and sustain it by providing the essential shelter which protects it. ${ }^{43}$ 
Moreover, architecture is ideal for the expression of stories following Benjamin's model of layered meaning. ${ }^{44}$ The way a building relates to time allows it to reflect its occupants and uses, but it is also a reflection of its designer and its environment. The paradox between the (comparative) permanence of architecture and its ability to interact directly with, and be changed by, people other than its creators (as opposed to some other arts) allows it to collect this richness. As Edward Hollis writes in The Secret Lives of Buildings: "For stories and buildings alike, incremental change has been the paradoxical mechanism of their preservation." ${ }^{45}$

One of the main aims of this thesis is to move away from our preconceptions regarding the idea of 'narrative architecture'. We understand this in most cases to be a linear relationship to a timeline of events which can be represented by the occupant's journey through a series of experiences ${ }^{46}$. View, light, shadow, and mood are manipulated to create a sense that we are travelling alongside the line of thought in the architect's mind.

The narrative in these instances is a static application because it is connected to a very particular time, place and sequence ${ }^{47}$. Narrative can play games with time: pacing, rhythm, time-lapse and so on: but it cannot ignore the perceived linear progression of one moment to the next ${ }^{48}$. Architecture, however, is most closely tied to the our experience of space. The moment of experience is not related to a linear perception of time. One way to understand this is to consider the narrative which runs through an exhibit in a museum. Sophia Psarra explains: "While narratives in other media are based on representations of time and space, museum narratives are organised in space depending on the ways in which the artefacts are positioned in a layout." ${ }^{49}$ This organisation of space might suggest a linear pathway through the exhibit, but it does not represent how it will be occupied by all those who experience it. The true experience would be different for someone who entered from the 'wrong' end of the exhibit, or someone who could only spend ten seconds with each artefact, or someone who was only interested in the display in the corner of the room. Tschumi refers to this as a "program of indifference ${ }^{50}$, when the sequencing of spaces and the sequencing of events are independent of one another. It is my argument that much of our day-to-day experience of buildings is like this; our autonomy as users means that we make choices and change our environment in ways the architect might not have planned for.

Also not considered is the fact that direct, physical experience is not the only way to experience a space. Representation of the building is increasingly important as information becomes more available. The effect of multiple representations of a building is to provide a number of different

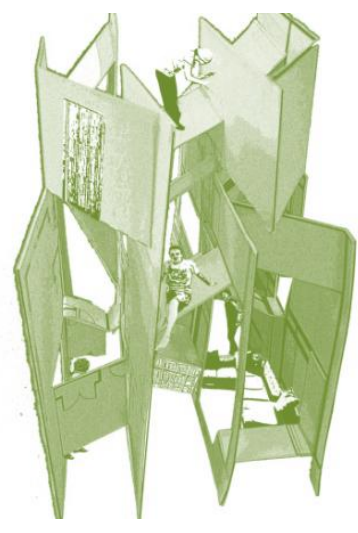


viewpoints simultaneously, and these viewpoints will affect how the building is experienced. If the representation includes abstractions such as floor plans and sections, what the viewer understands of crafted views and pathways will be coloured by their prior knowledge. The sensory exploration combined with what we are shown in representation leads to the construction of the image in the mind. This "mental model" ${ }^{51}$, can then be explored from an intellectual point of view. Our accumulated knowledge of this building and the others we have visited will come together to form our impression of the space $^{52}$.

Our buildings do tell stories about us, whether or not the architect had the intention of including narrative $s$ a design methodology Everything we do, say and create tells stories about us ${ }^{53}$. The question then is why do we not respond to architecture in terms of the stories it can tell us? I am of the opinion that the reason 'narrative architecture' has not reached the status of a 'traditional' narrative media is a misunderstanding of how experience and time are related to the impact of what is being communicated. Written and filmed narratives have an advantage over architecture in that the authors of these types of works dictate the direction and pacing of an audience through the course of the narrative ${ }^{54}$. If we return to an even more traditional concept of storytelling, we find that there is room for interpretation and a more inclusive experience which could relate to how we experience architecture.

\section{Show not tell - a lesson for architects}

A particular issue in architecture is that of representation. How we represent our buildings, particularly to the public, can greatly affect how the narrative is experienced. Buildings are not simply understood through spatial experience ${ }^{55}$. Public buildings or large-scale constructions often use the media to inform people about the conceptual framework to the design, giving a representation to the public of how the architect wants people to interact with the intellectual properties of a building. This restricts the public's ability to understand and interact with architecture in an autonomous way. We might ask whether there is something we are able to learn from the representation of stories in traditional narrative media which could be applicable to the representation of stories in architecture.

Narratology (in literature, the study of narratives) has a formalised discourse ${ }^{56}$, but much of what makes a good story is recognisable instinctually, or is personal to each reader. The advantage of traditional narrative media in storytelling is that the reader or listener has no choice but to engage with 
the words and create the images for themselves. The role of the audience is a crucial one; they take the words of the storyteller and reconstruct the entire story in their own way. When it is then repeated or discussed, the understanding of the reader will change how it will be represented ${ }^{57}$.

In architecture, however, there is not the same guarantee of mystery. The reader does not have to rely on his own imagination to create the spaces because the architect has created them for him. The role of the user is suddenly not so important compared with the will of the architect. The user has no free will of their own to reinterpret the experience of the spaces as this has been designed by another hand.

The problem comes down to how we represent ourselves and our stories when we talk about our buildings. When we present our designs as analysis rather than as stories we do not leave much room for this layering of interpretation ${ }^{58}$, or the opportunity for the story to be retold. This can be seen in our profession: what recent public architecture has been built without an official published statement from the office stating precisely what we are supposed to see in it? When this occurs, what happens to the opportunity to decide for ourselves what we can see in the building?

In traditional narrative fields, it is accepted that the creator of a work does not always have to explain every element of the story in order for the person receiving the story to understand it. Moreover, it is generally agreed to be bad practice to 'tell' the audience what is happening when you could use character actions and dialogue to 'show' them ${ }^{59}$. To explain to the audience that the hero character is noble, selfless and heroic could be problematic if the hero's actions contradict that statement, not to mention that it would make for dull reading. A better method is to show that the character is all these things through his actions and leave the audience to realise the truth of those actions themselves. The proof of the success of the character will be when others are able to look at his actions and understand him to be the hero. This is not an absolute rule, but it is a good guideline ${ }^{60}$, particularly when dealing with the concepts which require the most emphasis.

The story is more effective if there is some room left for the audience to bring to it their own knowledge of human interaction and their own understanding of the world being presented. A story is not a text book; it does not seek to tell the audience some distinct and quantifiable information. Walter Benjamin writes: "... it is half the art of storytelling to keep a story free from explanation as one reproduces it." ${ }^{6}$ The story can only achieve its true "amplitude" 62 when the audience is given a chance to reinterpret the elements as they are presented.

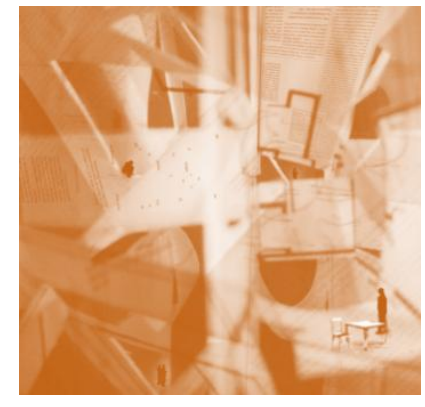


The storytelling maxim of 'show, don't tell' when applied to design encourages everyone to think critically about architecture and the environment they live in, including the architects themselves, encouraging consistency and therefore quality in design. Storytelling is a personal expression and therefore must also encourage originality in design. Traces of the architect will always linger in the building $^{63}$. To give over the right of interpretation is not to detract from the designer's role in creating something innovative. To rely on post-rationalisation and explanation is to deny architecture the right to speak for itself, directly to each individual. If we are to use words alongside our designs, they should seek to support the story already being told by the architecture, not to explain what should already be apparent. Moreover, the designer should have the humility to accept that someone with a different education or social background might project a different meaning onto the building ${ }^{64}$. This might even be a meaning which could never have been accounted for by the architect ${ }^{65}$.

As architects, we seem to forget that the public already has a sophisticated relationship with architecture; more so than with other arts. Even without the benefit of an architectural education, people encounter buildings everyday and are perfectly capable of putting those buildings to whatever use is necessary ${ }^{66}$. When we tell them what a building is supposed to represent, it does not necessarily aide their ability to understand it or even affect their experience of it. In some cases the public's view of a building comes to dominate: we see this in the case of large buildings which attract imaginative nicknames ${ }^{67}$ like Wellington's 'Beehive' (parliament building) and 'Cake Tin' (Westpac Stadium), Norman Foster's 'Gherkin' in London and the Olympic 'Bird's Nest' stadium in Beijing. The story of the building in these cases is forever altered by the name attributed to it by the public, but it is also this act which brings some architecture into the realm of general acceptance. In other cases, the architecture's original purpose might be overhauled completely, layering a new story over the old. This is the case in many ancient structures (the Pantheon was a Roman court and then a Christian church, the Parthenon has been a temple, a church and a mosque) as well as new ones in times of economic change, with offices being turned into apartments and homes being turned into offices ${ }^{68}$. The traces of the old function are still there. The example of building a Christian church on a sacred Pagan site shows how it was deemed advantageous to assimilate two rituals by layering one over the other. The story is reinterpreted again, with new emphasis. It is in no way detrimental for a building to accumulate this kind of meaning. On the contrary, it must enhance the richness of the spaces and serve as proof of the design's merit, as well as making the passing of time visible ${ }^{69}$. 
It could be difficult to conceive that a new building will accumulate this sort of meaning; that it will be layered with histories over time and that its influence and purpose will evolve to match the changing needs of society around it. The responsibility of the architect is to provide this opportunity and to not give over a static object, tied to a particular time and purpose. Christopher Alexander argues that for a building to achieve timelessness, the architect must be 'egoless'. "When a place is lifeless or unreal, there is almost always a mastermind behind it. It is so filled with the will of its maker that there is no room for its own nature. ${ }^{.70}$ Because of the longevity of a building, and because we know it will evolve and change along with its inhabitants, we must cast aside the notion that is purely ours. We must understand that we have to allow our buildings to evolve and change if we wish for them to remain. There must be clarity in our designs that lets them speak for themselves beyond expressions of function. If we want our stories to be built on through our architecture, we must express those stories in the architecture and not have to rely on telling people what they are meant to see.

\section{John Hejduk: Constructing a Story}

John Hejduk's 'masque' projects lie somewhere between the story told through architecture and the architecture contained within a story, and this is why I have chosen to use this work as a case study. The series, designed around characters such as 'the timekeeper', 'the inhabitant who refused to participate' and 'the suicide' are mostly made up of drawn figures collected together with poems and writings which explore the process behind their realisation ${ }^{71}$. The described built forms do not encompass the full effect of the collected drawings, poems and characters. As Lily Chi writes: "With the Masques, somewhere between drawing and text, object and function, we find ourselves embroiled, morally implicated in the thick of plots - parables, fables, mysteries - the beginnings and outcomes of which lie a little beyond the way."

Together, all of these elements contribute to the story, although they may seem disparate at first. In fact, it is their very ambiguity which leads to their most fascinating qualities, as James McGregor argues: “... it's these many threads to his

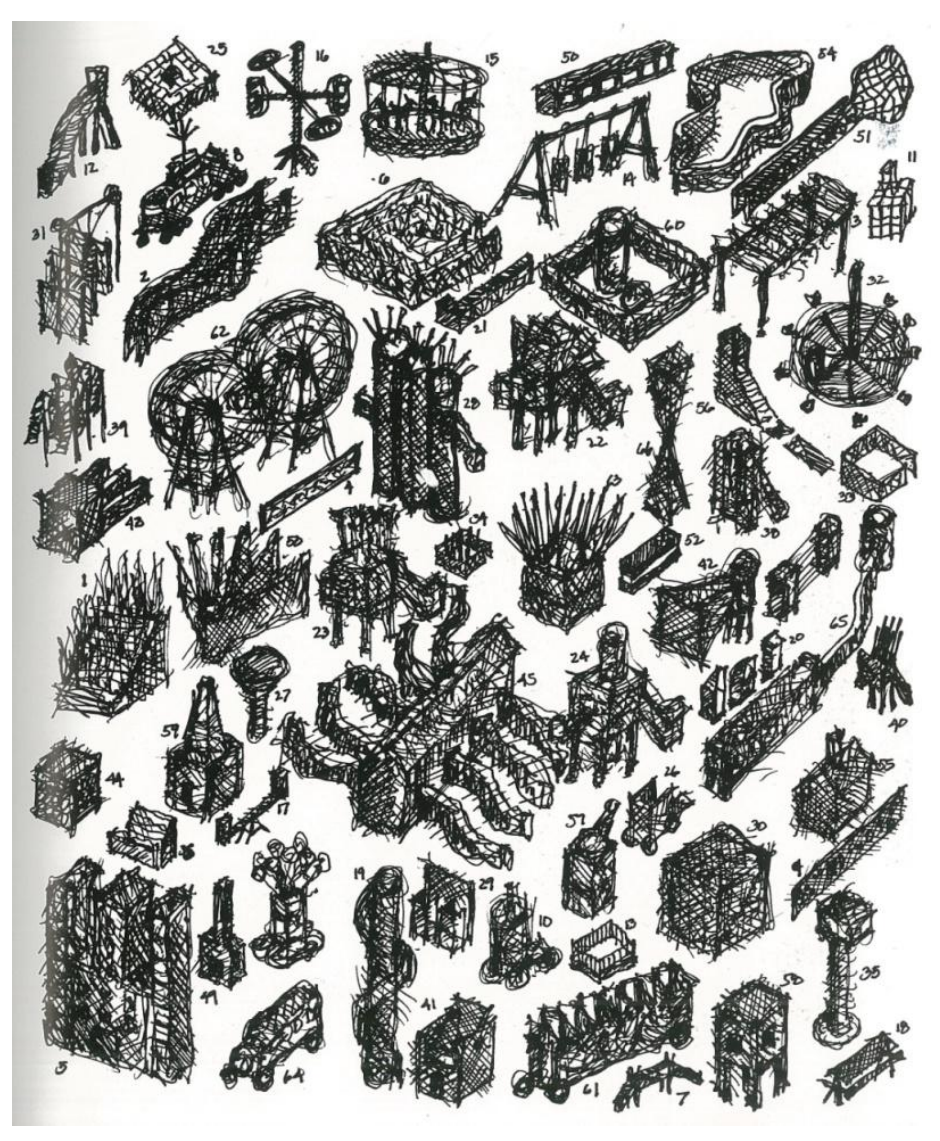

FIGURE 1: "BERLIN 1983" JOHN HEJDUK, MASK OF MEDUSA, P195

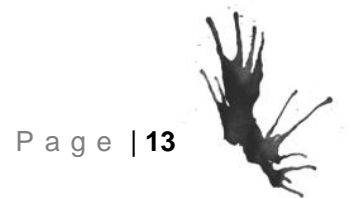


[Hejduk's] stories, the indeterminate relationships between them, and the incompleteness of the whole that makes the masques what they are. If the masques have the character of childish fascination, of naive wonderment, then this is all part of the attempt to keep the realm of possibility open." ${ }^{\text {B3 }}$ By keeping the story open to interpretation, Hejduk is letting the viewer interact with his work giving them autonomy to piece together the story and work out the meaning of the architecture. Chi writes that: "Hejduk's constructions resist 'optical' consumption even as built works and necessitate recourse to the poems and stories alongside of which they had been conceived." 74 There is a limitation with this ${ }^{75}$, in that the full force of the buildings cannot be read without the text, thus compromising the functionality of the building. However, this interplay does highlight the fact that there is more to the buildings than can be seen at first glance, and that they must be interpreted.

In fact, in one instance Hejduk openly invites contributions to the design process, writing that "the arrangement of these structures is only a suggestion. The concept of another structural ordering is open."76 The intent of the architect, therefore, is only one possible meaning here - more meanings will come as a result of human interaction and only this interaction can determine the ultimate meaning of the masques ${ }^{77}$. If we return for a moment to Benjamin's Storyteller, this interaction and layered meaning ${ }^{78}$ shows Hejduk's respect for the craft. The connections are not "forced" ${ }^{79}$ but are left to be discovered by the viewer.

These projects may not be buildings in a functional sense, but they do provide a bridge into architecture through storytelling. Hejduk builds a living city out of the characters, hinting at their juxtaposition through his drawings depicting their strange relationships and rituals. There is the sense that it is alive. The city is a story made up of many stories, "...perpetuated by each inhabitant yet encompassing those inhabitants within its folds." ${ }^{80}$ The architecture comes into play when "what is blurred beyond recognition is the distinction between subject and object, function and form." ${ }^{81}$ We can then view Hejduk's masques as the architecturalisation of stories and of characters which are continuously evolving through the relationships they evoke. They will always be ready to adapt to new interpretations, like the living city have created.

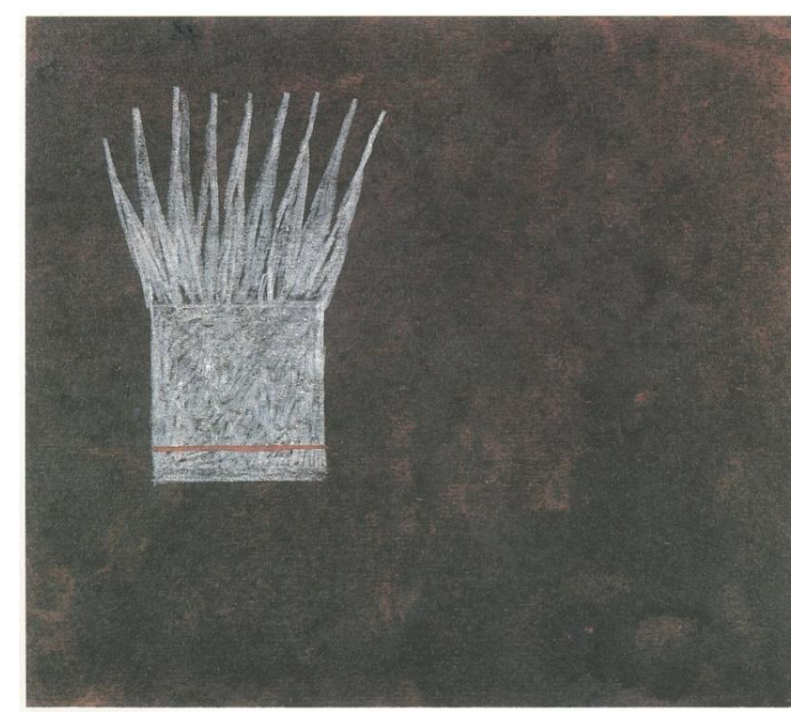

FIGURE 2: "THE HOUSE OF THE SUICIDE" JOHN HEJDUK, THE LANCASTER/HANOVER MASQUE, P64. 
The masques are not tied to a time but simply to their characters, they exist outside of a traditional 'narrative' sequence. Although some have functions: 'the gymnasium', the 'house' etc ${ }^{82}$; they do not always conform to our understanding of those forms. The combination of drawing and text provides a multi-layered understanding of the places inhabited by Hejduk's characters and the stories which belong to them. This gives an impression of a story which drops the ego of the architect in favour of the community. McGregor writes that: "From the moment he marks paper, Hejduk becomes another occupant of the masque, a craftsman participating in the community rather an architect deciding its future. ${ }^{83}$

McGregor writes of the individual buildings in Hejduk's Masques that "Buildings translate subject as object; they make character continually and materially present, and therefore encourage the objectifying gaze." ${ }^{84}$ This is exemplified by the tension between the way characters are named and the way they are expressed; the names are general, impersonal, but the characterisation is welldeveloped and particular. This is not any suicide, this is The Suicide. The generic naming allows the objectification to take place, while the development of the character saves the architecture from becoming generic. One thing that is consistent among these loosely collected projects is that the architecture comes from and is the only representation of character. The impersonal naming style in the texts is a clue to this as it takes away from our ability to visualise the character in human terms. We are left with only the architecture to give us a clue to this personality ${ }^{85}$.

This is not the permanent architecture that sits as a backdrop to a scene. This is an architecture which involves and is part of the action of life. "Life has continuity as an incipient story which emerges from and is perpetually refigured across a background of continuously overlapping lived stories." ${ }^{86}$ This is realised in Hejduk's Masques, as together they make a story which is separate to their individual stories, a continuing plot woven from many smaller plots. The architecture is as fleeting as the lives of the characters it invokes, because without them its meaning is changed. And yet there are also parts which are immortal, divorced from time and setting. The unnamed characters might be found anywhere within our reality.

Hejduk understands architecture's ability to tell stories without a reliance on a linear experience of space. The story is specific and general simultaneously; specific to the architect and to the inhabitant, but general in that it must sit within its context and must provide some opportunity for interpretation. These two roles are in a symbiotic relationship although they appear as opposites, with the general providing a framework for the story and the specific contributing to build upon that framework. The 
apparent opposition, like so many architectural binary constructions, actually proves to be complimentary ${ }^{87}$.

Hedjuk's work, like architecture within fiction, is free of excessive constraints on programme, budget or site except for those he sets himself. The Masques are built examples of architecture that lives within a story. More than that, they are the story, the characters and the plot; and they teach us how story might be incorporated into the practice of architecture without resorting to manipulating a linear path through a single narrative. The use of narrative provides an intellectual component to this work which makes architecture out of the sometimes vague shapes and stories. The cycle between form, function and the story references the cycle of storytelling, where the viewer or the inhabitant of the work takes on the task of formulating his own meaning of the work, thus becoming storyteller himself ${ }^{88}$.

The use of language and visual mediums side by side reflects architecture's ability to appeal to the physical and the intellectual, to be interpreted by both the senses and the conscious mind. In Hejduk's work there is an interdependent relationship between drawings and texts. The two parts fit together, not to form a whole, but to provide the starting point of an architecture which can then adapt to our interpretation of it.

\section{Conclusion}

In defining the differences between storytelling and narrative, it is my argument that we begin to see a shift in how we can approach narratives in architecture. Since storytelling is so dependent on the interpretation of the reader, the use of it in our buildings would eliminate the manipulation of linear expressions of narrative which we see so often in buildings.

It is a natural conclusion to want our buildings to tell stories and to become a part of the stories of our lives. Storytelling is a part of how we communicate, and if we want our architecture to be more than just shelter then we must consider ways of developing the narratives it contains. The linear approach is not a solution because it is not related to the experience of architecture. Our experience of space is layered with other experiences and other meanings, brought together from every other space we have visited and all the information we can put together from the site. It is much more complex than a simple sequencing of events. 
In the example of Hejduk's Masques, there is a precedent for this non-linear relationship, where the architecture becomes a part of character rather than remaining as setting. The strength of the Masques is that they do not 'tell' us their stories, but they do 'show' all the elements we need in order to piece it together. The emphasis changes according to the reader, ensuring that on some level, at least, the projects will always have the alluring sense of being about everyone they touch. Text and architecture are inextricably linked in the masques, to the point where the built form lacks any sort of coherency without the accompanying written elements. It leaves the reader to pick up the pieces and interpret for himself, but this autonomy does come at the price of allowing the built form of architecture to speak for itself, through its own language. It is a step towards an answer, but it is not yet storytelling through architecture.

\footnotetext{
1 Jeremy Hsu, "The Secrets of Good Storytelling: Why We Love a Good Yarn," Scientific American Mind 19.4 (2008): p46.

2 "Story." Def.C Baldick, "The Oxford Dictionary of Literary Terms," (Oxford: Oxford University Press, 2004), vol.

${ }^{3}$ Walter Benjamin, "The Storyteller," lluminations: Essays and Reflections (New York: Schocken Books, 1969) p3.

${ }^{4}$ Benjamin, p3

${ }^{5}$ Roma Gill, ed., Romeo and Juliet (Oxford: Oxford University Press, 1998) p.xxxii.
} 
${ }^{6}$ Gill, ed., p.v.

${ }^{7}$ Gill, ed., p.iv.

${ }^{8}$ Benjamin, p6.

${ }^{9}$ Harold Rosen, Stories and Meanings (Sheffield, UK: National Association for the Teaching of English, 1985) p14.

${ }^{10}$ Rosen, p6.

${ }^{11}$ Rosen, p15.

12 Rosen, p17.

${ }^{13}$ David Premack and Guy Woodruff, "Does the Chimpanzee Have a Theory of Mind?," Behavioral and Brain Sciences 1.4 (1978): p515.

${ }^{14}$ Alan M. Leslie, "Pretense and Representation: The Origins Of "Theory of Mind"," Psychological Review 94.4 (1987): p423.

${ }^{15}$ Christopher Alexander, The Timeless Way of Building (New York: Oxford University Press, 1979) p9.

${ }^{16}$ Leslie: p416

17 Rosen, p9.

${ }_{18}$ Rosen, p7.

${ }^{19}$ Benjamin, p1.

${ }^{20}$ Benjamin, p4.

${ }^{21}$ Rosen, p10.

${ }_{22}$ Rosen, p12.

${ }^{23}$ Rosen, p12.

24 Rosen, p12.

${ }^{25}$ Benjamin, p1.

${ }^{26}$ Benjamin, p5.

27 Rosen, p9.

${ }^{28}$ Benjamin, p5

${ }^{29}$ Rosen, p14.

${ }^{30}$ Rosen, p14.

${ }^{31}$ Benjamin, p4.

32 Rosen, p8.

${ }^{33}$ Benjamin, p4

${ }^{34}$ Benjamin, p4

${ }^{35}$ Hsu: p46.

${ }^{36}$ Benjamin, p11.

${ }^{37}$ Benjamin, p2.

${ }^{38}$ Rosen, p8. 
${ }^{39}$ Benjamin, p6.

${ }^{40}$ Lily Chi, "Narration and the Architectural Program: The 'Mythical' Status of Architectural Fictions," Writing/History/Architecture/Myth, ed. Michael Linzey (Auckland, New Zealand: The University of Auckland, 1991) p84.

${ }^{41} \mathrm{Chi}, \mathrm{p} 80$.

${ }^{42} \mathrm{Chi}, \mathrm{p} 84$.

${ }^{43}$ Paul Goldberger, Why Architecture Matters (New Haven: Yale University Press, 2009 ) p2.

${ }_{45}^{44}$ Benjamin, p6.

${ }^{45}$ Edward Hollis, The Secret Lives of Buildings (New York: Metropolitan Books, 2009) p14.

${ }^{46}$ Sophia Psarra, Architecture and Narrative: The Formation of Space and Cultural Meaning (New York: Routledge, 2009) p2.

${ }^{47}$ Psarra, p4.

48 Psarra, p4.

${ }^{49}$ Psarra, p4.

${ }^{50}$ Bernard Tschumi, Architecture and Disjunction (Cambridge, Mass: MIT Press, 1996) p159.

51 Branko Mitrovic, "Architectural Formalism and the Demise of the Linguistic Turn," Log.n17 (Fall 2009): p23.

${ }^{52}$ Mitrovic: p23.

53 Rosen, p12.

54 Psarra, p4.

${ }^{55}$ Psarra, p3.

${ }^{56}$ Rosen, p11.

57 Benjamin, p4.

${ }^{58}$ Benjamin, p4.

$59 \mathrm{~J}$ Evanovich, IL Yalof and A Evanovich, How I Write: Secrets of a Bestselling Author (New York: St. Martin's Griffin, 2006) p45.

${ }^{60} \mathrm{~F}$ Prose, Reading Like a Writer: A Guide for People Who Love Books and for Those Who Want to Write Them (New York: Harpercollins, 2006) pp24-25.

${ }^{61}$ Benjamin, p4.

62 Benjamin, p4.

63 Alexander, p37.

${ }^{64}$ Hollis, p10.

${ }^{65}$ Hollis, p13.

${ }^{66}$ Goldberger, p172.

${ }^{67}$ L Krier, DA Thadani and PJ Hetzel, The Architecture of Community (Washington, DC: Island Press, 2009) p31.

${ }^{68}$ Hollis, p9. 
${ }^{69}$ Goldberger, p194.

${ }_{71}^{70}$ Alexander, p36.

${ }^{71}$ John Hejduk, The Lancaster/Hanover Masque (London: Architectural Association, 1992) p13.

${ }^{72} \mathrm{Chi}$, p82.

73 James McGregor, "The Architect as Storyteller: Making Places in John Hejduk's Masques," Architectural Theory Review v.7.n.2 (2002): p60.

${ }_{75}^{74}$ Chi, p82.

${ }^{75} \mathrm{Chi}$, p82.

${ }^{76}$ John Hejduk, Victims: A Work (London: Architectural Association, 1986) p111.

${ }_{77}^{77}$ McGregor: p62.

${ }_{78}^{78}$ Benjamin, p6.

${ }^{79}$ Benjamin, p4.

${ }^{80}$ McGregor: p63.

${ }^{81} \mathrm{Chi}, \mathrm{p} 80$.

82 John Hejduk, Mask of Medusa (New York: Rizzoli International Publications, 1985) pp428-38.

${ }^{83}$ McGregor: p67.

${ }^{84}$ McGregor: p66.

${ }^{85}$ McGregor: p65.

${ }^{86}$ Chi, p81.

${ }^{87}$ Tschumi, p43.

${ }^{88}$ Benjamin, p5. 


\title{
CHAPTER TWO: STORY CONSTRUCTIONS
}

\author{
"In a labyrinth, one does not lose oneself \\ In a labyrinth, one finds oneself \\ In a labyrinth, one does not encounter the Minotaur \\ In a labyrinth, one encounters oneself"'
}

In this chapter I analyse architecture within fictional narratives to explore how architecture is used to tell stories. The three examples here have been chosen because in each, architecture is presented as more than just setting; it is character and catalyst. Architecture has been used as the driving force behind the action. The three narratives are: The Library of Babel, by Jorge Luis Borges, The Castle by Franz Kafka and House of Leaves by Mark Z. Danielewski.

In reality architectural projects are constrained by physical and spatial problems - issues of site, programme, budget and construction ${ }^{2}$. All of these things will leave their mark on the spaces as built, and may detract from the realisation of the architectural concept ${ }^{3}$. It is difficult then, to assess the narrative qualities of built works without reference to these things. In the case of John Hejduk's Masques we saw that storytelling came at the expense of function due to reliance on textual elements. ${ }^{4}$

With this in mind, I wanted to look at architecture within what I have referred to as the 'traditional' methods of storytelling; that is storytelling through language systems. The choice to look into these narratives reflects the fact that more development in narratology has taken place in the field of literary criticism ${ }^{5}$. The methods used in literature for expressing narrative have become very familiar. Within the realms of fiction we find the greatest scope for architecture which is divorced from the constraints normally placed on it by reality. That is not to say that architecture which exists within these fictions has no constraints placed upon it; there are still the constraints of the world within the story, and additionally there are constraints placed on it by the needs of the narrative ${ }^{6}$. If the heroine has to stare longingly across the plains from the top of her ivory tower, then there must be a tower made of ivory with a window in it that overlooks the plains which is accessible to the heroine. The difference is that 
we are designing within environments of our own construction and so we also have the control of these environments, through manipulating the narrative itself. The building's context also becomes part of the design. This approach to the surrounding environment can be seen in John Hedjuk's Masques $^{7}$.

Architectural allegory is popular across all forms of fiction, and buildings are often used as characters rather than just a background to the action of the story ${ }^{8}$. This is due to the dominant role architecture plays in structuring our lives; it will always be included in works which discuss the issues inherent in the human condition ${ }^{9}$. This use of architectural metaphor extends even to philosophers. Mark Wigley goes so far as to say that "The architectural metaphor is not simply one metaphor among others. More than the metaphor of foundation, it is the foundational metaphor [...] The architectural motif is bound to philosophy." ${ }^{10}$ The need to express ourselves through architectural metaphor shows how deeply our experiences with buildings have affected our subconscious interpretations of the world.

A common stylistic thread in the three stories discussed below is that they leave much to the interpretation of the reader. This is reflected in the labyrinthine architecture they describe. The labyrinth offers both a sense of containment and a kind of autonomy: containment in that it is a prison which defies escape, and autonomy in that it offers an infinite number of paths down which the characters might search for their freedom ${ }^{11}$. It is used to create a varied environment within the contained world of the narrative, although the level of variation may depend on the needs of the story.

The fascination with the labyrinth begins with the Greek myth of the prison made for the Minotaur ${ }^{12}$. Although modern scholars make the distinction between 'maze' as a puzzle with many choices and 'labyrinth' as a complex pattern made of a single path ${ }^{13}$, logic tells us that King Minos' prison on Crete must have been the former ${ }^{14}$ and so I will use 'labyrinth' here with the former definition. A labyrinth is no mere maze however; a maze is a puzzle which might be solved by exiting, where the object of the labyrinth is to find the centre point of many converging and diverging paths ${ }^{15}$. The object is to find that which is hidden and lost, and not to leave ${ }^{16}$. In the case of Borges' and Kafka's labyrinths below, it might not even be possible to leave.

The mystery embodied in the labyrinth represents the internal mystery of the mind made physical ${ }^{17}$. It expresses the human condition which lies at the heart of all storytelling. The struggle to find what is hidden in the labyrinth also reminds us of the cycle of storytelling itself ${ }^{18}$. The choices being made represent new interpretations of the path, each time coming closer to the 'truth' at the centre. 


\section{The Library and the Tower}

The labyrinth is used as an architectural model for the writer's universe in Jorge Luis Borges' story The Library of Babel. The narrator describes the universe as an endless library composed of interconnected hexagonal rooms. The books, arranged at random, contain every combination of letters possible, meaning that although there must be the true story of your own life hidden somewhere within, the vast majority of the books are unintelligible. Although the inhabitants have come to understand that no two books are the same ${ }^{19}$, so far the library has proven to contain no information at $\mathrm{all}^{20}$. Without a catalogue to provide a map or cipher, there is no way of telling the genuine history of the universe from all the millions of deceptive or counterfeit histories ${ }^{21}$.

Whatever the narrator writes could - and eventually, would - be found in one or another of the books, as well as every possible variation that could be made by changing one letter, writing in code or translating into other languages, false translations and conflicting accounts ${ }^{22}$. The narrator's text already exists, as does a much better version of it, but looking for it in the vastness of the library would take an immeasurable length of time.

The library Borges describes represents a notion of the inner self and the collective unconscious ${ }^{23}$, but it is represented as a physical environment; we find recognisable spaces in the room, the vault, and the library. Architecture is used here to explain concepts which are not spatial in normal understanding ${ }^{24}$. The architecture of this narrative shows how built forms might bridge the gap between physical and intellectual worlds by explaining intellectual concepts in spatial terms. The architectural realisation of the metaphor is complete; the architecture is the story ${ }^{25}$. The effect of the architecture in exploring this concept is important to our understanding as readers.

Since Bouges wrote his story in $1941^{26}$, many have tried to discern how the library would look and the space that it would take up. This can be calculated from interpreting information in the text ${ }^{27}$ Furthermore, with the invention of computers one could presumably simulate the library by generating text at random in blocks four hundred and ten pages long (the length of the books in Bourges' library ${ }^{28}$ ) while stipulating that once a block has been generated it is never to be duplicated exactly by the programme. However, these kinds of simulations do not give the necessary scale to the problem

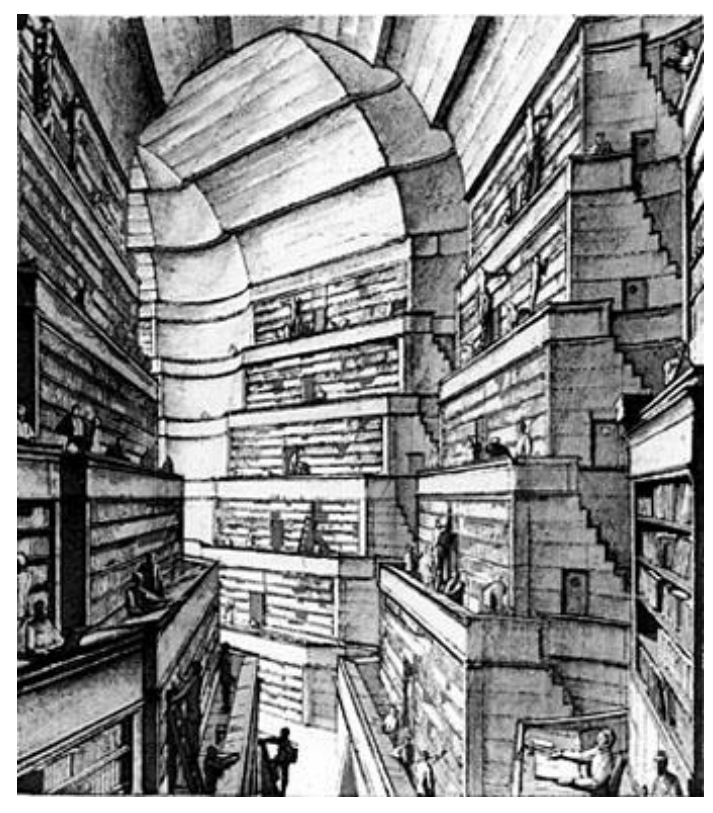

FIGURE 3: "HAUTE GALERIE CIRCULAIRE" ERIK DESMAZIERES, (C)2007 ARTISTS RIGHTS SOCIETY (ARS), NEW YORK/ADAGP, PARIS. 
presented by Bourges' writing; the imagery of the words and the relatable spatiality of the library archetype provide a platform for understanding the complex thought processes behind this story ${ }^{29}$.

Borges has presented in this narrative a labyrinth composed of a repetitive and homogenous series of rooms, which only seems to prove its vastness. The concept of the entire universe as a series of rooms is a fascinating impossibility as such a structure could never be built by mortal hands ${ }^{30}$. The scale of this problem is so vast that it is necessarily contained within an understandable archetype such as a library, and it could not be presented in all its incomprehensible size outside of a textual description.

The labyrinth exists within us. In the Library of Babel we are shown the frightening improbability of success in our search for truth ${ }^{31}$. Yet the narrator still expresses some hope that the search is not entirely in vain. The library must be finite because the number of variable books can be calculated ${ }^{32}$, so it must somewhere contain that catalogue of catalogues which would explain it. The narrator tells us that in the Library of Babel there is a mythical circular room containing one massive circular book which explains the properties of the library ${ }^{33}$. Even in the midst of this endlessly repeating labyrinth, the inhabitants have been able to imagine that somewhere is the ultimate truth, hidden at the centre of the maze.

This room connects this narrative to the story of the tower of Babel and the search for a truth which might not exist and which, if it does exist, is impossible to reach. In the Old Testament story of the tower which lends its name to Borges' Library, the inhabitants of Babel set out to construct a tower to connect the mortal world with heaven. God punishes their hubris by cursing them to speak many languages, causing the construction process to fall apart and the tower to fall. Searing commentary on the need for good communication in the building industry aside, the story is the inspiration for the theme of hopelessness in the search for divine truth ${ }^{34}$ expressed in Borges' narrative.

The tower reaches for that which lies at the centre of the labyrinth; truth and enlightenment, a relief from mystery ${ }^{35}$. It also carries the same connotations of imprisonment, isolation and a final destination. These central truths exist only through our faith in them; we have not the capacity, as mortal beings, to reach them ${ }^{36}$. We can only imagine and believe that they are lurking somewhere just outside our grasp. The destruction of Babel shows that the true height of the tower, although it may seem simple enough, is always frustratingly beyond what we manage to accomplish. Ultimately the tower of Babel came close enough to this 'truth' to warrant its destruction.
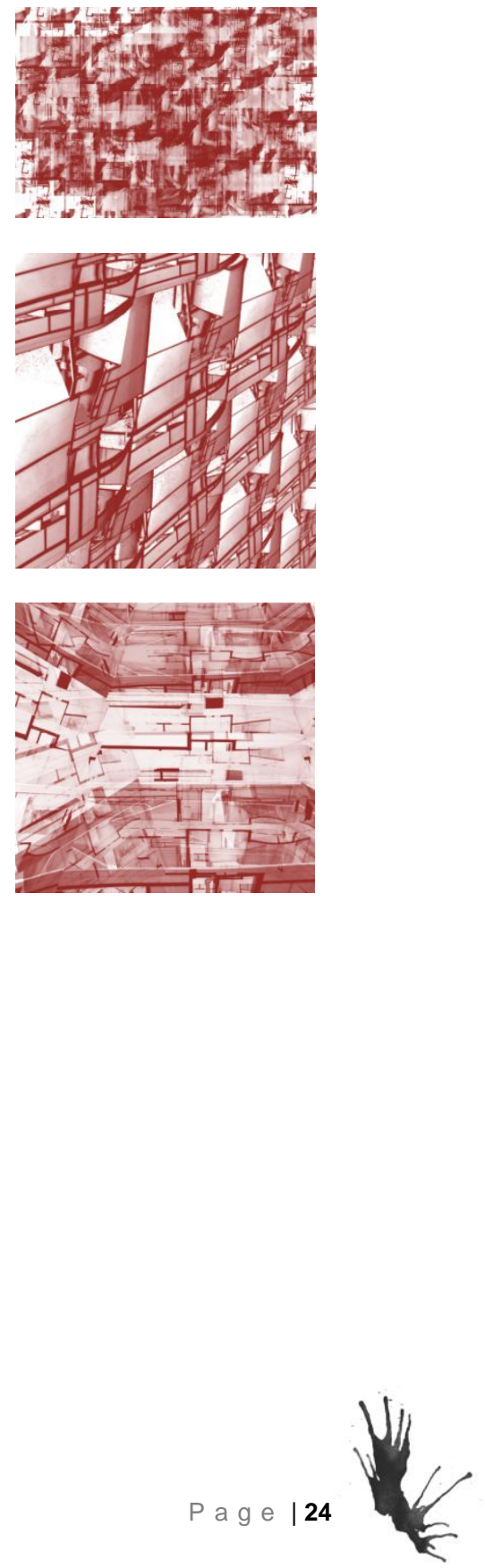
The reader has some prior understanding of the library archetype, and so they can use this to construct their own interpretation of the writer's intent and thus complete their crucial role in the cycle of storytelling ${ }^{37}$. The library is particularly powerful in that it is a storehouse for the very information stories seek to interpret, as Sophia Psarra explains: "Despite their obvious differences buildings like libraries, museums and archives have a similar identity ... Their expressive strength is based on their function as repositories of knowledge." ${ }^{38}$ The success of the story's metaphoric power is in the interpretation and in the significance of the library as a symbol and archetypal structure.

The familiar library archetype is used by Borges to allude to something much more complex and universal. The architectural metaphor gives a spatial dimension to the conceptual framework of Borges' library universe. The labyrinth he describes is so far beyond what we are able to understand that it must be qualified in terms of a scale we can relate to; the scale of the room and the book. However what results from this vast, repetitive structure is a sense of frustration from the character of the narrator. Those inside the library search for an order which may not exist. Every interpretation of the purpose of the library, like every interpretation of its volumes, cannot be proven and therefore gives no relief to the inhabitants. The architecture of the labyrinth shows that interpretation has a limit as a tool for understanding space; endless interpretation will resist a solution to the story.

\section{The Perpetual Castle}

Franz Kafka's novel The Castle is set within a landscape which embodies the labyrinth, using the inherent contradictions between containment and autonomy to set up a framework for the narrative. The protagonist, $\mathrm{K}$, arrives in a village where he is not wanted and yet he cannot be allowed to leave. The people of the village appear to be slaves to the bureaucratic processes of the mysterious castle which sits over them, and yet there is little interaction between the village the castle. What interaction may occur does so with a great reluctance on both sides. $\mathrm{K}$ spends the duration of the novel attempting to reach the castle (which he never achieves) and dealing with the frustrating insistence that he is not to belong.

The physical relationships of the setting mirror the social arrangement of the village, as $\mathrm{K}$ discovers the first time he tries to walk to the castle.

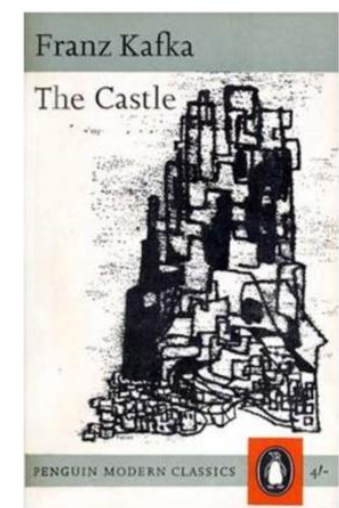

FIGURE 4: THE CASTLE, COVER FROM THE PENGUIN EDITION. 
"On he went, then, but it was a long way. This road, the village high street, did not in fact lead to Castle Hill, it only went close to it but then curved away, as if on purpose, and although it took one no farther from the castle, nor did it come any nearer. K. constantly expected the road to turn in the direction of the castle at last, surely it would, and it was only because he expected it that he kept going; obviously, given his weariness, he was reluctant to leave the road, he was also surprised at how long the village was, it went on and on, nothing but tiny houses and iced-up windowpanes and snow and nobody around - finally he tore himself loose from the grip of the high street, a narrow lane swallowed him up, even deeper snow, his feet sank in, it was hard work extracting them, he began to perspire, abruptly he came to a halt and could go no farther., 39

Just as the landscape seems to shift when he tries to reach the castle, so too do the arguments of the villagers change to counter whatever effort he makes to reach the castle. The labyrinth is created through the interaction of the characters and the setting. The containment of the labyrinth is invisible; interaction with it proves that it is cyclic in nature. Frustration with the plight of $\mathrm{K}$, although he is an increasingly unsympathetic character, shows our natural tendency is to want the village and the castle to communicate somehow and to end the nightmarish limbo in which we, as the reader, find ourselves on his behalf ${ }^{40}$.

With the villagers so controlled by the bureaucracy of the castle, $\mathrm{K}$ is the only character with any kind of autonomy in the novel ${ }^{41}$. Even so, his choices ultimately lead him nowhere as the town takes on the shape of his struggle. The endlessness of Kafka's labyrinth, while presenting quite a few choices to the character on how to proceed, also limits him by providing no opportunity to escape. Claustrophobia is a theme carried on through many of Kafka's works, hinted at through the controlling attitudes of the other characters and by restricting the characters' movements through the architecture of the setting ${ }^{42}$.

Any effort to change the status quo in the village proves to be futile; the castle which overlooks it represents a solution which is never to be reached ${ }^{43}$. The frustrating journey of $\mathrm{K}$ is also reflected in the dialogue of the various characters who, when called upon to give some sort of explanation to K's predicament, talk in circles with strange logic that does not relate to the reality of the situation Although the town and its inhabitants do not appear unusual at first glance, they come together in such strange ways as to build a labyrinthine purgatory out of the village.

As in the Library of Babel, there is the presence of hope - in this case the image of the castle atop its hill - to provide a purpose to the characters' action. The architecture of the castle itself reveals the
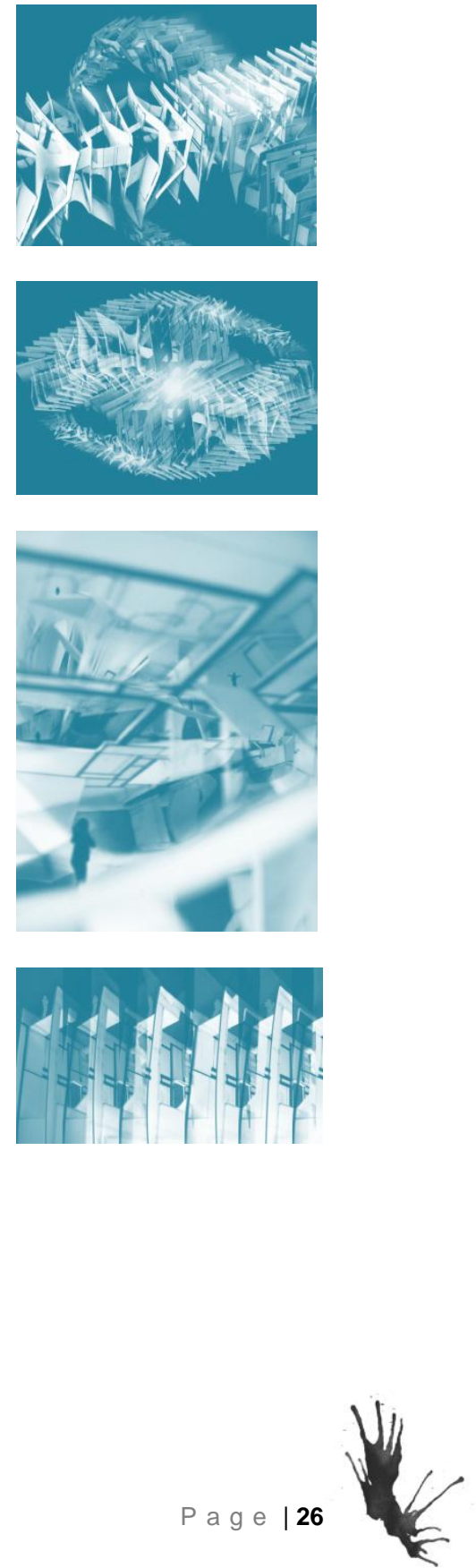
ambiguity of that hope: it is not really a castle at all, but a close-knit collection of smaller buildings, like a small town ${ }^{44}$. The only thing that makes it a castle is that everyone in the village refers to it as such. Whether all of the buildings constitute the entity known as the 'castle', or whether only the main tower structure could be called that, is left open ${ }^{45}$. This ambiguity is reflected in K's hope of finding a purpose within the village, as the reader cannot be sure if this is viable, or not, from the reactions of the other characters.

This also highlights another aspect of the narrative; the constant reinterpreting of events in order to justify the actions of the castle officials ${ }^{46}$. Every character in the story has their own way of explaining the situation, each as circular as the last. The documents which might serve as a way out of K's problems are so vague as to be virtually meaningless, and every person the character encounters cannot offer him a clear way forward because of this. This reveals is price of the labyrinth. When encountering an infinite number of paths, although we have the freedom to choose our own way, we will not gain anything by moving.

Kafka's narrative touches on the issues associated with the infinite nature of the labyrinth which were explored by Borges. The constant frustration of not being able to reach the destination of the Castle demonstrates the futility of trying to change the status quo, a theme felt deeply by the author during his lifetime ${ }^{47}$. The labyrinth is unfeeling towards the struggle of the characters. It does not respond to the interpretations of it; does not relent to the hope of finding some purpose within the maze. It remains unfathomable, and its outer limits cannot be sensed.

\section{Labyrinths of the Domestic}

Mark Z. Danielewski's House of Leaves makes unusual use of narrative and stylistic tools to tell the story. In fact, several narratives run through the course of the book, but for the purposes of this research I will concentrate on the one which describes the house on Ash Tree Lane, home of Will Navidson and his family. This narrative follows the format (for the most part) of an academic text which discusses a documentary film (The Navidson Record) supposedly made by Navidson about the house and the strange occurrences which mark their stay in it. The narrator whose story runs alongside that of the Navisdon Record reports that the film does not exist, even within the world of the novel: however this does not stop the story of the house having a detrimental effect on the characters who come across the report. 
The house appears normal at first, but when the family returns from a short vacation they notice that it has changed in their absence. A hallway between two bedrooms has appeared where there was no hallway before ${ }^{48}$. When the house is measured, it is discovered that the interior measurement exceeds that of the exterior, and consequent measurements prove that the interior space is expanding, while the exterior dimension remains the same $e^{49}$. A while later a doorway appears in the living room wall, leading to a featureless hallway which extends into the distance. There is no evidence of the hallway from the exterior of the house, even though it appears from inside to continue over the yard ${ }^{50}$. The characters feel compelled to explore this new hallway and its endless series of ever-expanding, featureless rooms. The emptiness and the strangeness of the place drives the characters to strange reactions.
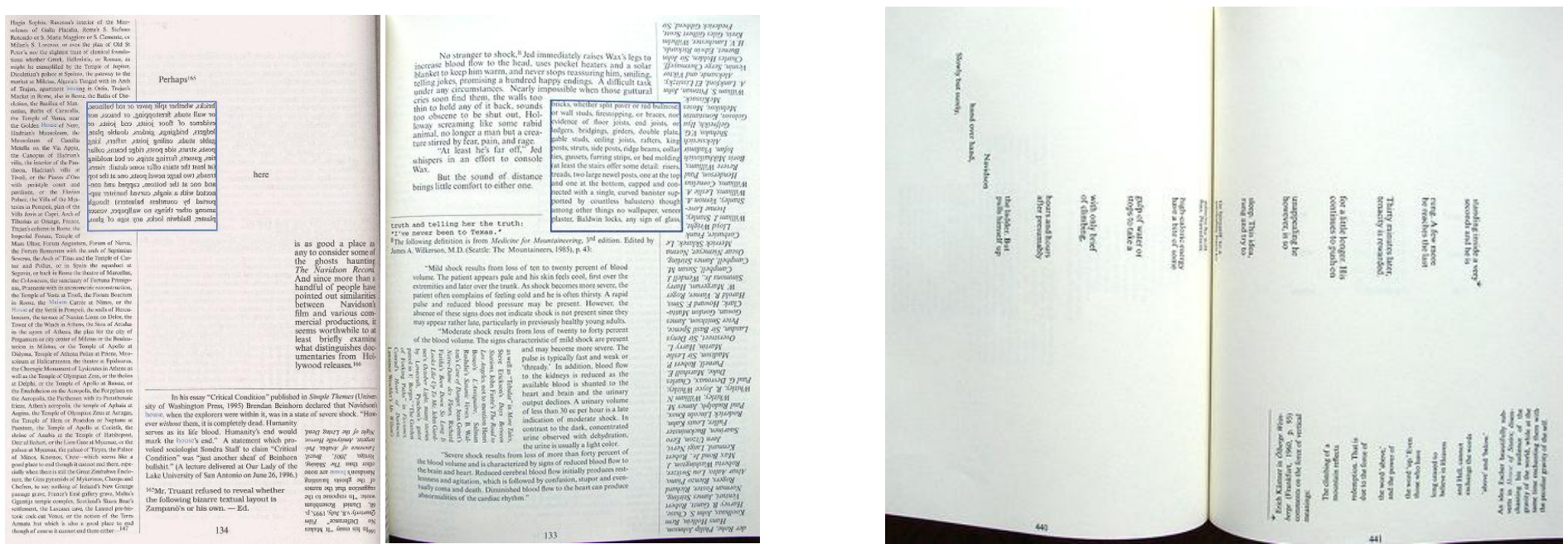

FIGURE 5: PAGES FROM HOUSE OF LEAVES, PG 133-4 AND PG 440-1, SHOWING USE OF FORMATTING TO CREATE LABYRINTH.

This book presents a labyrinth on a domestic scale and also on a textual one. The use of formatting techniques - font, colour (in some editions) and page layouts - require the reader to engage with the text as the characters move through the different narratives. The changes which occur in the house are reflected in the formatting of the text. For example, when a corridor begins to tighten, the words are constricted to a square in the centre of the blank page which contracts over consequent pages. 
When a character is climbing a ladder or staircase, the words also follow a path over the page which suggests this movement. The formatting is also used to suggest the unreliability of the narrators, by striking through any reference to the labyrinth of Minos, and colouring any instance of the word 'house, ${ }^{, 51}$.

Even more so than the other two narratives I have discussed already, this book explores how the labyrinth changes depending on the person who moves through it. Their individual choices and interpretations lead the characters to obsession, insanity, murder and death. The way the house changes could also be seen as the house revealing itself, and revealing the true nature of the characters as they interact with it ${ }^{52}$. Their fears seem to set off its changes, and their expectations alter the experience of the place. They find, for instance, that vast rooms crossed in one direction will be even larger on the return ${ }^{53}$.

The setting of the house allows the narrative to concentrate on the characters in this way, as the house is a building which is related most intimately to the body ${ }^{54}$. Even a mundane house will take on the personality of its inhabitants ${ }^{55}$. But even as the house in this narrative reveals its inhabitants, the constantly changing shape of the interior defies the attempt to occupy it: "... unoccupied space will never cease to change simply because nothing forbids it to do so. The continuous internal alterations only prove that such a house is necessarily uninhabited." ${ }^{56}$ The inability to inhabit the house is part of what makes it so disturbing.

An interesting feature of this labyrinth (considering its situation within the domestic scale of the house) is that sometimes the spaces which appear are incomprehensibly huge. In one instance, as Navidson is exploring the hallway alone, the walls, ceiling and floor disappear completely into black, and he feels that he is standing on an island of solid ground in the middle of some great void ${ }^{57}$. When he manages to move on from this void into a narrowing hallway, he remarks that: "These walls are actually a relief ... I never thought that this labyrinth would be a pleasant thing to return to." ${ }^{58}$ Some sense of containment is a comfort compared to the previous experience of nothingness. This recalls the idea that with too much autonomy within the labyrinth - if there is no limit to the space or the possible paths - it is impossible to gain any ground towards a destination.

The final escape from the house is only made possible when Navidson and his partner, Karen, are at the very brink of despair. Navidson is dying, and they are lost in the void of the labyrinth; then, suddenly, they appear on the front lawn ${ }^{59}$. Once outside, they have escaped the containment of the labyrinth. The house has let them go as they finally achieve what they arrived there to do: they have
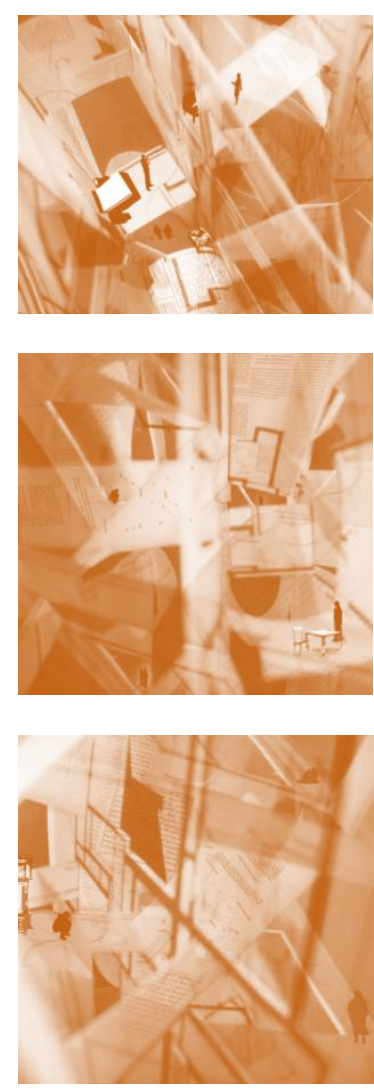
learned what they mean to each other. The labyrinth has revealed its secret, and the prison has served its use.

The labyrinth described here changes depending on the interpretation of it. In this space where no guidance towards a particular interpretation is available, the architecture of the space has no solid form. It cannot be understood by its users as the constant change gives no clue as to how it could be occupied.

\section{Conclusion}

Through these three narratives, the architecture of the labyrinth is used to explore theme and character. The degree of autonomy we actually have when we are presented with a multitude of options becomes apparent through the characters interaction with their setting. As the possibilities for interpretation approach the infinite, the actual progress made in reaching the desired goal becomes less. However, so long as that goal remains visible the plot will still advance.

Architecture within fiction has endless interpretation because of the ambiguity of words when describing space. In the examples above we see three different uses of the labyrinth to evoke and question this ambiguity. The Library of Babel uses a repetitive and homogenous labyrinth of hexagonal rooms to hint at its endlessness. Kafka's Castle presents a village which behaves like a labyrinth even though there is no visible containment. House of Leaves on the other hand gives us a labyrinth which changes and transforms those who enter into it.

The themes of these narratives are represented by their architecture. The archetype of the labyrinth gives both the freedom to interpret and the containment within a concept which storytelling desires. The implications of this study for architecture are to show the limits of interpretation. When confronted with the endlessness of the labyrinth, it is impossible to reinterpret space in any meaningful way. It is not enough to hint at a purpose to the story: it must be shown so that the story can continue with a new application of narrative. 
${ }^{1}$ Hermann Kern, Through the Labyrinth: Designs and Meanings over 5,000 Years (New York: Prestel, 2000) p23.

${ }_{2}^{2}$ Bernard Tschumi, Architecture and Disjunction (Cambridge, Mass: MIT Press, 1996) p140.

${ }^{3}$ Sophia Psarra, Architecture and Narrative: The Formation of Space and Cultural Meaning (New

York: Routledge, 2009) p5.

${ }^{4}$ Chi, p82.

${ }^{5}$ Harold Rosen, Stories and Meanings (Sheffield, UK: National Association for the Teaching of English, 1985) p10.

${ }_{7}^{6}$ Rosen, p14.

${ }^{7}$ Lily Chi, "Narration and the Architectural Program: The 'Mythical' Status of Architectural Fictions," Writing/History/Architecture/Myth, ed. Michael Linzey (Auckland, New Zealand: The University of Auckland, 1991) p81.

${ }^{8}$ Mark Wigley, "The Translation of Architecture, the Production of Babel," Assemblage.8 (1989): p12.

${ }^{9}$ Chi, p84.

${ }^{10}$ Wigley: p12.

${ }^{11}$ Mark Frisch, You Might Be Able to Get There from Here: Reconsidering Borges and the Postmodern

(Madison, N.J: Fairleigh Dickinson University Press, 2004) p24.

12 Kern, p42.

${ }^{13}$ Kern, p23.

${ }^{14}$ PR Doob, The Idea of the Labyrinth from Classical Antiquity through the Middle Ages (Ithaca: Cornell University Press, 1990) p40.

${ }^{15}$ Frisch, p25.

${ }^{16}$ Kern, p23.

17 Frisch, p24.

18 Walter Benjamin, "The Storyteller," Illuminations: Essays and Reflections (New York: Schocken Books, 1969) p6.

19 Jorge Luis Borges, "The Library of Babel," trans. Emece Editores, Ficciones (New York: Grove Press, 1962) p83.

${ }^{20}$ Psarra, p90.

${ }^{21}$ Borges, p83.

22 Borges, p82.

${ }^{23}$ Frisch, p58.

24 Psarra, p5.

${ }^{25}$ Psarra, p90.

${ }^{26}$ William Goldblom Bloch, The Unimaginable Mathematics of Borges' Library of Babel (New York:

Oxford University Press, 2008) p10.

${ }^{27}$ See Bloch.

${ }^{28}$ Borges, p80. 


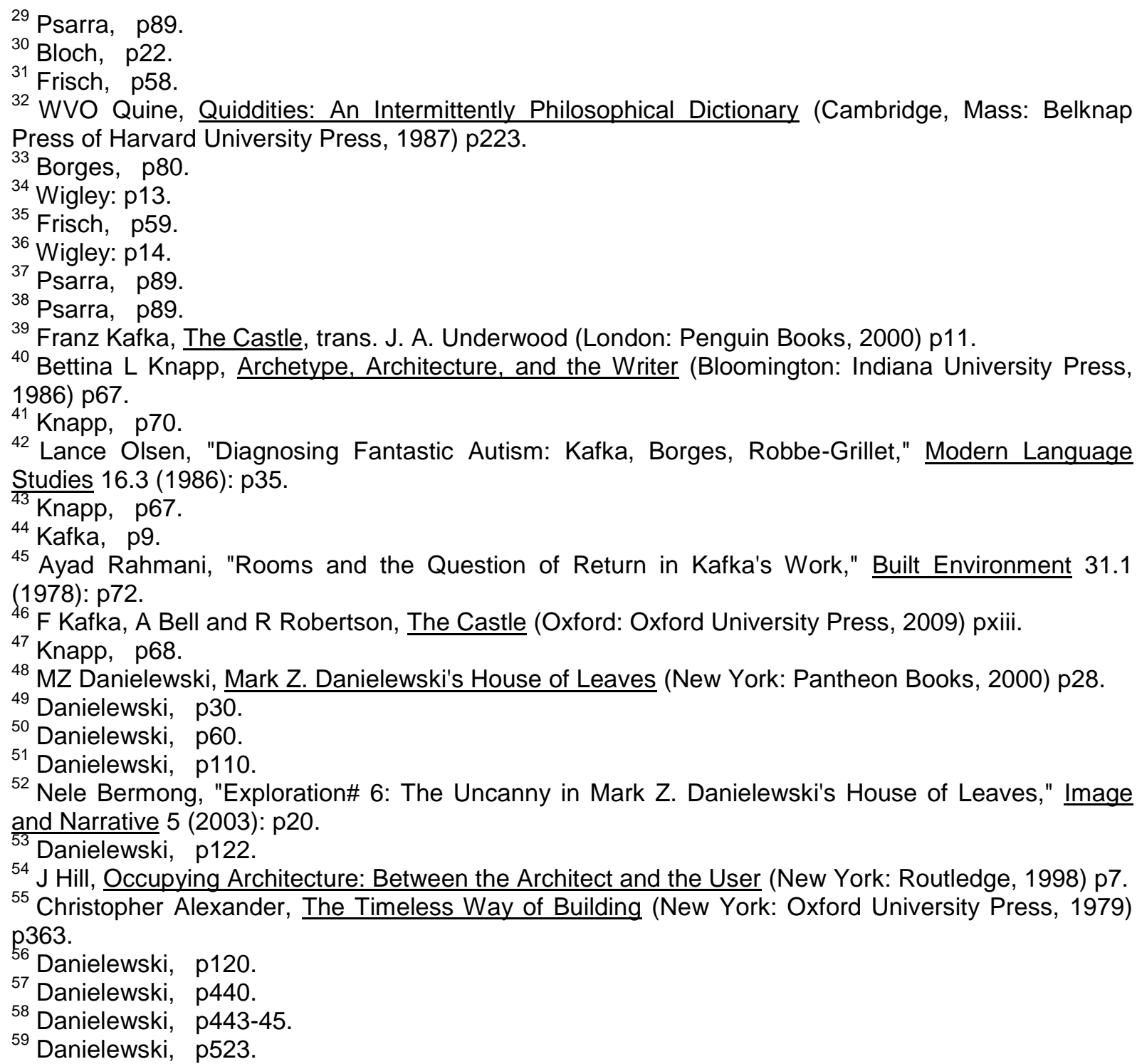

45 Ayad Rahmani, "Rooms and the Question of Return in Kafka's Work," Built Environment 31.1 (1978): p72.

F Kafka, A Bell and R Robertson, The Castle (Oxford: Oxford University Press, 2009) pxiii.

${ }^{47}$ Knapp, p68.

${ }^{48}$ MZ Danielewski, Mark Z. Danielewski's House of Leaves (New York: Pantheon Books, 2000) p28.

${ }^{49}$ Danielewski, p30

${ }^{50}$ Danielewski, p60.

51 Danielewski, p110.

${ }^{52}$ Nele Bermong, "Exploration\# 6: The Uncanny in Mark Z. Danielewski's House of Leaves," Image and Narrative 5 (2003): p20.

${ }^{53}$ Danielewski, p122.

$54 \mathrm{~J}$ Hill, Occupying Architecture: Between the Architect and the User (New York: Routledge, 1998 ) p7.

${ }^{55}$ Christopher Alexander, The Timeless Way of Building (New York: Oxford University Press, 1979) p363.

56 Danielewski, p120.

57 Danielewski, p440.

58 Danielewski, p443-45.

${ }^{59}$ Danielewski, p523. 


\section{CHAPTER THREE: INTERPRETATION}

The story relies on the interpretation of the audience to maintain its cycle and to endure beyond the possibilities of mere narrative. Language systems offer a certain ambiguity which provides the opportunity for this interpretation to occur ${ }^{1}$. The question is whether architecture can achieve this level of interpretation on its own, in order to convey a personal and mutable impression to those who encounter it.

A certain level of autonomy is desirable for the audience. When there is an opportunity for the audience to find their own way through the story, there is more opportunity for the cycle to continue and for the reader to become the next storyteller ${ }^{2}$. This autonomy is created within the narrative through the practice of 'showing' and not 'telling'; that is, the subtext is not forced upon the audience ${ }^{3}$. In practice, this allows a greater emphasis on those parts of the story which are implied, as the audience has a chance to imagine a personal relationship with the message when they are allowed to come to it by themselves ${ }^{4}$.

The linear conception of narrative in some architecture does not provide for this autonomy because it directs a path through a space. This is inefficient as the concentration is fixed on a certain way of using space, not taking into account that no two experiences will be the same ${ }^{5}$. Architecture endures for a long time and it stands to reason that a building will come into contact with many different interpretations over its life ${ }^{6}$. We should embrace this collection of meaning, guiding future inhabitants to add to and change the conceptual nature of the space.

I found that the work of John Hejduk, while providing the opportunity for interpretation between text and image, relied too heavily on language systems to be read as purely architecture. The relationship between the various mediums was such that any attempt to experience one without the other would result in a deficient reading of the space ${ }^{7}$. A building should be able to speak for itself and to provide its own context outside of any explanation. It should have some autonomy within its own medium, particularly when built and inhabited.

By looking into fictional narratives I was able to question the idea of autonomy further as it related to the labyrinth. The labyrinth is a common character in all three of the narratives discussed. Its endless 
nature and its diverging pathways take the autonomy of the human characters and stretch it to its absolute limit, making a prison out of their infinite options. In fiction we have the option of questioning the limits of space; however in architecture we are responsible for creating real space. The level of interpretation found within the labyrinth is not desirable for architecture, and yet interpretation is important to the process of storytelling. There needs to be room for audience interpretation, but there also needs to be room for the author interpretation to guide the experience. Too much autonomy on the part of the audience will lead to a labyrinth from which there is no escape; that is to say, the design will not have a coherent conceptual framework. It will be completely re-imagined by those who inhabit it. Meanwhile, too much authorial dictation on the part of the design intent will not allow the building to contain or adapt to the constantly changing shades of human life ${ }^{8}$.

\section{Inkblot Experiments}

At this stage of the research, I wanted to work with images to create a design experiment. This would lead me away from the temptation to try and write architecture. Although language systems are developed for storytelling, and although language provides the ambiguity which leads to interpretation, I wanted to work in a visual medium which would help me to reach an architectural solution.

A person's ability to provide interpretation of an abstract image gives some proof of a 'theory of mind'. The Rorschach test is one tool which uses the patient's interpretation of a series of inkblots to diagnose psychological problems. The theory is that, based on the analysis of the abstract form, a psychologist can provide insight into the subject's subconscious thought process. The blots are used as a way of stimulating the interaction between the patient and the therapist ${ }^{9}$. Although the test is sometimes discredited as a tool for diagnosis ${ }^{10}$, it is still interesting as a narrative tool as it allows interpretation to occur without any real author, as the inkblots are essentially meaningless. 

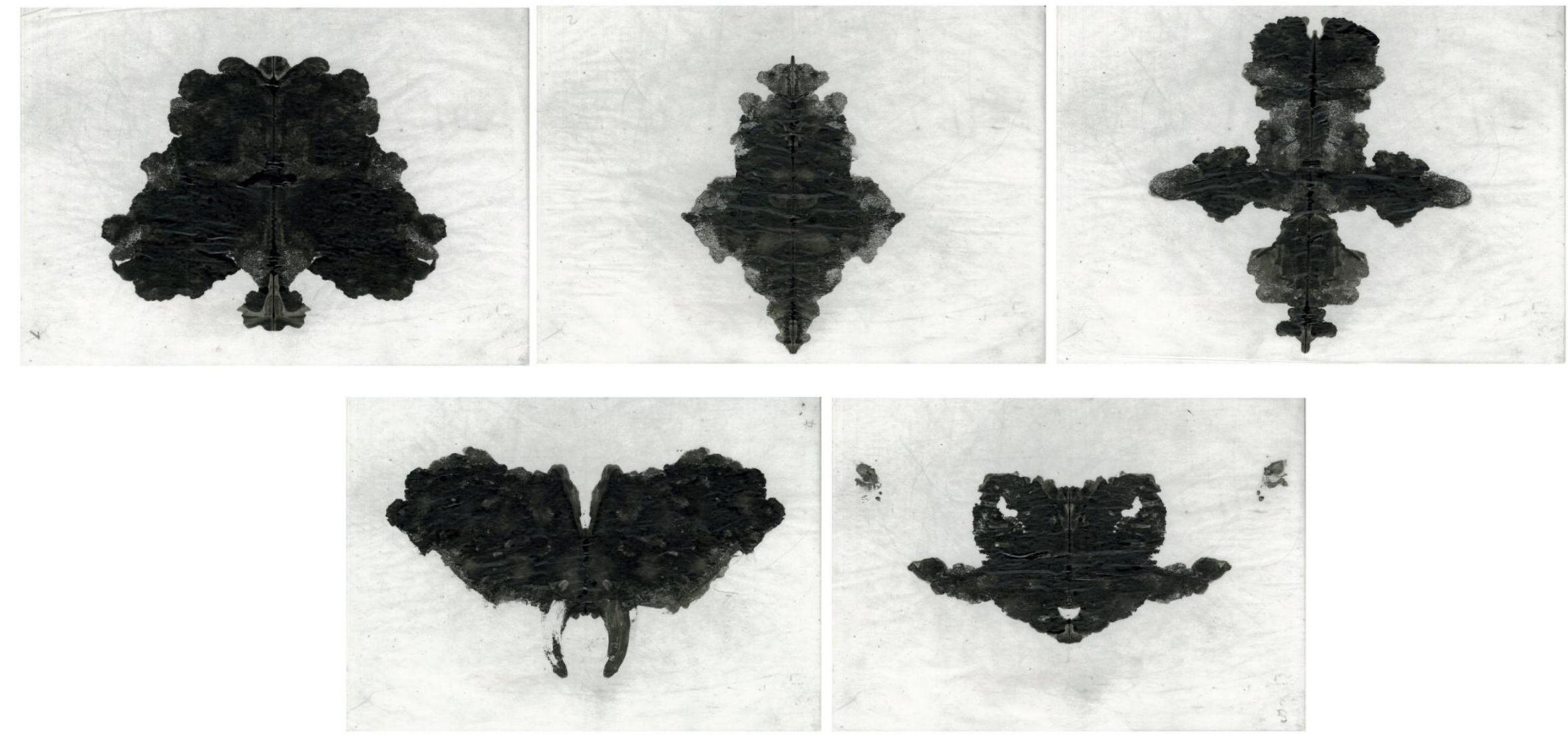

FIGURE 6: CREATED INK BLOTS.

I began by creating my own set of inkblots to work with, to divorce the images from the pro forma set of analyses associated with the test. They were mostly 'random', although I did tamper with a couple in order to create a greater variety of shapes. The way the ink ran was never completely in my control, so the inkblots were mostly independent of my influence. My analysis began with investigating the individual blots, using a light table to uncover the intricacies of the ink texture. By interpreting the texture of the blots through pencil drawings and through the computer, I came across common elements. These elements, I concluded, were what allowed the blots to be reinterpreted in so many different ways. 
Each blot appears symmetrical, but is in analysis more complex than this. The illusion of symmetry is one of the few things showing a human hand in the creation of the image, so it creates a suspension of disbelief by suggesting some ordered meaning in the shape. The semblance of mirror symmetry suggests more regular geometries to the mind, aiding in the assignation of an intellectual concept to what is essentially abstract. Each blot has an ambiguous outline, giving them a semi-fractal nature and hinting at boundaries without exactly defining them. This recalls the endless nature of the labyrinth with an infinite number of paths to choose from. The high contrast of the black ink on the background was another common element. This contradicted the ambiguity of the outline by suggesting a contained field of finite space, as in the labyrinthine structures of fiction. Finally, the complex texture revealed when the ink was held up to the light gave the images depth, allowing them to provide yet more options for interpretations in different directions.

The inkblot let me be both creator and audience. The cycle of storytelling - from author to audience and back again - was repeated in me as I reinterpreted the drawings. I applied my own rules to each interpretation to decide where to put the lines, uncovering the patterns made by the ink. This led to the development of a process by which the blots were transformed.
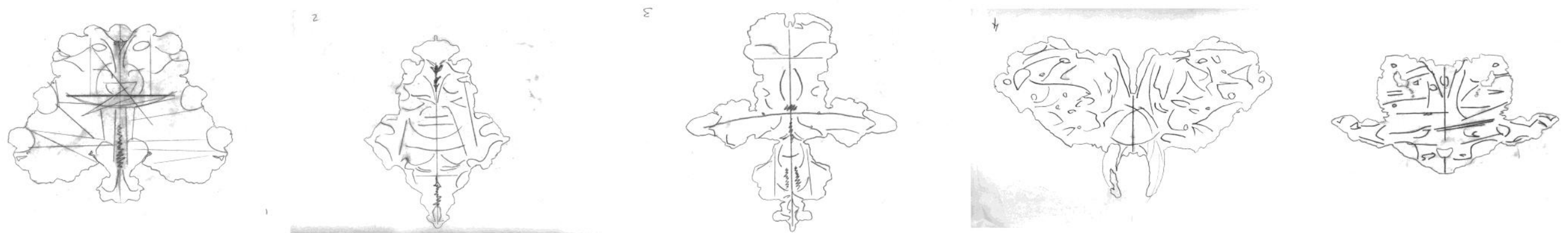

FIGURE 7: INITIAL EXPERIMENTS WITH INK BLOTS. 


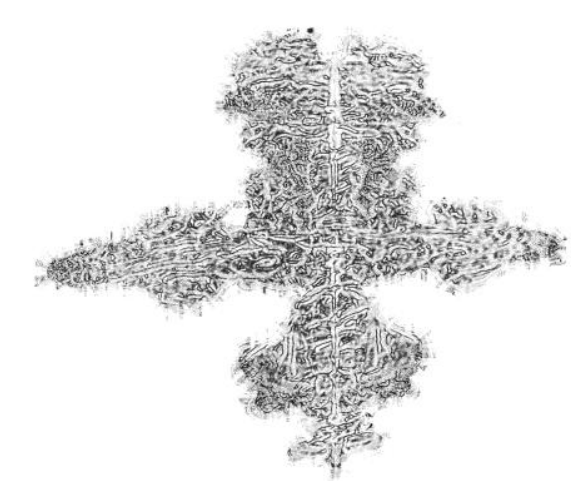

$\varepsilon$

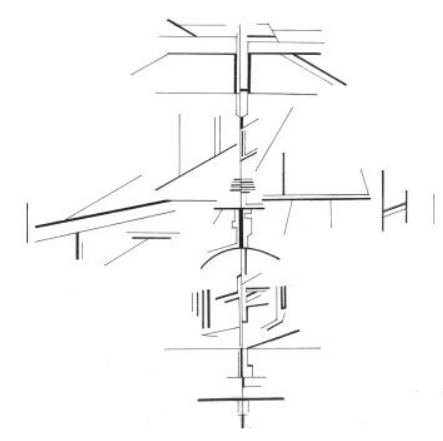

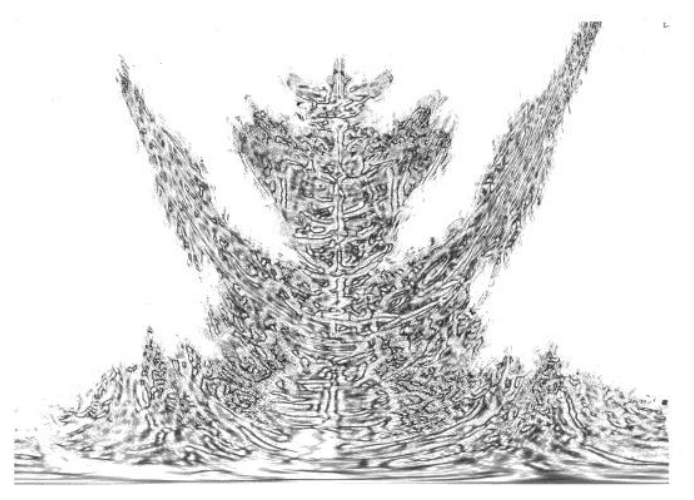

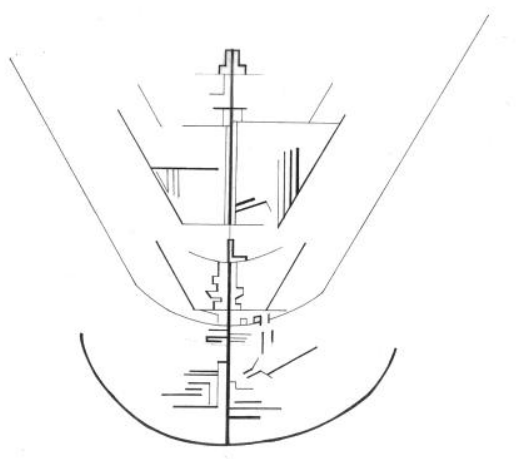

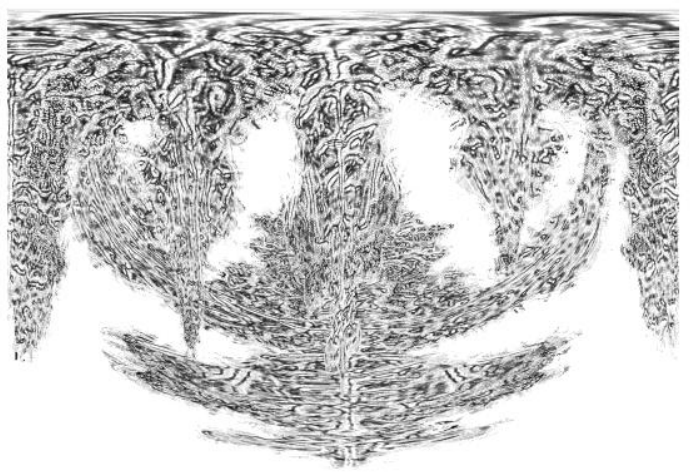

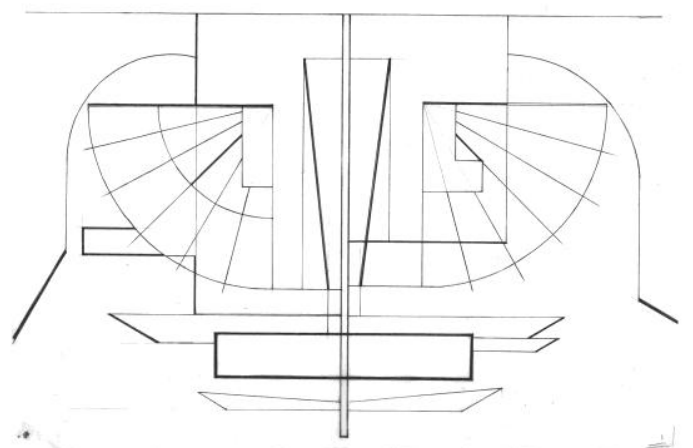

FIGURE 8: APPLICATION OF NARRATIVE THROUGH LINE WIDTHS.

By eliminating irregular curves and concentrating on simplifying existing geometry, I reduced the inkblot down to its dominant patterns. This was aided by the use of image filters on the computer, which enhanced the texture of the ink. This simplification allowed me to apply my own reading of the patterns, thus adding my own changing element and creating a new object which was affected by my understanding of the image. Through this simplification, I discovered that the most important decision I had to make was where the lines would begin and end. This would determine how much of the new image was my creation and how much it was influenced by the original inkblot. The lines I chose to draw were influenced by my intuitive reading of the texture of the ink. 

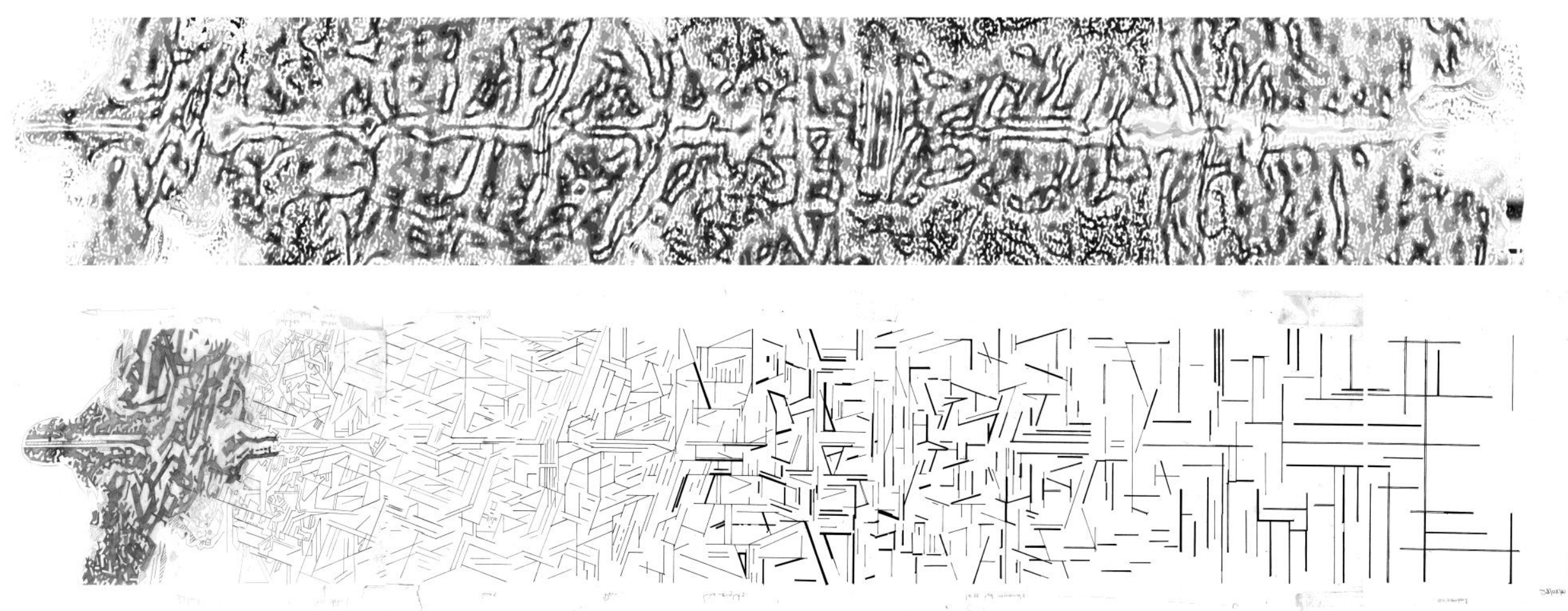

FIGURE 9: DRAWING ALONG THE SPINE OF THE INK BLOT REVEALS PROCESS OF INTERPRETATION.

Once the lines had been drawn, I proceeded to apply to it a narrative through experimenting with line weights. The different thicknesses of lines were applied mostly through an intuitive consideration of the aesthetics of the image. Some, but not all, were influenced by the texture of the inkblot itself. Others were influenced by errors in my drawing process. This personal exploration revealed that when working with images in this way the narrative, once applied, was not linear; it was a consideration of the whole as a story which was revealed through applying the process. The finished product bore the marks of this process when compared with the original inkblot. 
I then explored this process through larger drawings, investigating how a different scale might affect the image and also hoping to reveal the process. I used a section taken along the spine of one of the inkblots I had created, blowing it up to a much larger scale. The spine was interesting as it suggested the symmetry I had discovered in the other images, although when blown up to a larger scale the imperfect nature of that symmetry became more apparent.

Over the length of this image I applied the different stages of the process described above, beginning by using very little simplification and becoming less and less complex as I moved down the axis of the spine. I moved from a detailed interpretation of the texture to a more generalised one, restricting the angles that I could use to describe the texture of the image. As I got closer to the end, I applied line weights to describe a narrative. Over the length of this image, my own interpretation of the ink texture became clear, and the process of interpretation was revealed.

The simplification to geometric patterns allowed the narrative to be reapplied in a different way, creating a new story out of the base image. Progressing from one to the other revealed that while the process of applying narrative works in a linear way, the narrative itself comes across only in the final image. Breaking down the ink texture reveals of the story, and the reapplication of narrative completes the cycle of storytelling.

The inkblots did not, however, translate immediately into a spatial narrative. My attempts to reinterpret them using three-dimensional modelling techniques did not wield satisfactory results as the materials did not bring across the interpretive qualities of the ink that the drawings retained. The modelling process presented a dead end in terms of the reinterpretation of the images. I also tried to apply a grid to the image in order to build it up into a three-dimensional object, but this undermined the complexity in the texture.
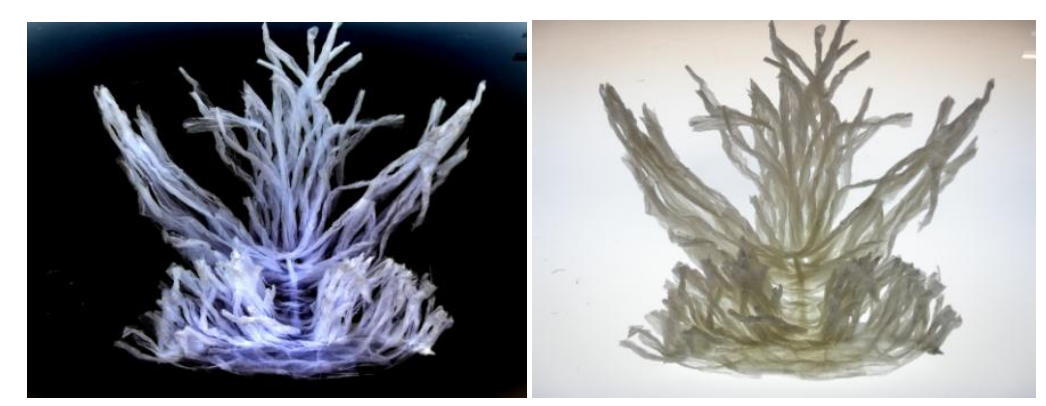

FIGURE 10: INK BLOT MODEL MADE FROM BUTTER PAPER. 


\section{Conclusion}

Although the inkblots provided a way to investigate the limits of interpretation within a visual expression of storytelling, there were limits to their effectiveness when moving into a spatial narrative. The amount of autonomy I had to choose how to represent the patterns meant that many of the decisions I was making were arbitrary. The resistance to being reinterpreted into a spatial form also meant that I could not proceed from the inkblots into an architectural expression.

The ambiguous nature of the inkblot, while providing the opportunity for abstraction, led me into a labyrinth of choices when I tried to represent it. The random nature of its generation meant that it resisted the attempt to ascribe meaning to it. The image had no underlying concept when it was made, and therefore any interpretations are equally meaningless except in the mind of the creator. There is no way to trace an evolving concept from one audience to another, as the concept will only retain consistency within a single individual. The ambiguity of the inkblot means that there are an infinite number of interpretations possible.

From this experiment I have uncovered a process which allows me to reinterpret images by concentrating on where lines begin and end, and using line weights to apply narratives to the images. This process of simplifying and transforming represents a personal questioning of the story within the image. It transforms the inkblot, which is randomly generated so as to not have any inherent meaning, into a personal story of one person's interpretation.

These experiments have provided a way forward into an architectural expression of the story. Although they are not successful themselves in becoming architecture, there is a possibility that the lessons learned here about the process of interpretation could be applied to a form which has more inherent architectural connotations. The next step is to take the interpretive qualities of the inkblots and apply them to architecture, creating a balance between storytelling and the endless interpretations of the labyrinth. 
${ }^{1}$ Bernard Tschumi, Architecture and Disjunction (Cambridge, Mass: MIT Press, 1996) p146.

2 Walter Benjamin, "The Storyteller," Illuminations: Essays and Reflections (New York: Schocken Books, 1969) p6.

${ }^{3}$ Benjamin, p4.

${ }^{4}$ Benjamin, p4.

${ }^{5}$ Edward Hollis, The Secret Lives of Buildings (New York: Metropolitan Books, 2009) p9.

${ }^{6}$ Hollis, p8.

7 Lily Chi, "Narration and the Architectural Program: The 'Mythical' Status of Architectural Fictions," Writing/History/Architecture/Myth, ed. Michael Linzey (Auckland, New Zealand: The University of Auckland, 1991) p82.

${ }^{8}$ Christopher Alexander, The Timeless Way of Building (New York: Oxford University Press, 1979) p36.

${ }^{9}$ AS Reber, The Penquin Dictionary of Psychology (New York: Penguin Books, 1985) p112.

${ }^{10}$ Scott O. Lillenfield, James M. Wood and Howard N. Garb, "What's Wrong with This Picture?," Scientific American Mind 284.5 (2005): p82. 


\section{CHAPTER FOUR: FIOOR PL ANS AND THRESHOLDS}

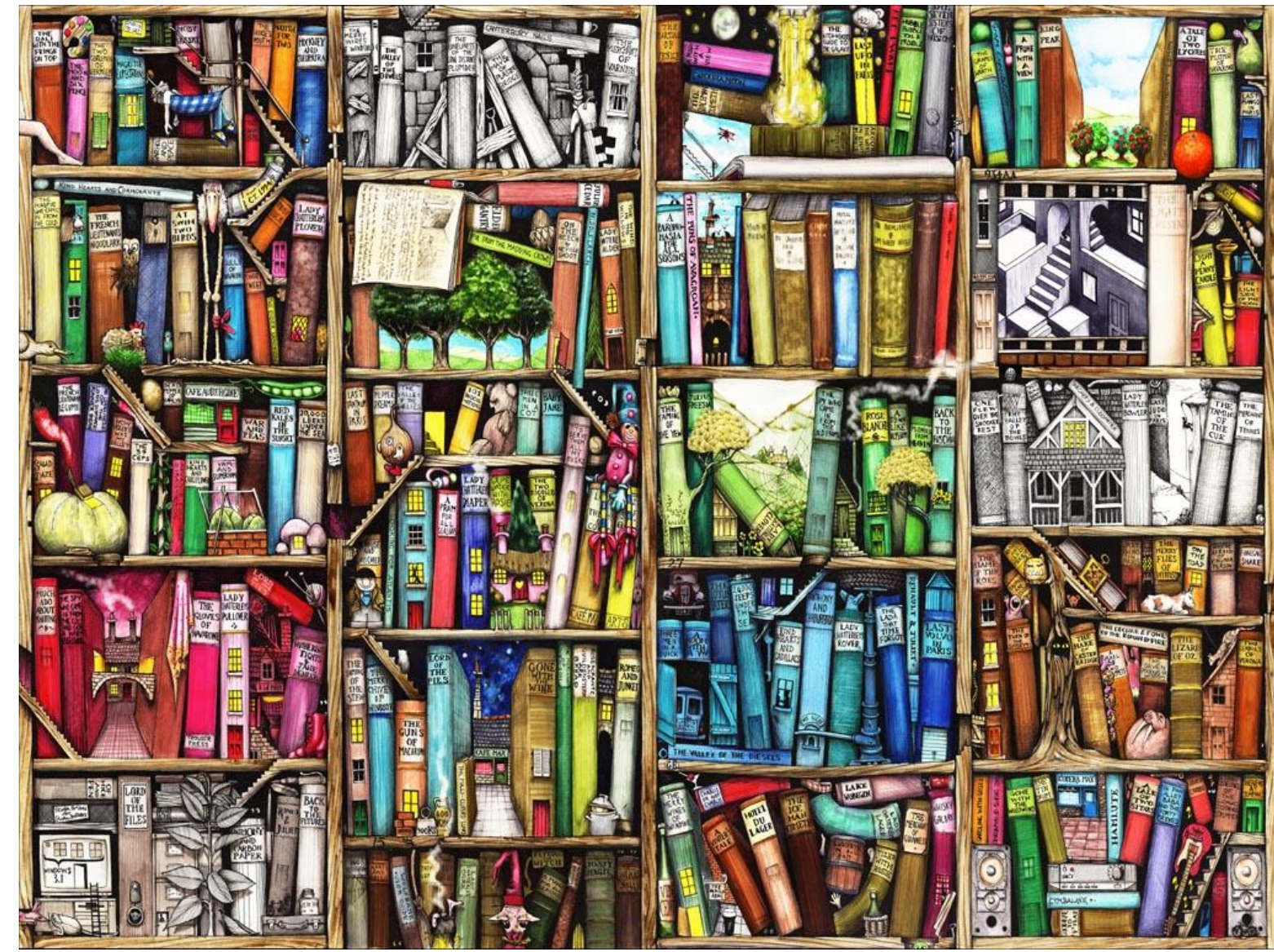

FIGURE 11: COLIN THOMPSON, HOW TO LIVE FOREVER. LONDON: RANDOM HOUSE, 1996.
Following the inkblot experiments, I decided to work with a focus towards an architectural solution. The work with interpretation had led me to a process which I could now apply to an architectural form. Due to their potential for reinterpretation, I chose to work with floor plans. The use of floor plans in the representation of an architectural work gives a concise and complete view of the whole, while allowing the built form to be broken up into discrete spaces. When indicators such as labels are removed, the plan gives plenty of room for interpretation while still representing the architecture as seen from a privileged place of knowledge. 
Sophia Psarra writes that: "Crossing a boundary that separates the inside from the outside is like entering a fictitious world, like opening a book to read a story." The floor plan is a representation of these boundaries, suggesting that movement into and through the story. The lines on the floor plan simultaneously represent the separation and interconnectivity of different rooms. Though we might be inclined to view these thresholds as suggesting a linear sequence, the lines themselves do not dictate direction; they merely divide and negotiate the movement between spaces.

Consideration of the nature of thresholds led me to create a small sketch model. This model was constructed from butter paper and shows a single opening with multiple thresholds. The threshold lines were emphasized so that they would catch the eye as it moves through the model.
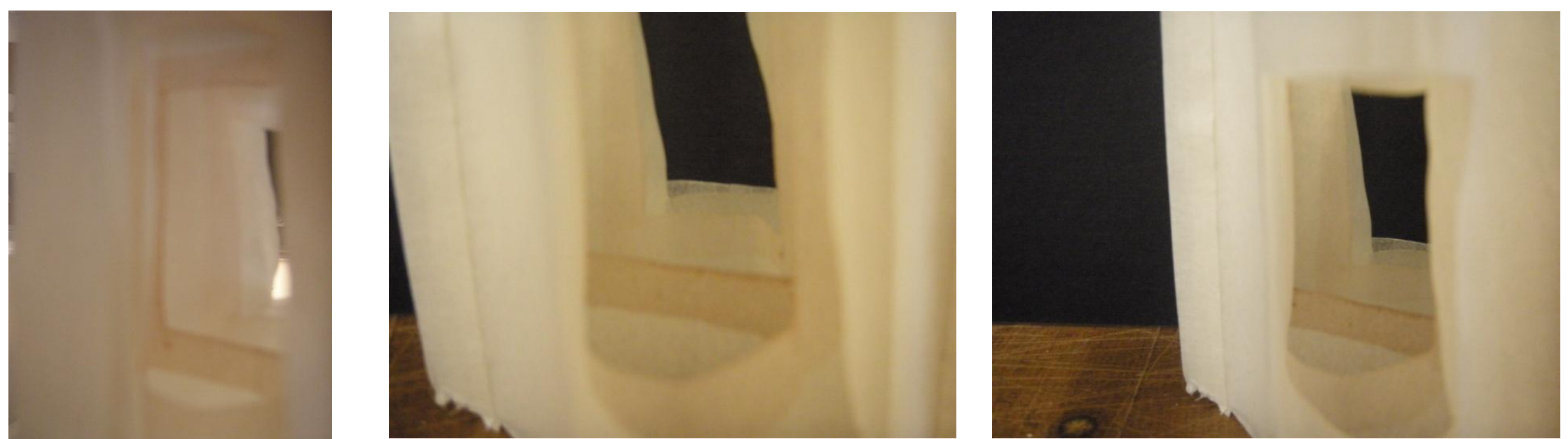

FIGURE 12: VIEWS OF THRESHOLD SKETCH MODEL.

The sketch model shows how a threshold is not a barrier between two spaces; it defines the zone of movement between contained spaces. This recalls the paradox between the containment of space and the autonomy to choose a path through the space which is found within the labyrinth. The model uses layering and transparency to suggest the idea of interconnectivity as the eye moves across each dividing line. The threshold layering shows how the experience of moving through space us punctuated by the thresholds which divide it. 


\section{The House}

To begin with, I had to select a plan which would provide scope for interpretation throughout the process. I decided to work with a house for a number of reasons, chief among them being that the house is a familiar building in most peoples' lives. It is the first building that we have any sort of relationship with, and it is the building type we always return to; despite its sometimes mundane character it is the building which attracts the most stories due to these personal relationships ${ }^{2}$.

I still wanted to approach the interpretation of the plan from a relatively blank canvas as I felt that this would give me a greater scope for applying my own narratives. This is why I chose to take the plan from a home designed by $\mathrm{G} J$ Gardner, an Australian-based design-build company which specialises in affordable homes. Their plans were available from their website, and I selected one of these ("Thames House"3) to be manipulated into new architecture through the process of interpretation.

The choice of this particular plan was mostly due to its asymmetry and its use of right angles, which would make the task of rearranging the layout of the plan much easier. Although Thames House is perhaps not something we could identify as 'architecture' there was potential in the shapes of the floor plan to reinterpret this into something new. The potential interpretation in these floor plans comes about from the way these houses are sold; as commodities waiting to be personalised. In its representation Thames House really is the blank canvas I needed to begin my process of interpretation.

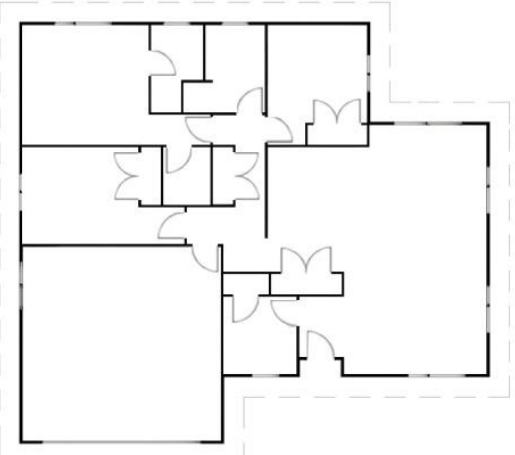

FIGURE 13: “THAMES” HOUSE, G J GARDNER NEW ZEALAND. 


\section{The Plan}
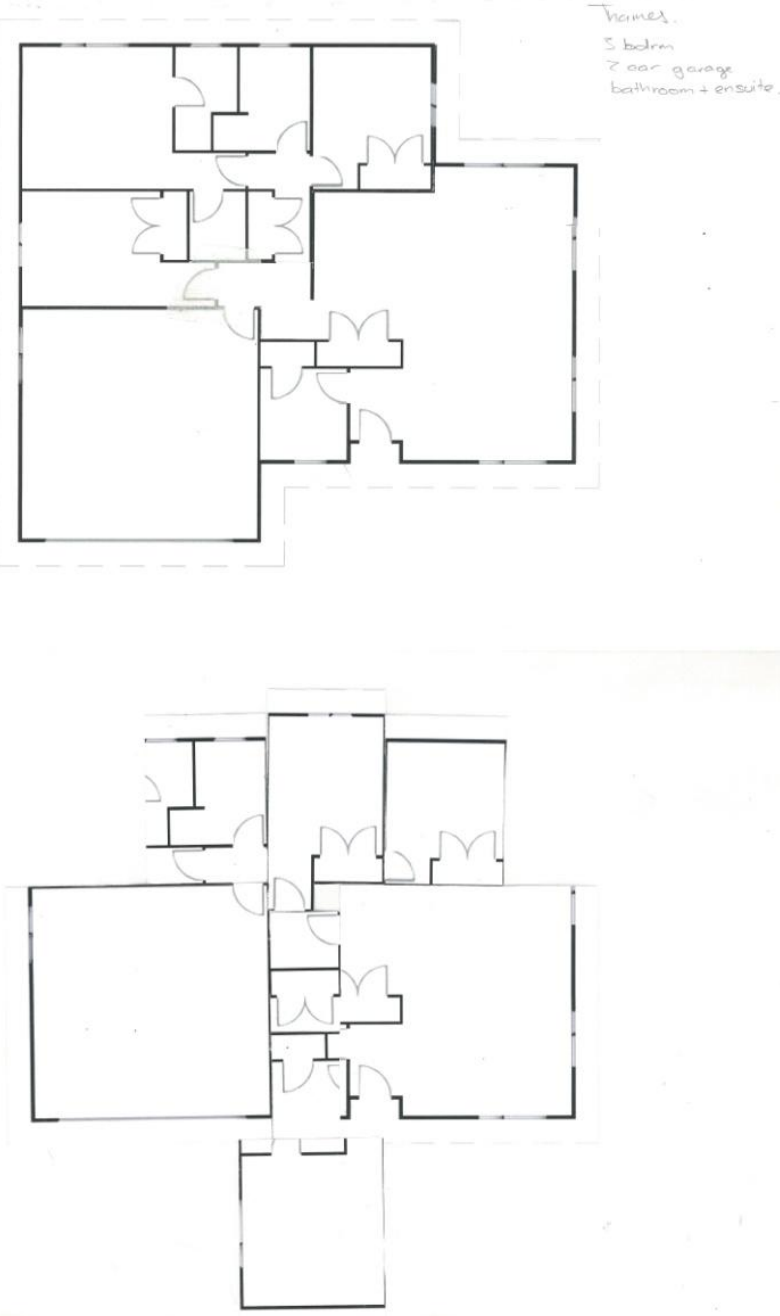

I started by changing the arrangement of the floor plan to give its outline some symmetry. This dramatic change to the layout of the plan divorced it from the intent of the original design and its programmatic concerns, no longer conforming to definitions of bedroom, bathroom, kitchen, etc. The illusion of symmetry, which was such a defining characteristic of the inkblots in my design experiments, connected the story of my research processes to the new plan. I could now see the plan as a part of my own narrative. 


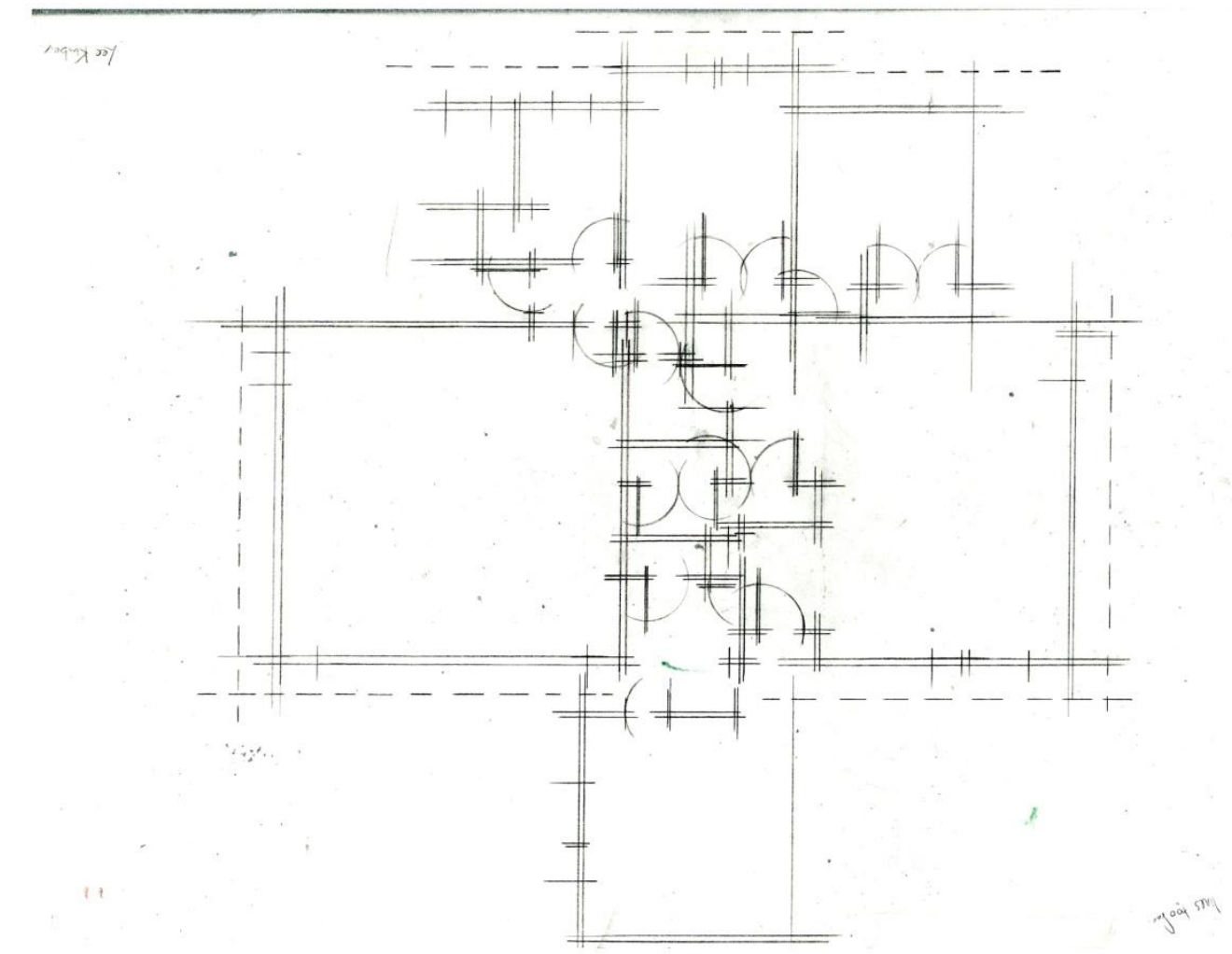

FIGURE 15: PLAN WITH LINES TAKEN BEYOND THEIR NATURAL END POINTS.

I now had the opportunity to reinterpret that narrative using some of the processes I had uncovered with the inkblots. I concentrated on the lines which made up the plan, ignoring the idea that they constituted three-dimensional elements such as walls; instead interpreting them as two-dimensional threshold maps. This allowed me to ignore the functional requirements of providing accessibility between two spaces. I began to experiment with the termination of lines, extending them beyond their natural ending points to explore the patterns in the plan. This was a part of the interpretation process which had been suggested by the inkblot experiments, as the point where lines begin and end was where the reinterpretation of the texture began to occur. 


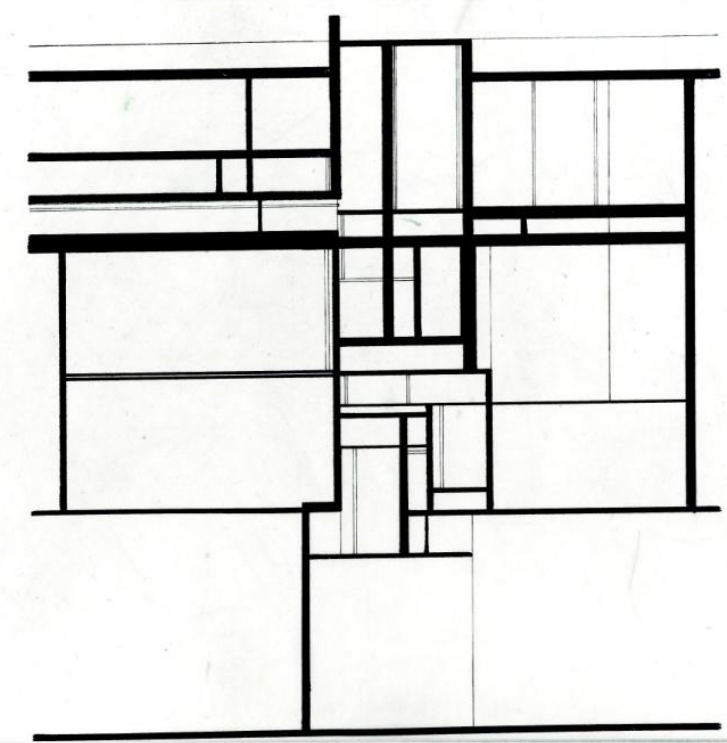

FIGURE 16: THRESHOLD MAP 1

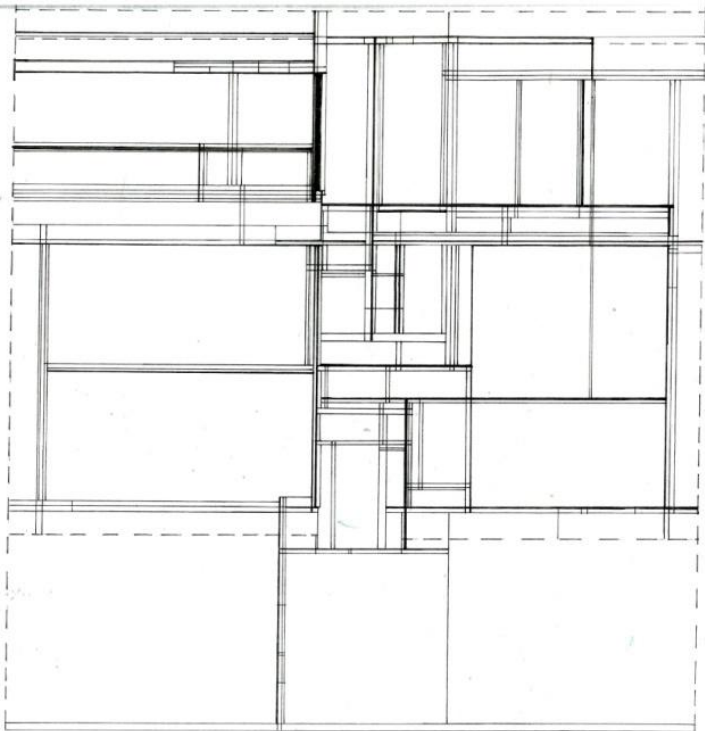

After continuing the lines to their intersections on the plan and eliminating the curves from the door swings, I had created a threshold map which was very orthographic and did not carry the depth I had found in the complex texture of the inkblots. I then began to apply different line weights in a similar process to the one I had used with the inkblots, using this to create my own narrative and to emphasise my subjective interpretation of the image.

I have called this image a 'threshold map' as it is no longer a part of the floor plan. The threshold map does not necessarily conform to a top-down sectional representation of spaces, and could be interpreted as section, elevation or plan. By removing the graphical conventions of the plan, we remove its relationship to a particular view. This also addresses the preconception that the threshold is a line which can only be crossed in a horizontal direction and thus is a representation of a linear path through a space; the new threshold lines have no orientation and therefore cannot be held to a linear movement.

I continued this process to create one more image by overlaying the overlined plan and the line weight plan. Out of this I made a more complex lined drawing which incorporated both the ordered nature of the line weight plan and the ambiguity of the overlined drawing. The layering process I had used recalled the idea of layering of meaning from Benjamin ${ }^{4}$, and the use of palimpsest as employed by Tschumi $^{5}$, adding new meaning to the drawings though the application of my interpretation.

FIGURE 17: THRESHOLD MAP 2 
These four interpretations of the original plan come together to form a set of drawings which demonstrate a narrative sequence of interpretation. This narrative is particularly clear when the drawings are set side by side. The thresholds have a relationship from one drawing to the next and when layered on top of one another they constitute a progression of interpretation which adds to their meaning. Moreover, the lines had ceased to be related to the walls they had originally represented. The threshold lines were now suggesting many different ways of moving across the plans; and when they were layered up there was even the possibility that they could be negotiated in more than two horizontal directions. With this in mind, and considering the layered nature of the sketch model I had made earlier, I decided to take the drawings and move into three-dimensional representation.
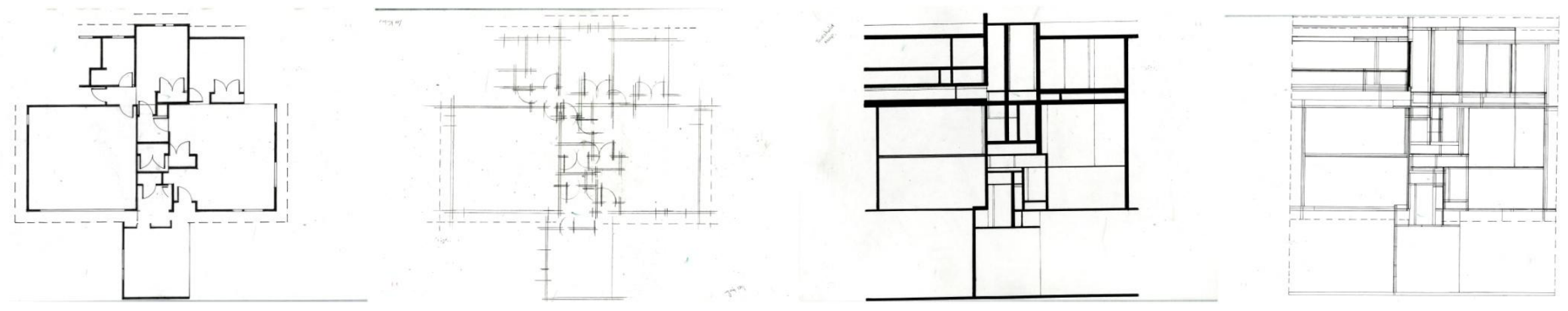

FIGURE 18: SET OF FOUR PLAN INTERPRETATIONS 


\section{Threshold Models}

The models were constructed by considering the way the drawings had been created, through the layering of different interpretations. I wanted to express the way that a person might move through these interpretations and how that journey might affect their understanding of the original plan. I began by layering the images and cutting into them at the thresholds.

I wanted to show how these thresholds might be reinterpreted in three dimensions to remove the preconception of linear movement across a plan. I used the spaces which broke away from the twodimensional plane of the plan to make a three-dimensional plan between all four of my drawings. I have called these objects the 'threshold models'.
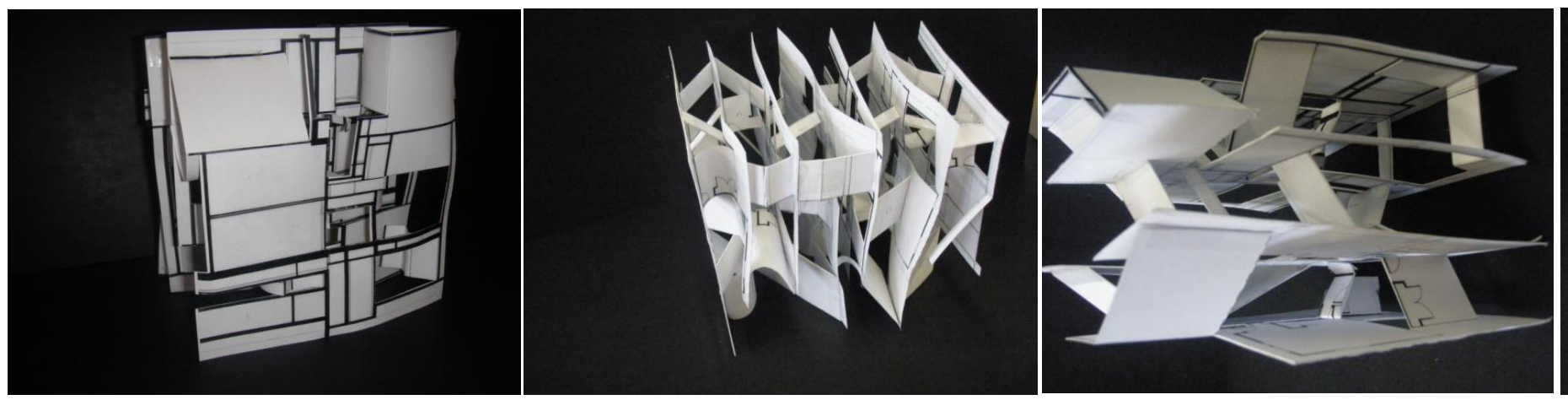

FIGURE 19: SOME IMAGES OF THE THRESHOLD MODELS

Each model was slightly different, owing to the materials used or the configuration of layers. This meant that I was constantly reinterpreting the way the structure worked and the appearance of the spaces in-between the layers. The shapes of the forms were often determined by the first cut, as the rest of the structure depended on this foundation. The material used also determined the nature of the model; harder materials had more structural integrity but fewer options in terms of void spaces due to their inflexibility.
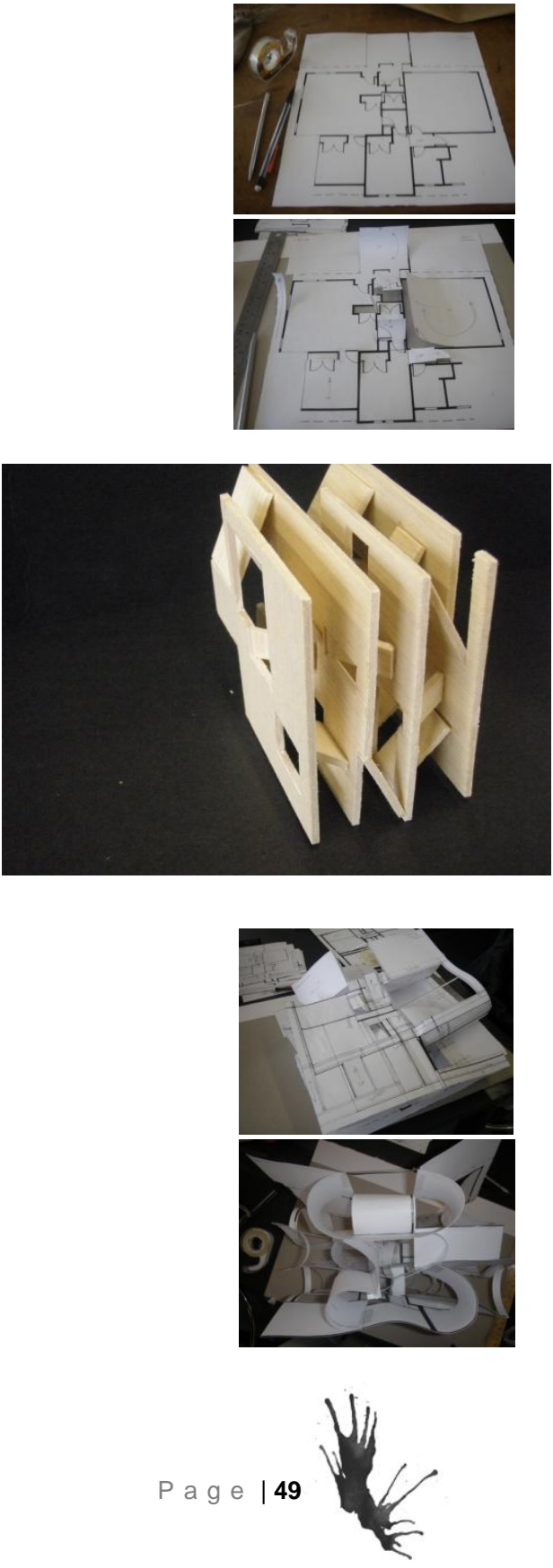

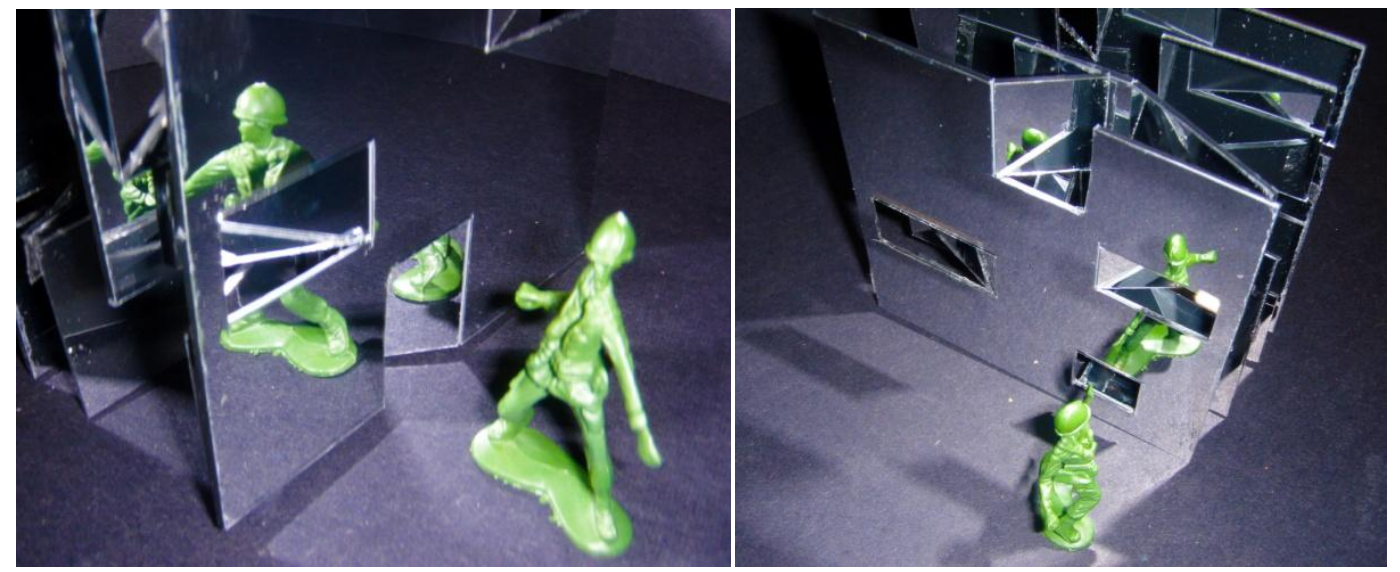

FIGURE 20: THE MIRROR MODEL
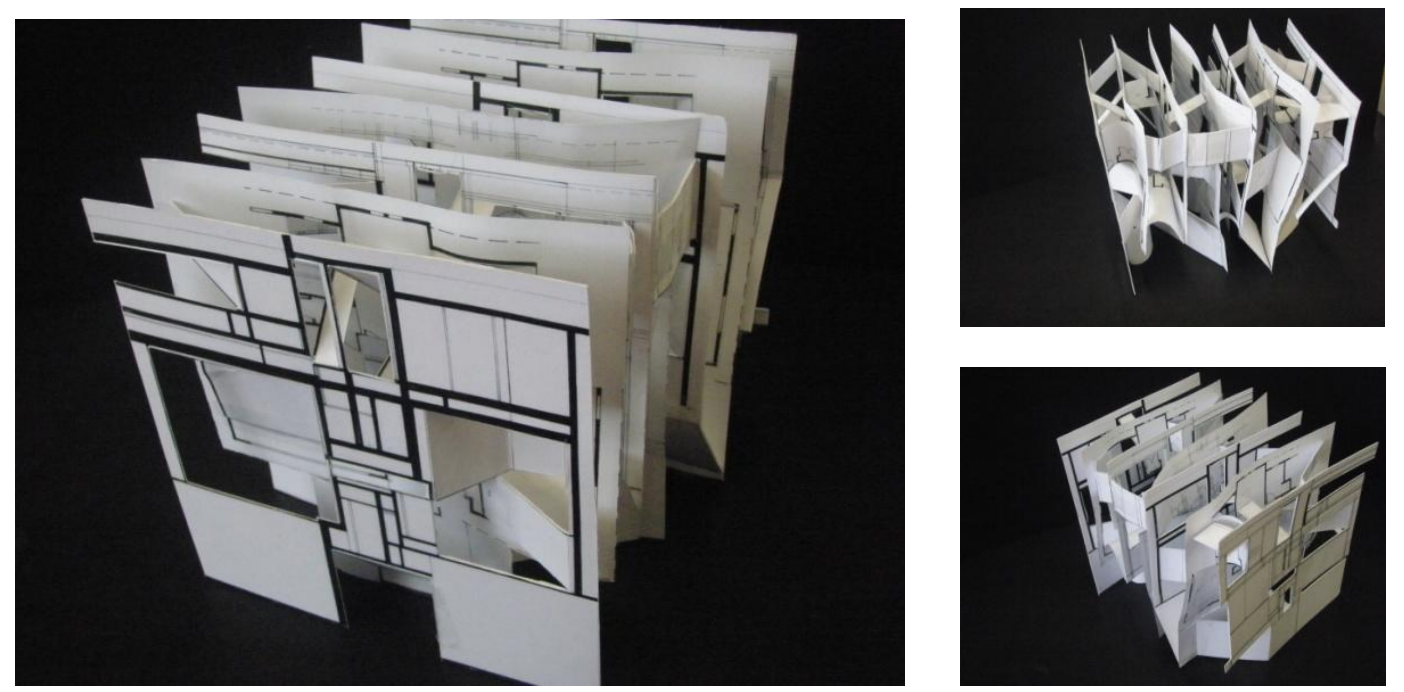

FIGURE 21: THE HARD/SOFT MODEL
One of the more successful models made out of a 'hard' material was the mirror model. The photographs of this model show how it conceptualises the interpretation of the image as it passes through the threshold models. The changing angles of the mirror transpose the image onto the different planes as it moves through the layers. This model was weakened, however, by a few factors: the mirror finish was only on one side of each layer, the nature of the material made the choices for voids quite limited, and there was no remnant of the original plan left on the surfaces. It is most useful in describing the conceptual basis for the paper models.

The most successful threshold model used a combination of hard and soft materials. It was also made stronger by the appearance of the threshold maps on either side of each layer. The spaces between the layers which are created by the voided spaces are more varied than a 'hard' model and yet structurally sound enough that it can be examined for its spatial qualities. The strength of the material within this model was related to the process of interpreting the plan; the earlier plans are on the soft paper as they are still undergoing interpretation and the later threshold maps are on the tougher card as they have been almost completely removed from the original floor plan and are represented as entirely new images. 
When examining the 'hard and soft' model, it became necessary to find the angle from which it was most naturally viewed. This involved yet another process of interpretation. While the model was constructed by placing one layer on top of another, it became apparent that it was best interpreted and understood from the side. From this angle it was possible to view the spaces created by the voids and reinterpretations of the thresholds, as well as affording the model with more structural integrity.

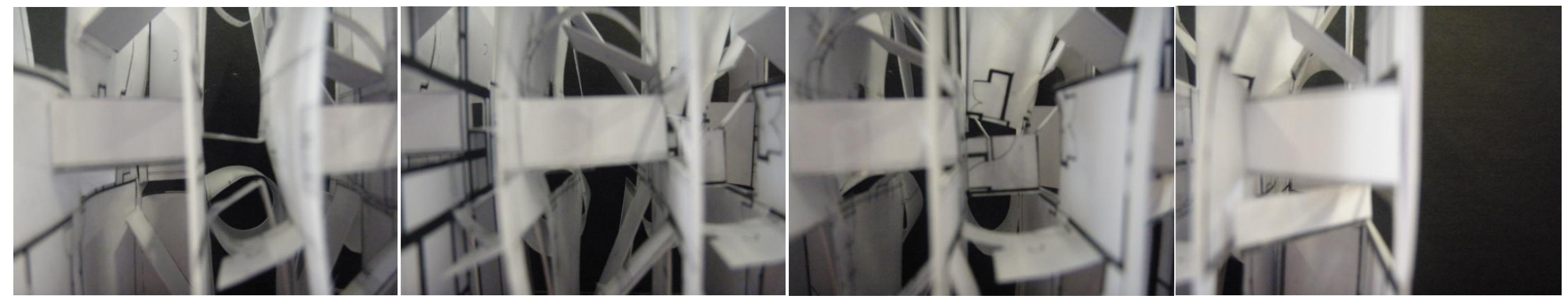

FIGURE 22: SIDE VIEWS OF THE HARD/SOFT MODEL

The spaces created within the model now favoured the vertical planes of the original layers. Through interpreting the model at different scales, different possibilities for inhabitation of the form became apparent. The model had retained the interpretive possibilities of the plan, unlike the attempts to make the inkblots three-dimensional. This was in part due to the architectural nature of the object created, which gave the option of being read at any number of scales.

The interpretation of the plan found within the model was also non-linear. The spaces it created did not suggest pathways, instead they created spaces which were a part of and formed by the process of the narrative. As the orientation of the models was ambiguous, the way spaces might be occupied was left open to the application of programme. A weakness of the models was that they lacked a purposeful narrative, as they were generated from an unoccupied plan. They would have to be reinterpreted through a narrative in order to avoid the problem of the labyrinth, with its infinite number of arbitrary choices.
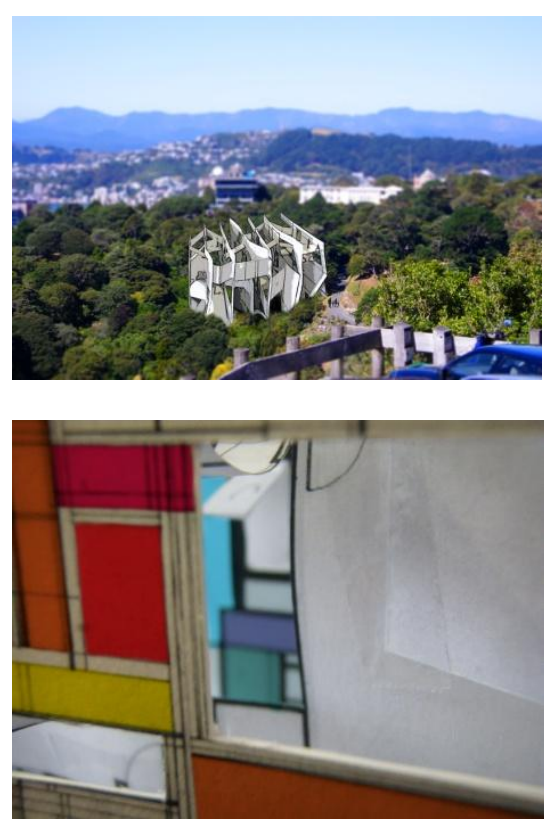

FIGURE 23: EARLY SCALE IDEAS U 


\section{Application of Narrative}

I decided to create a series of images using the models which focussed on the main themes of the narratives I discussed in chapter two. As these narratives had used architecture to discuss and explain their themes, the task was to find ways in which to translate those themes back into an architectura expression using the spatial models I had created. I wanted to express the labyrinths described in the three narratives while at the same time allowing the viewer to gain something towards their own interpretation of those themes.

I used a combination of photo-manipulation techniques to apply the narratives to the photographs of the threshold models. Through all of the images, I wanted to retain the depth of field that appeared when I looked into the models. I imagined the models at different scales to investigate how this depth might be used to change the meaning of the voids and panels. The models were combined and overlaid on one another to change their identity from single objects, in order to represent larger spaces. I used colour to tie the images to their various narratives, dividing them into three separate series. 


\section{The Library and the Tower}

The Library of Babel presents the audience with a repetitious and homogenous labyrinth of incomprehensible size. For this narrative I wanted to concentrate on the nature of the structure described, using a gridded overlay and a repetitive structure to the images while hinting at the endless variation found within the library.

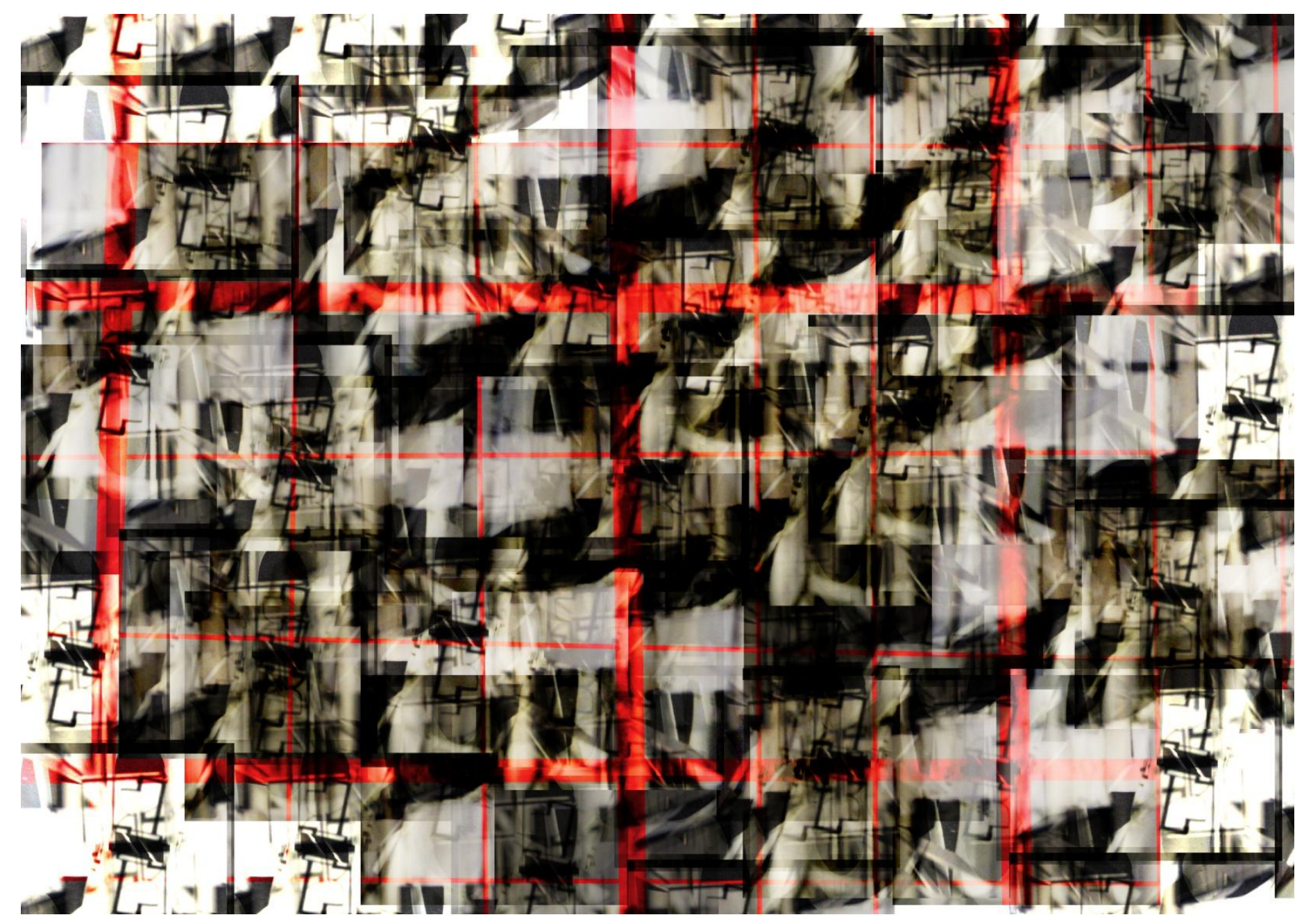

The Grid one particular view of the model. The more it was ranslated, transformed and overlaid upon itself, the harder it became to discern the pattern of voids, panels and lines which defined the thresholds. The grid highlights the pattern of the overlaid images, alluding to the homogenous structure of the library. The variation found in the image hints at the library's vastness and the confusing nature of the books within.

\section{FIGURE 24: THE GRID}

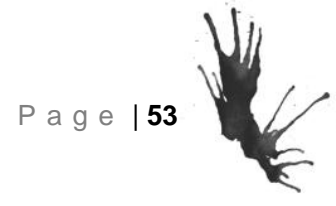




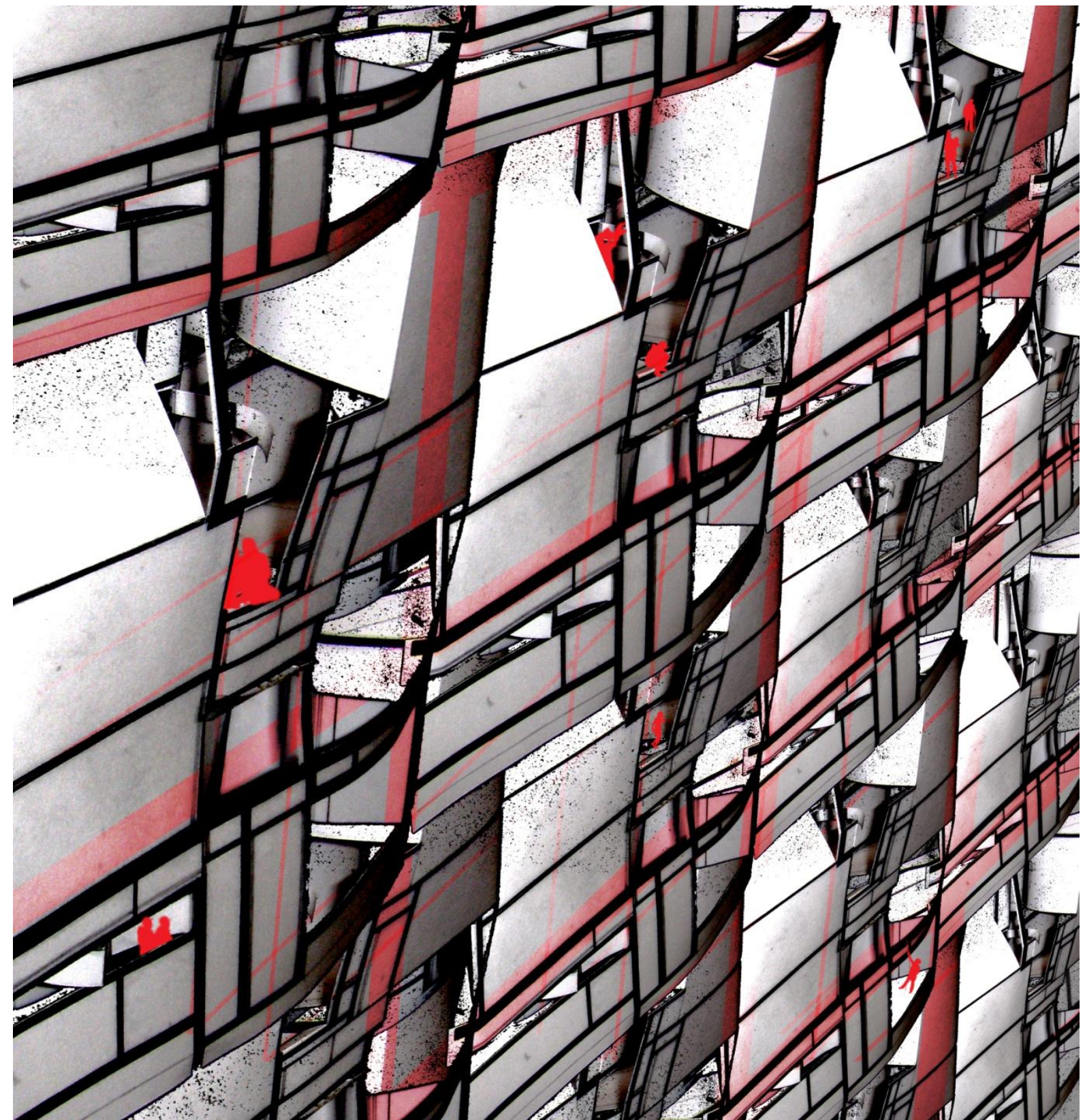

FIGURE 25: THE WALL
The Wall

This image gave some concept of scale and depth to the idea of the library by the addition of human figures. The repetitive panel structure alludes back to the homogeneity of the library. The repetition of the bold lines and the voided spaces gives a machine-like feel to the image. In this structure there is a hint of the alien quality of the immense library.

Lee Kimber - Truth in Fiction: Storytelling and Architecture 


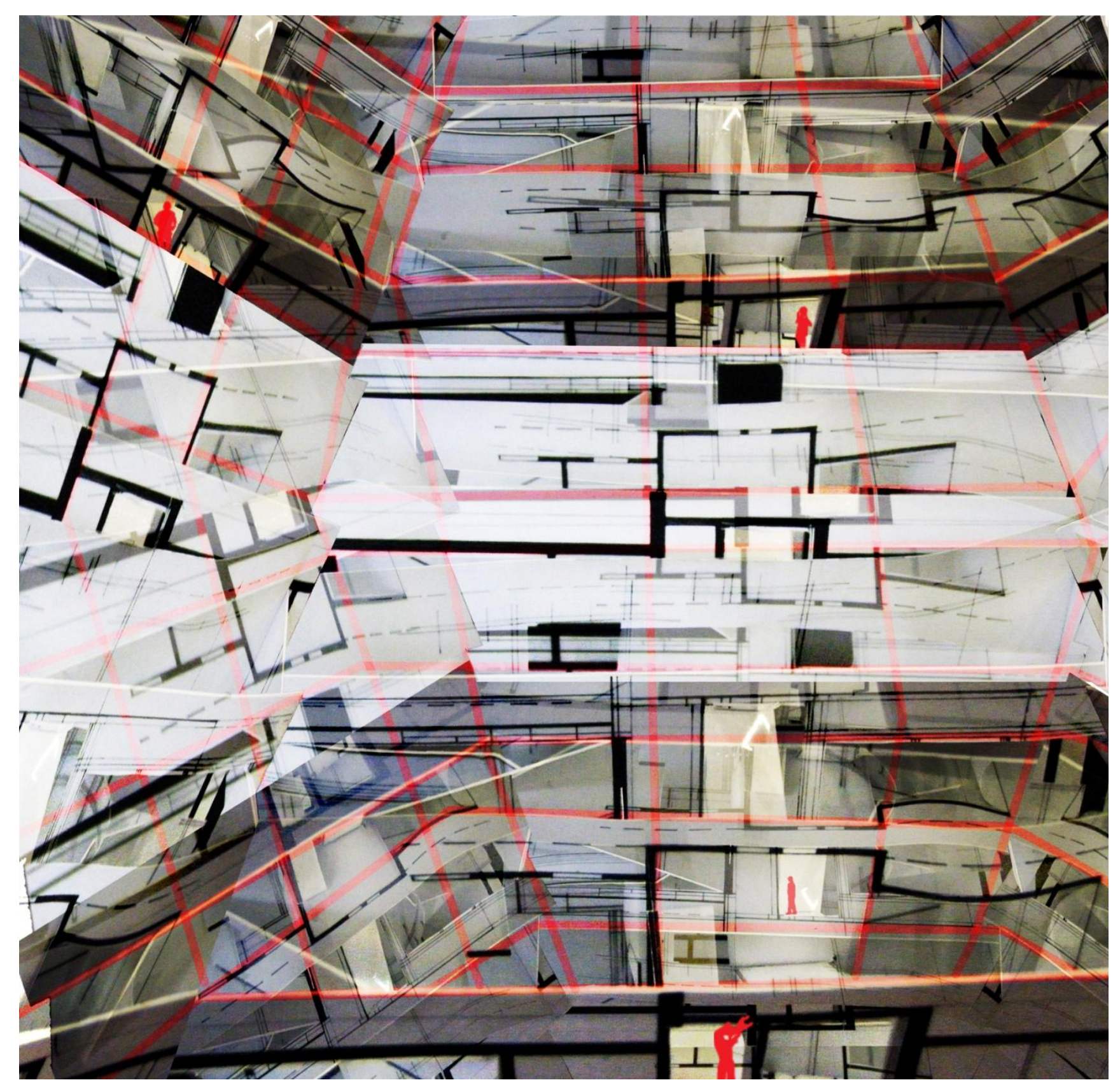

\section{Tessellation}

Here I attempted to arrange the images of the models so that they would form something like the hexagonal galleries described by Borges. In doing this, I have revealed another underlying structure which is highlighted by the grid overlay. Repetition is used again here, as well as indicators of scale. The instances of human habitation are separated across the void to imply the vastness and isolation of the library.

\section{FIGURE 26: TESSELATION}

Lee Kimber - Truth in Fiction: Storytelling and Architecture

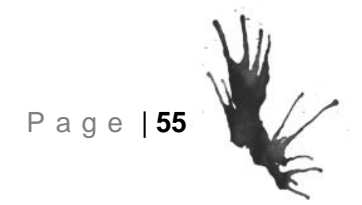




\section{The Perpetual Castle}

In The Castle, Franz Kafka uses the characters and the architecture of the setting to set up a labyrinth for the protagonist. He continuously struggles against the invisible barriers of the maze but he is never allowed to reach the Castle. For this series of images I concentrated on the cyclic and isolating qualities of the labyrinth.

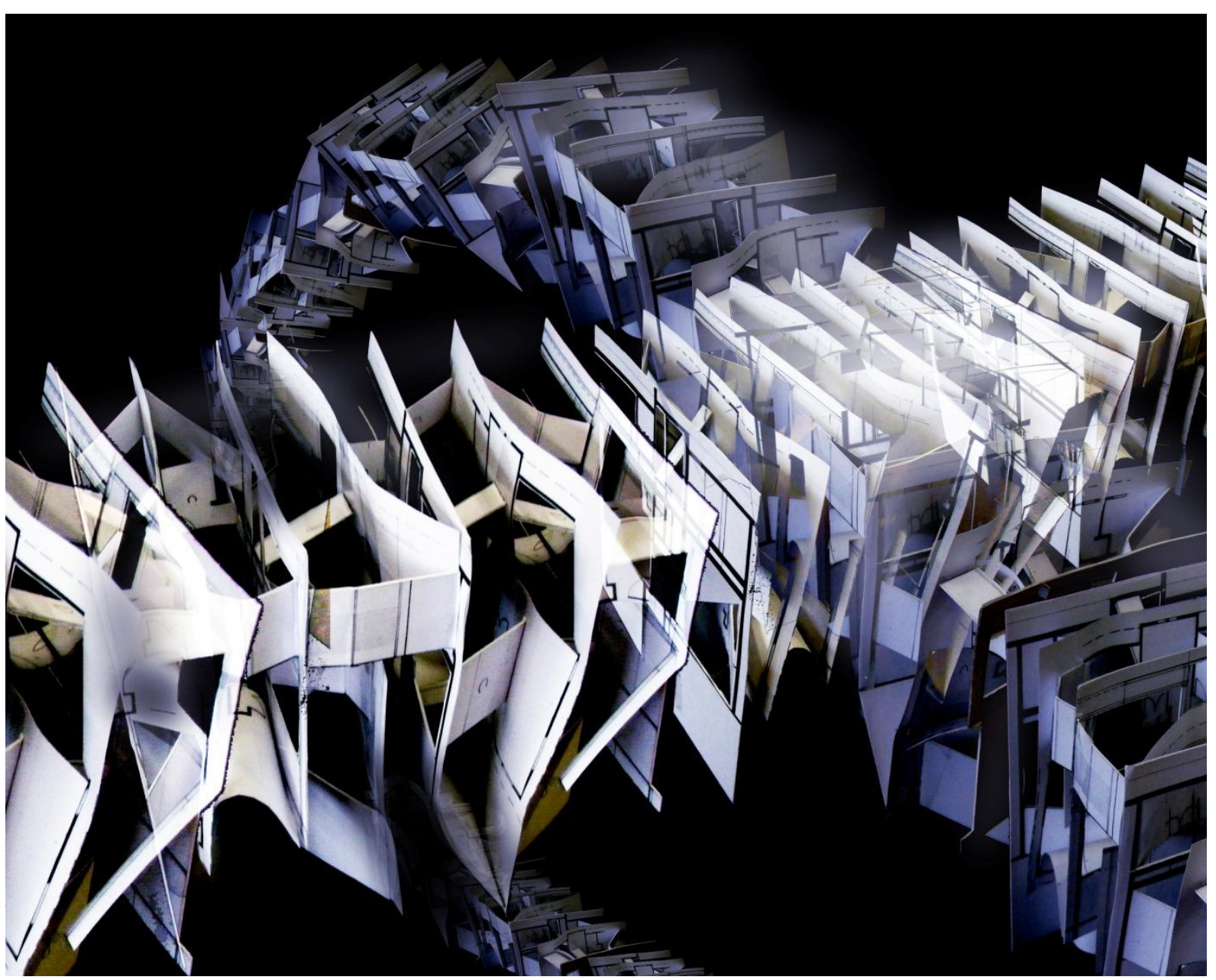

FIGURE 27: MOBIUS STRIP 1 


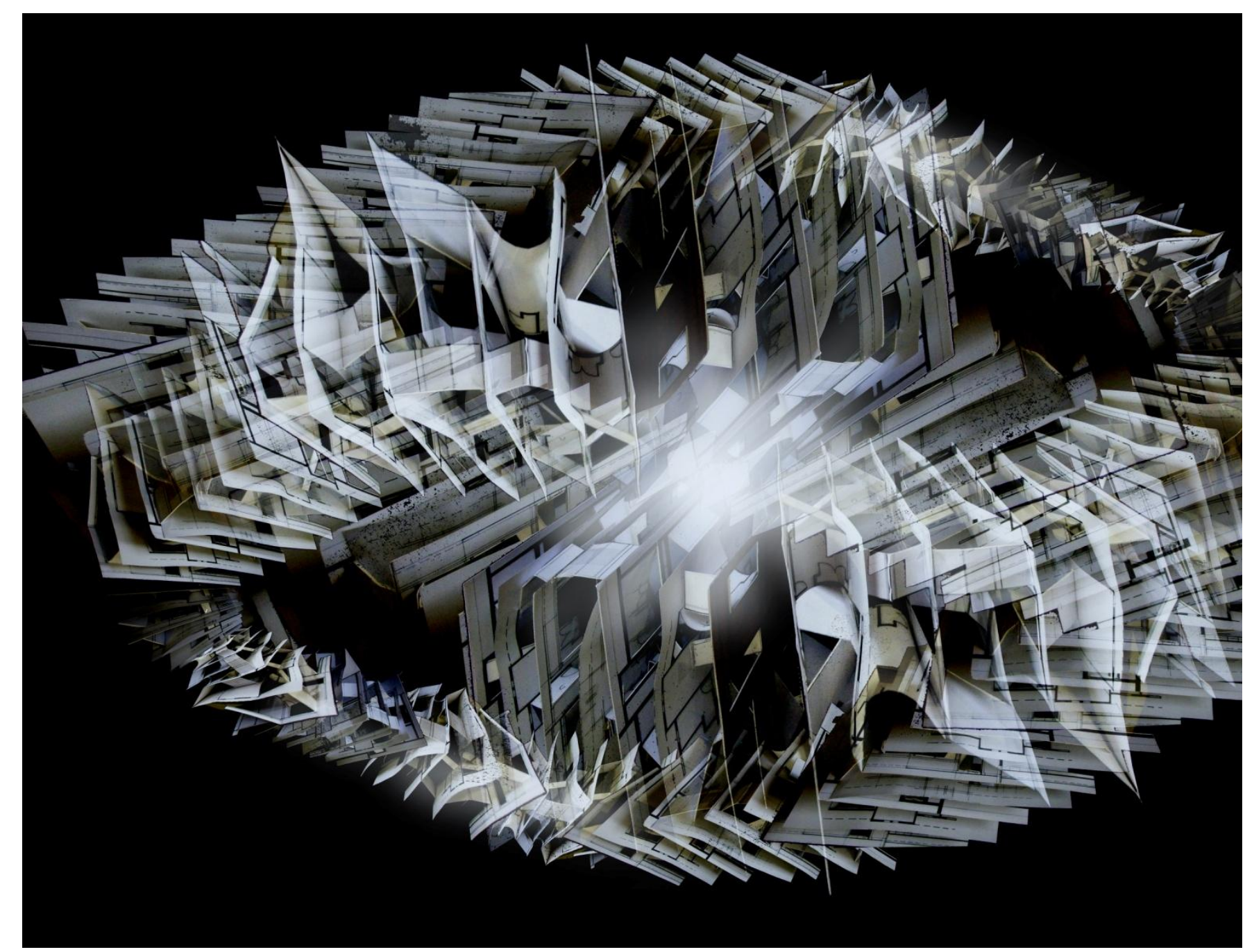

FIGURE 28: MOBIUS STRIP 2

Lee Kimber - Truth in Fiction: Storytelling and Architecture

\section{Mobius Strip}

These two images use overlapping images of the threshold models to imply an image of the Mobius strip, suggesting the continuous circular path of Kafka's labyrinth. At every step along that path, the vertical planes of the models create barriers to movement, and the blank background leaves no opportunity for escape. The light at the centre of the second image suggests a destination, but it is unclear whether this can be reached.

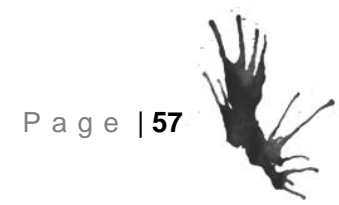




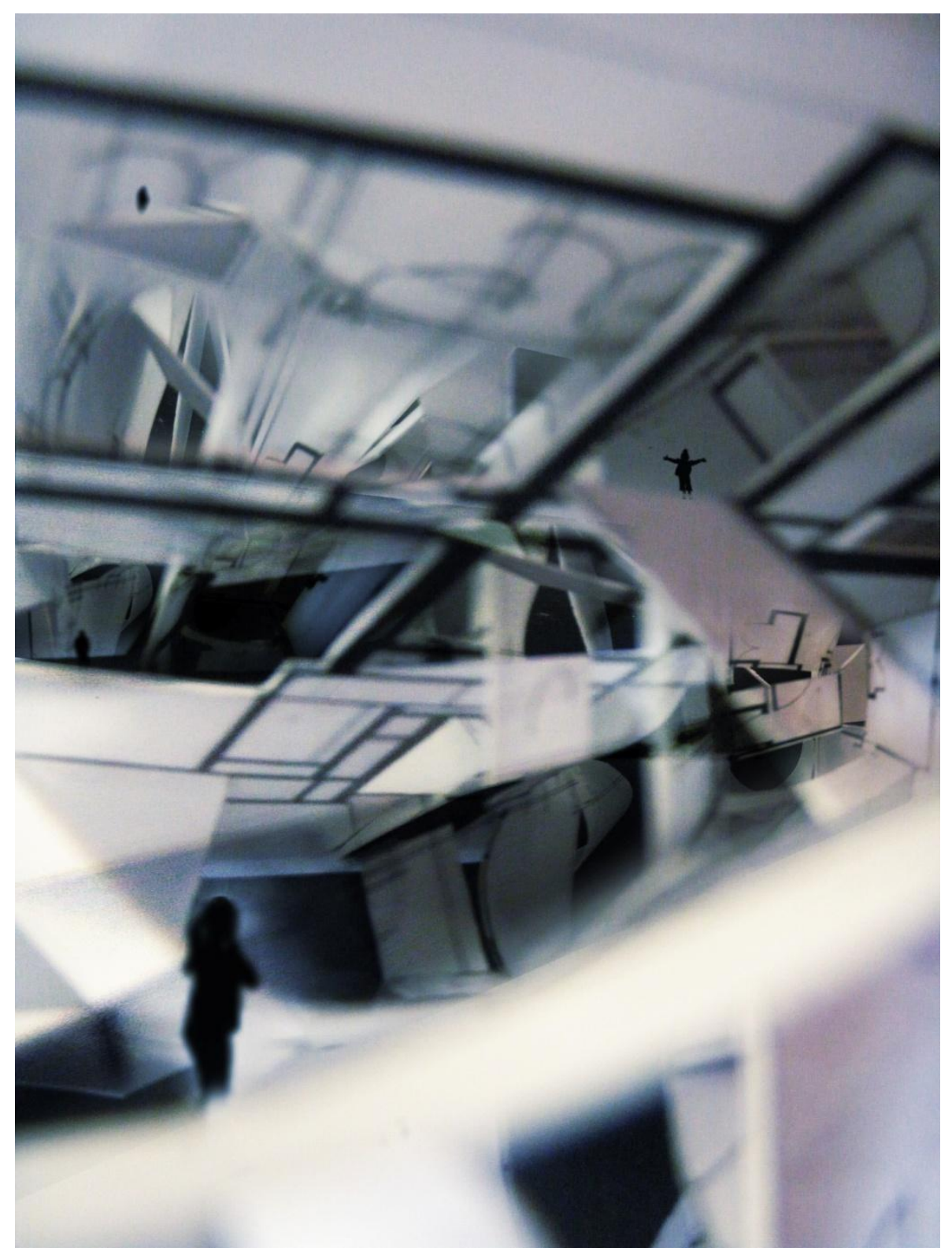

Isolation

Here I have used an image taken from inside one of the threshold models, using overlay techniques to separate the figures by erasing the pathways between them. The progression from the base of the image to the top is represented by the individual, isolated figures. It suggests a destination which they are striving to reach, however no pathway is visible which would complete their quest and there is no obvious end point which would signal the conclusion of movement through the space.

FIGURE 29: ISOLATION 


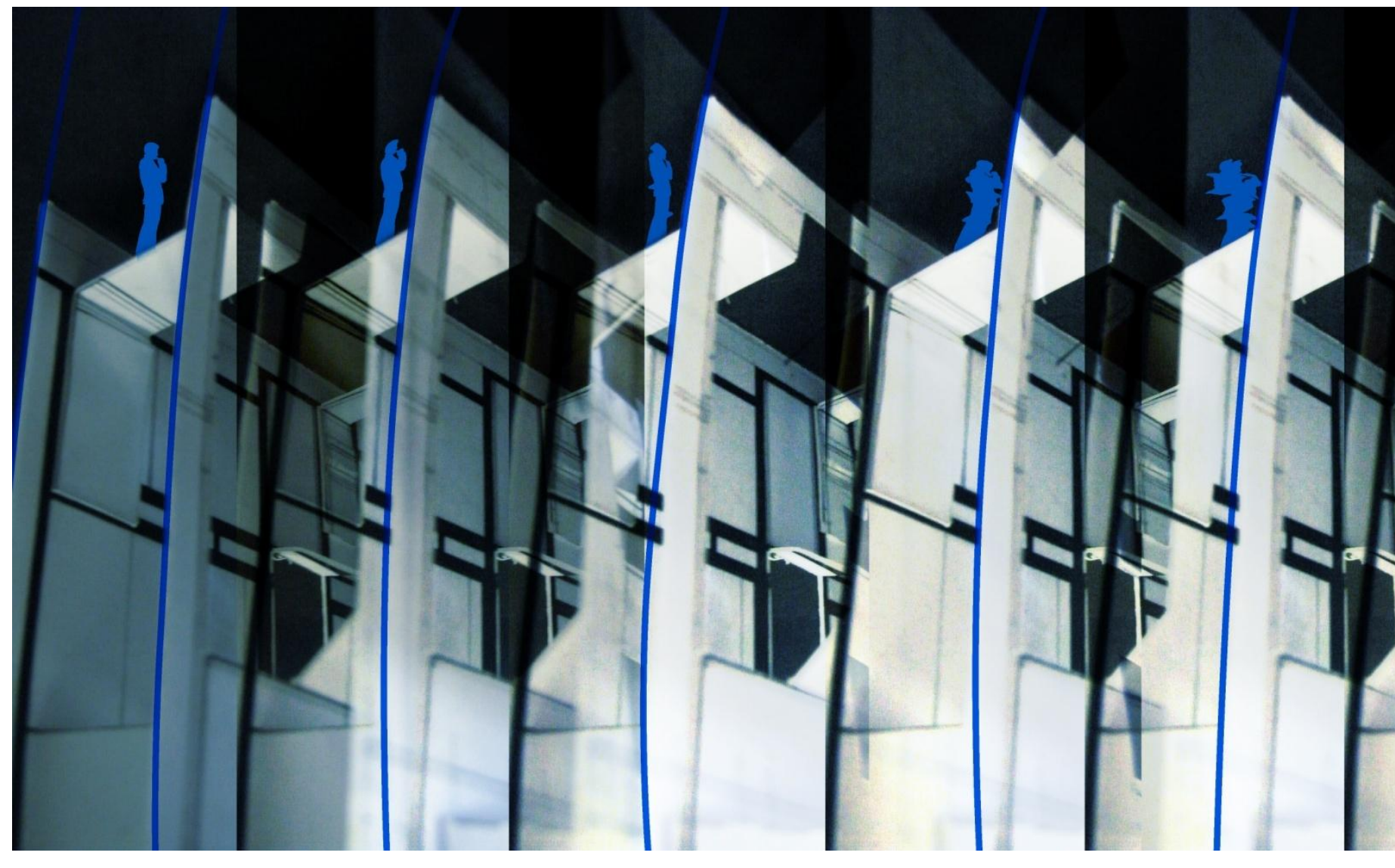

FIGURE 30: BARRIER

Barrier

This repetitive image uses the vertical planes of the threshold models to create obvious barriers to the movement of the figure. These barriers are emphasised through the use of blue lines. As the eye moves from left to right, the figure mutates to represent the changing of the labyrinth to fit the shape of the struggle. The light at the right of the image suggests an invisible destination, perpetually just out of reach. 


\section{Labyrinths of the Domestic}

The environment described in House of Leaves has interesting connotations in terms of the threshold models, as it is the only one of the three narratives on a domestic scale. This relates directly to the use of the $G J$ Gardner home in creating the threshold maps. For this series of images I decided to concentrate on recreating this domestic scale within the images as well as alluding to the mutable nature of the labyrinth. I also wanted to refer to the textual labyrinth constructed by Danielewski with his use of formatting and series of unreliable narrators.

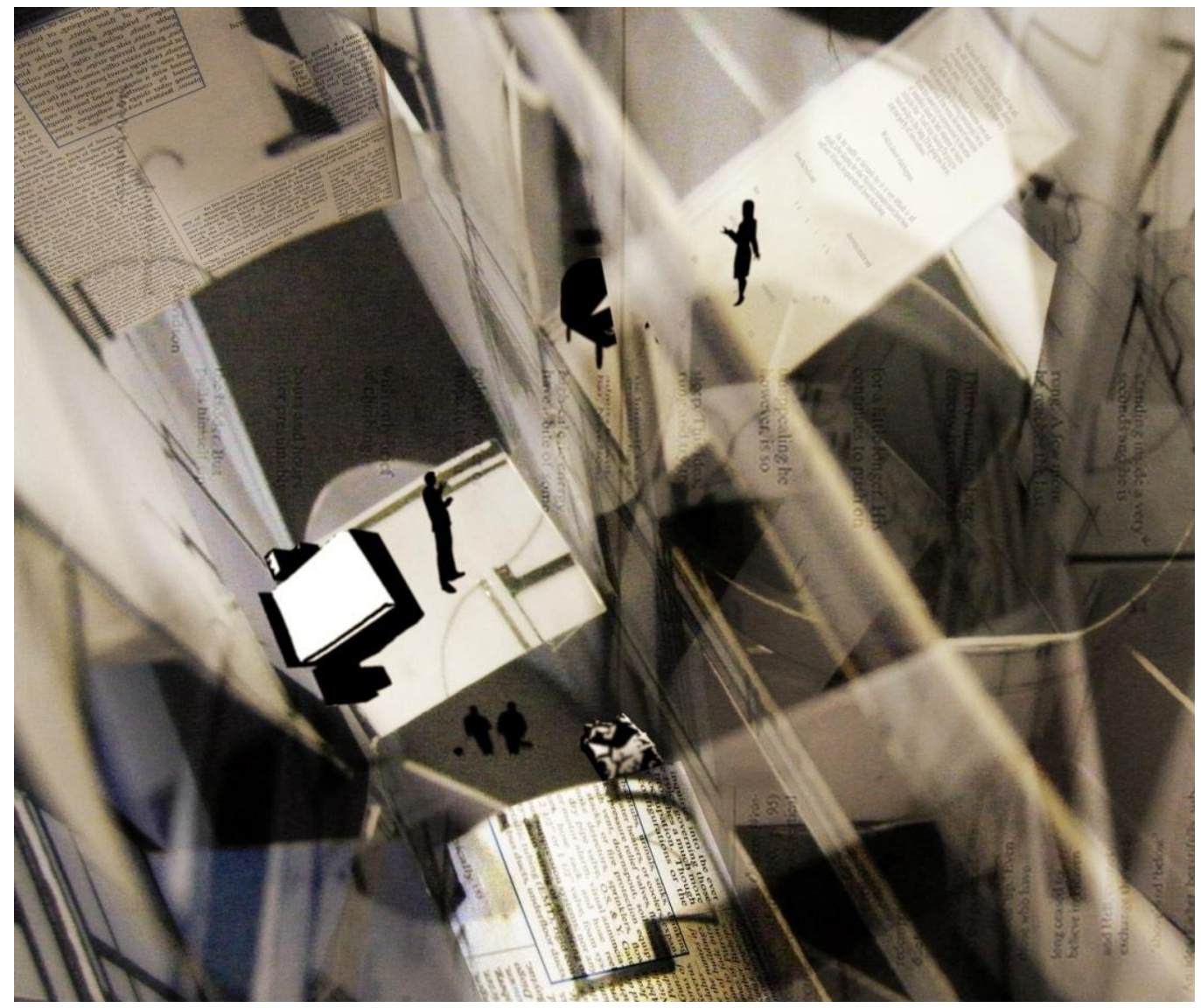

FIGURE 31: OVERLAYS

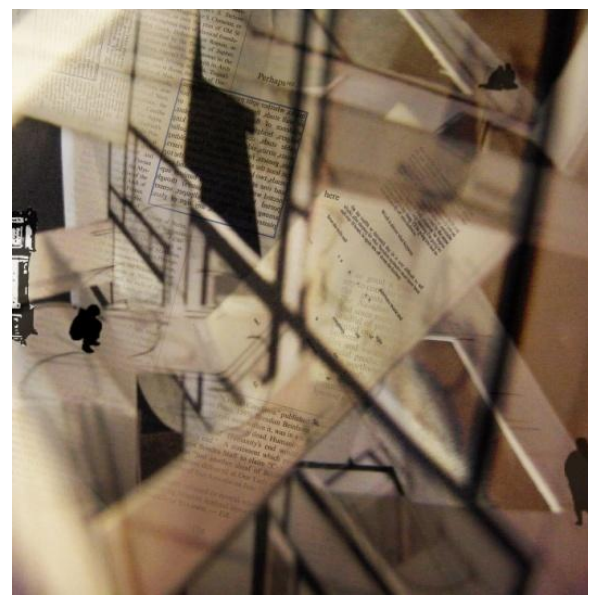

Overlays

The four images in this series were completed using a similar method. Two images of the interior of the model were overlaid to give a feeling of movement to the space. The depth of the image was exaggerated through the application of scaled figures and furniture which also alluded to the theme of the domestic. Finally, pages scanned from the book were overlaid on the planes of the model to reference the way the text has been used to construct the labyrinth within the novel. 


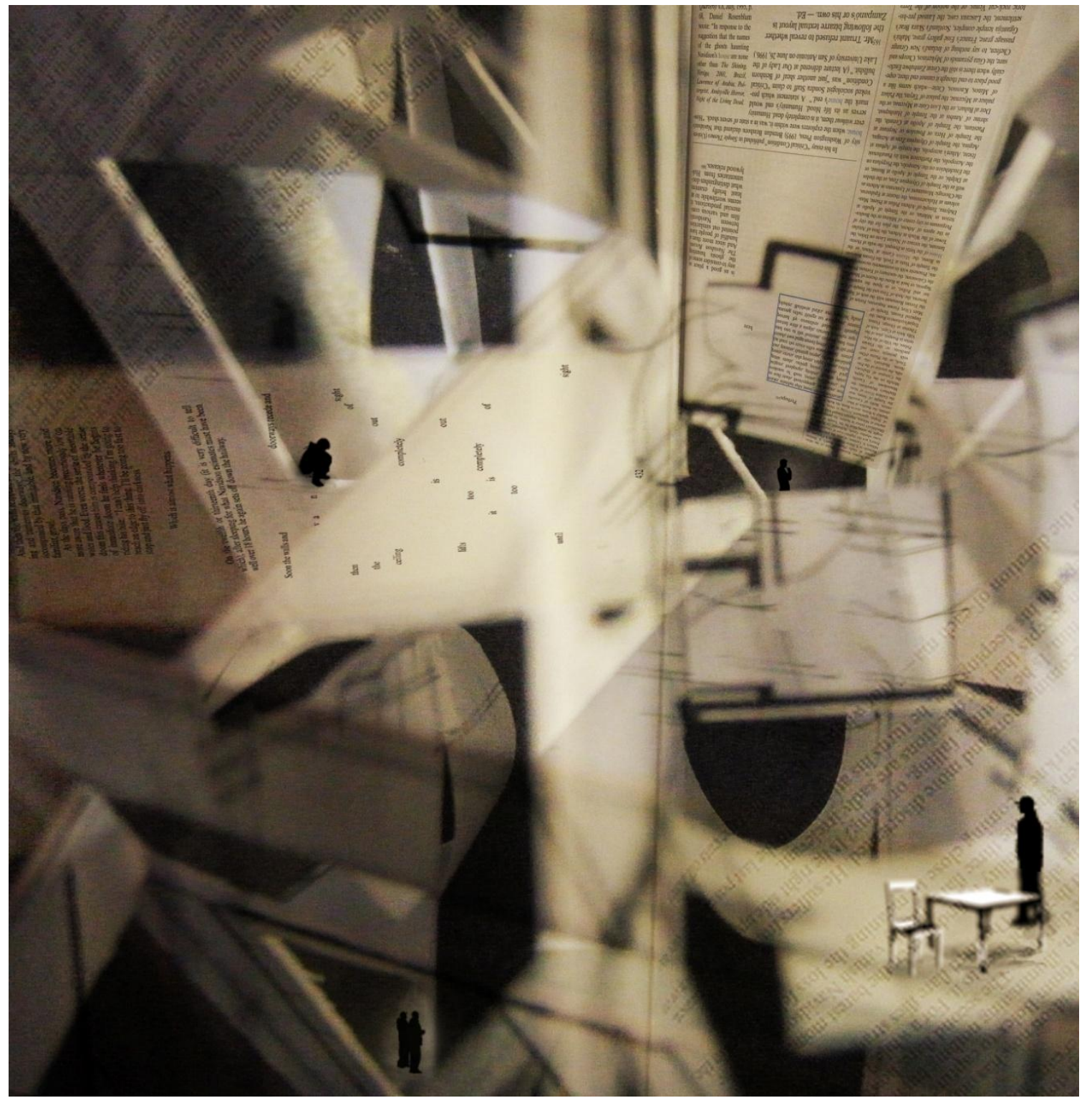

FIGURE 32: OVERLAY 2
The lines on the plans which are still visible in these images blend in with the text overlays to suggest new patterns and a new interpretation for the architectural conventions they represent. The labyrinths created by the overlays are sparsely inhabited with furniture, recalling the 'necessarily inhabited with furniture, recalling the 'necessarily Because of the ambiguity between what is solid and what is permeable, it is sometimes difficult to decide what is habitable space within the images. These details are left to the interpretation of the viewer. 


\section{Thames House Revisited}

The final series of images represents a return to the original scale of the home. It was important to reintroduce the threshold model back into the context of the house, as this would complete the cycle of storytelling from interpretation to a new narrative.

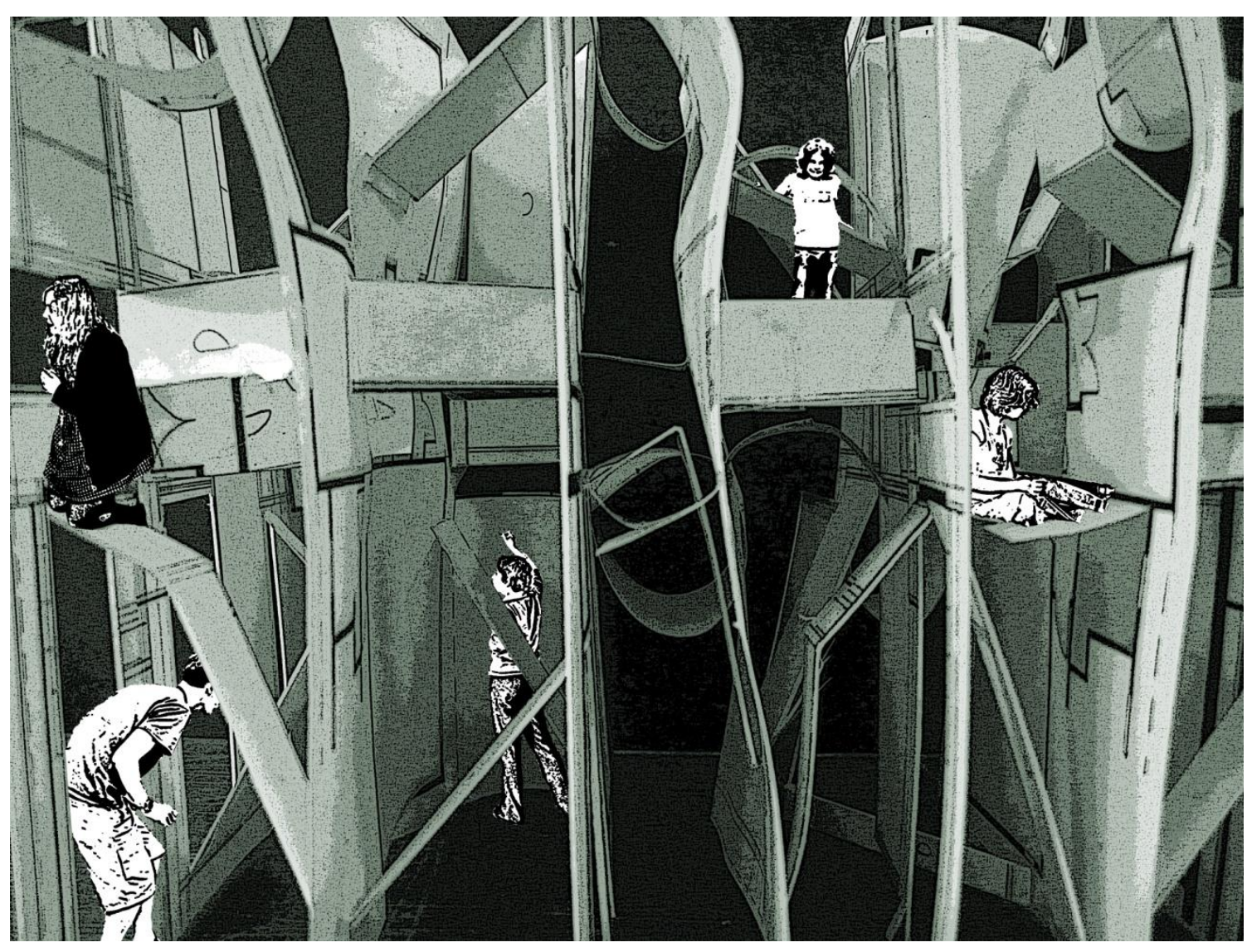

FIGURE 33: THAMES HOUSE OUTSIDE OF CONTEXT

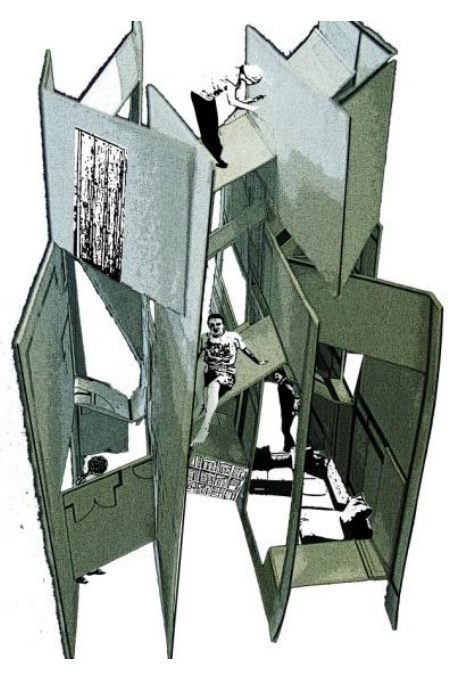

\section{Outside of Context}

These images use a familiar smaller scale and incorporate domestic furniture elements. I used more detailed figures from my own photos to represent the personal connection that these kinds of spaces will inevitably develop. The scale was such that it promoted exploring and a certain childlike quality to the interactions with it. Returning to a closer scale of human interaction promoted the interpretation of the various planes as bookshelves, hammocks and climbing frames. 


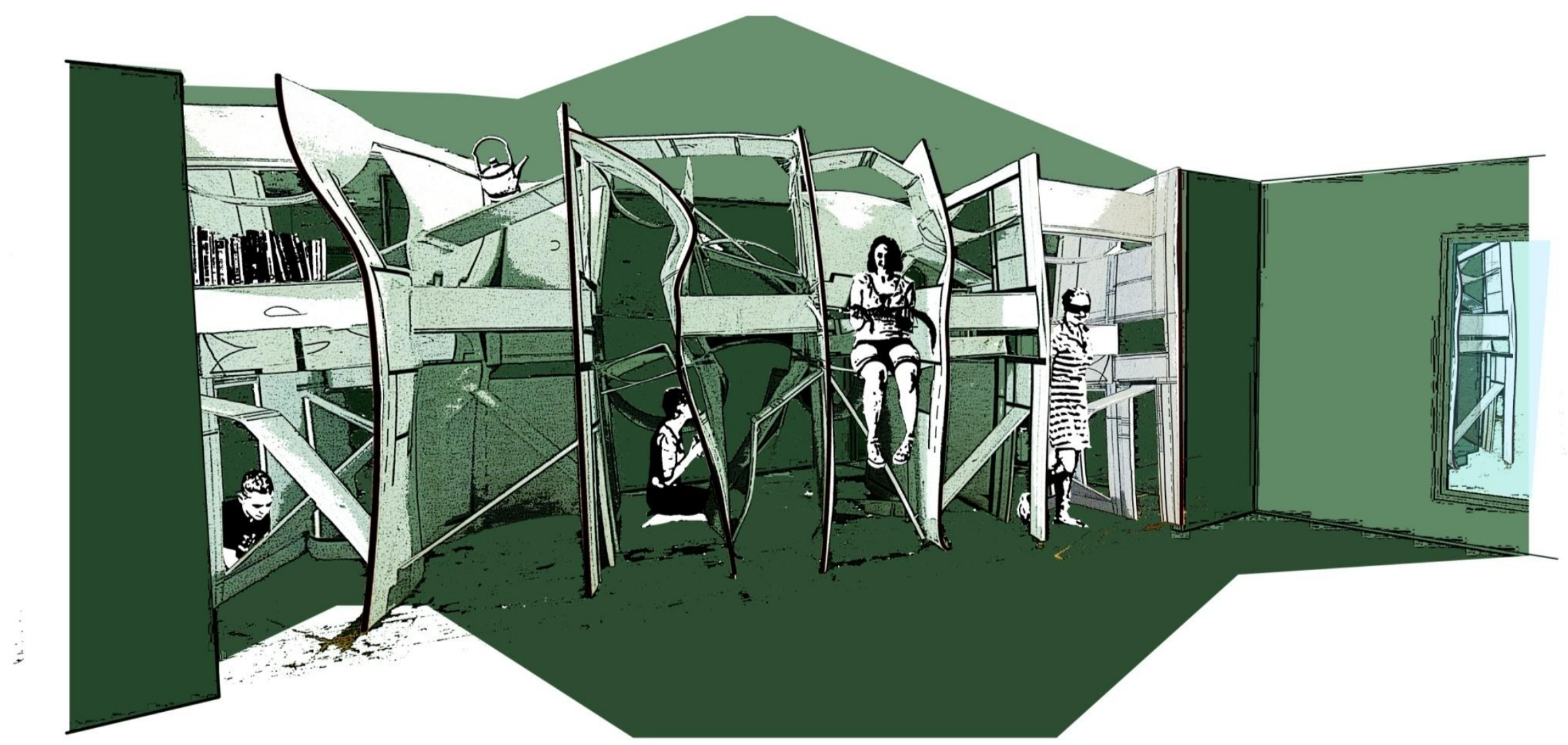

FIGURE 34: THAMES HOUSE REVISITED

Within Context

The final image shows the threshold model structure within the context of the original house, inhabiting the space left over by the initial restructuring of the plan. By favouring the vertical planes of the models, barriers were created which interrupted movement through the plan. The disruption to the way the house would normally be occupied gave it a new meaning in terms of programme. The installation of the intervention represents how the cycle of storytelling gives new meaning to the original narrative; updating it through interpretation. 


\section{Discussion and Critique}
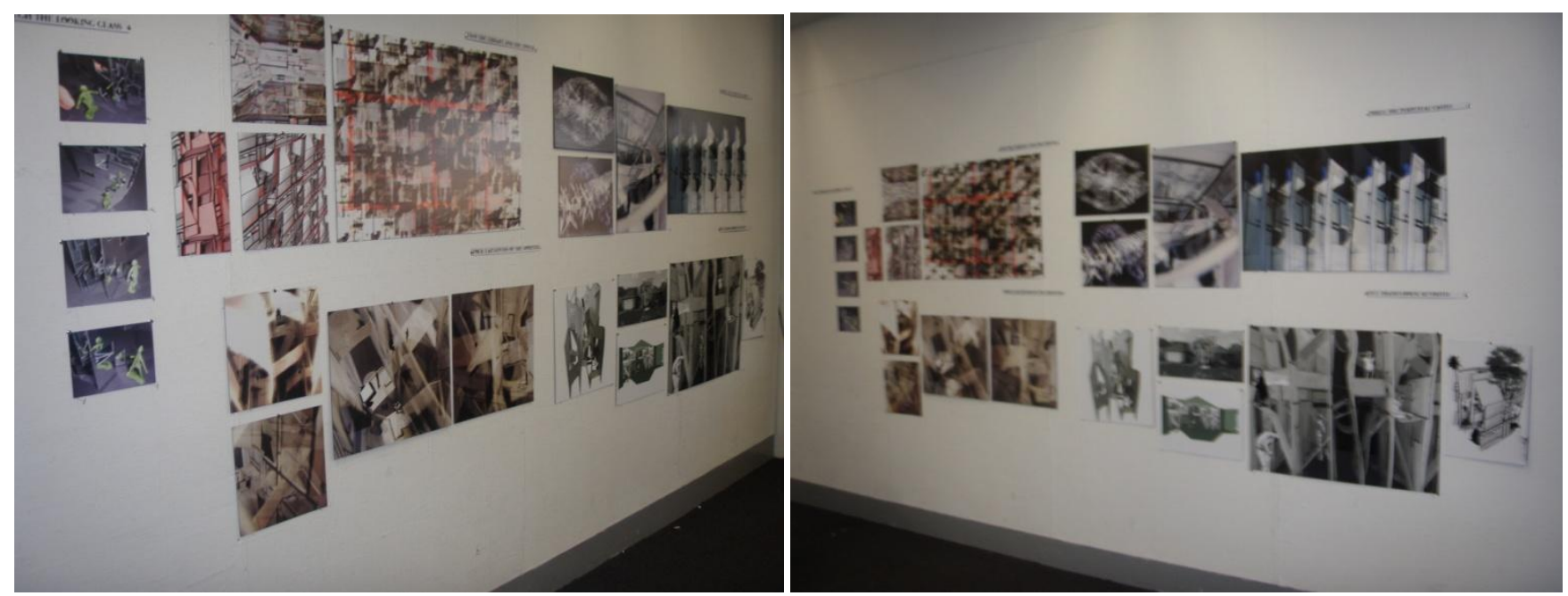

FIGURE 35: FORMAL PRESENTATION 26/10/2010

The creation of these images demonstrated that it was possible to carry out a non-linear narrative through architectural and visual mediums. Although the first three series of images refer to themes found within textual narratives, the process of reinterpretation has separated the themes from a textbased narrative and expressed them via a visual medium. These images and models do not rely on a sequenced narrative to become representations of their stories.

Throughout the creation of the images I have layered the various themes of the narratives as a visual representation of Benjamin's concept of layered meaning through storytelling ${ }^{6}$. Interpretation has been carried out by retelling the story through images. This shows that architectural mediums can be effective in reinterpreting stories both within this discipline and from other mediums.

There is a question of whether this kind of abstract work constitutes an architectural solution to the problem. As with the work of John Hejduk (which existed outside of the usual limitations set upon architecture by programmatic, site and financial concerns ${ }^{7}$ ), this work has few restrictions placed upon it except for those dictated by the narrative itself. It does, however, represent a step forward from 
Hejduk's Masques in that it is separated entirely from textual mediums and the need to explain itself. This was achieved by adopting a rule of 'show, don't tell' in the images. They are separate from the narratives which inspired them as they make no reference to specific characters or setting. While they represent core themes from the stories of those narratives, they do not rely on the structures used to contain their meaning. Although they may not yet constitute a functional 'architecture' they represent the product of a process which extracts storytelling from other sources and places it within built forms.

The images are still abstractions. Due to the nature of the original plan as an abstract representation of a house which would be further customised before being built, all interpretations of that plan remain abstract quantities. Furthermore the addition of fiction narratives adds to the ambiguity of the model structure, especially as these narratives use the labyrinth archetype which embodies endless interpretation.

The ambiguity present in these images could be lessened by the choice of an inhabited building at the beginning of the process, so that there is already a wealth of stories associated with its representation. These could then be reinterpreted through this kind of exploration. However for the purposes of this research, it was more interesting to me to find out if I could apply storytelling to a blank canvas, so that I could combine the image with my interpretations of the fiction narratives I had studied. The floor plan of Thames house used had enormous potential as an interpretive object, both due to its domestic programme and its nature as an architectural commodity. A more specific meaning might have resulted if I had applied this process to my childhood home, or to the New Zealand bach; structures which embody a wealth of stories as built.

The architectural implications of this research show that storytelling through architecture can be achieved, and that the built form viable as a method of reinterpreting stories. The narratives found in the final images are not linear, relating to the actual experience of space. However the process of storytelling itself is a linear one, as it is a sequence of reinterpreting thematic elements of the narrative. The important result of my research was to realise that the story itself is ambiguous, and should remain open to reinterpretation by those who would inhabit the space.

Conceptually, narrative within architecture should be considered as something which will change ${ }^{8}$. The narrative is that which structures a particular interpretation of the story; and yet, unlike the structure of a building, it will not remain if a new interpretation is applied. Buildings will always change with time, and narratives must change with them. As the definition of space within architecture constitutes a much more immediate experience of the architect's ideal than the use of a more ambiguous medium 
such as fiction, we must be careful to allow for new interpretation to occur within our buildings. This is not to assume that there is no room for our own intent ${ }^{9}$, as to give too many opportunities for interpretation would be to create an infinite prison of choices: a labyrinth.

The built form is a vehicle for the creative interpretation of stories, and buildings will attract more stories as they move through their lifetime. The separation of story and narrative within the architect's vocabulary allows us to understand that the application of narrative should not result in a linear organisation of space. A narrative design process might be linear, but the experience of space will ultimately be more chaotic than this. A linear narrative is lost to the understanding of space, being as this comes from a place of collected knowledge combined with immediate experience.

The use of design to uncover this process has managed to separate an architectural interpretation from the textual narrative it comes from. Reconceptualising the plan as an object which can be reinterpreted gave the option of making images which might be understood through many new interpretations.
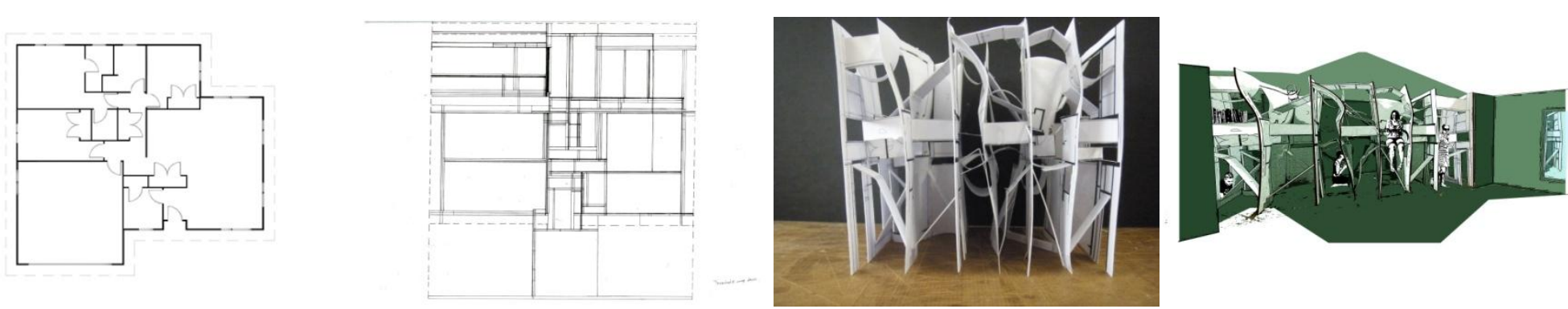

FIGURE 36: PROCESS OF REINTERPRETATION 
${ }^{1}$ Sophia Psarra, Architecture and Narrative: The Formation of Space and Cultural Meaning (New York: Routledge, 2009) p87.

${ }^{2}$ Alexander, p174.

${ }^{3}$ G J Gardner New Zealand, G.J. Gardner - New Zealand's Favourite Home Builders, 2010, Graphic

Cafe, Available: http://www.gjgardner.co.nz/cms/, August 2010.

${ }^{4}$ Benjamin, p6.

${ }^{5}$ Tschumi, p192.

${ }^{6}$ Benjamin, p6.

${ }^{7} \mathrm{Chi}, \mathrm{p} 83$.

${ }^{8}$ Hollis, p14.

${ }^{9}$ Alexander, p37. 


\section{CONCIUSION}

The aim of this research was to discover how the process of storytelling derived from the oral tradition might be adapted to architectural narratives. The experience of architecture is layered and non-linear, therefore the use of narrative as a sequencing tool does not relate to how stories will be understood from the perspective of the inhabitant. In storytelling, the interpretation of the audience ensures the ongoing cycle of the story. To recreate this interpretation within the process of designing and building would give the concepts which drive architecture more longevity, as they can be adapted over time.

In the introduction, there were two questions which guided the course of this research. The first was concerned with the preconception of narrative as a sequencing tool in regards to space, and how this affects the ability of users to construct their own personal understanding of architecture. The second was in regards to whether architecture could express narrative intent while still encouraging the opportunity for the addition of new interpretations from the users. Through the analysis of case studies and design experiments I have argued that both of these questions can be answered through the application of a non-linear narrative which responds to new interpretations and evolves into a story which obtains new meanings as it is retold.

Through the course of this research, I have argued that storytelling is a natural process of communicating abstract concepts. The initial step of defining a separation between the story and the narrative allowed me to review the current approach of applying narratives to architecture. Seeing narrative as a structuring tool for the representation of a story meant that architectural narratives as they are applied by architects might adapt over time, yet the retention of the story within the built work is not threatened by this change. Instead, constant reinterpretation of the story allows the architecture to gain new meanings.

Understanding the narrative as a single interpretation of a story changed the way I approached the analysis of the case studies. I wanted to see how much these narratives relied on interpretation of a theme, and how they expressed the nature of this interpretation. In the example of John Hejduk's Masques, interpretation was encouraged through the combination of textual and visual media. The 
use of poetry and written narratives alongside the images makes it necessary to read between the two in order to piece together the characters contained within the architecture. However the link to the text was so strong that the architecture failed to become self-referential and therefore could not generate further architectural stories.

In the written narratives I studied, the architectural metaphor drives the plot. The architecture of the labyrinth raises the question of autonomy within a realm of endless interpretations. The labyrinth constrains as much as it provides a large number of paths to choose from. The ambiguity and repetitive nature of the labyrinths in these narratives create an environment where the characters are contained by their own autonomy. Too many possibilities create an arbitrary environment which does not allow for any assignation of meaning. Some hope of leaving the labyrinth must be created to give purpose to the actions of the characters. It is left to the reader's interpretation as to the extent of the labyrinth and the nature of the centre towards which the characters strive. These analyses suggested the importance of understanding the limits of interpretation, and the need to provide some meaning within an environment.

The design phase of the research began with the exploration of how interpretation of a narrative might evolve through images rather than through text. Using an analysis of inkblots inspired by the use of the Rorschach test, the development of a process for reinterpretation began to appear. The use of architectural orthographic conventions such as line weights allowed for the application of a narrative which did not manifest as linear. However the abstract nature of the blots resulted in limitless interpretation opportunities, which led to an arbitrary application of the narrative. Due to this, the reinterpreted inkblots resisted attempts to shift into a spatial narrative.

The process uncovered by the inkblot experiments was then applied to an architectural representation: the floor plan of a generic design-build home. The choice of this particular floor plan allowed there to be a blank canvas as a starting point to the reinterpretation, while still beginning with a built object which could suggest an architectural solution. I began by investigating the thresholds and changing their extent as lines on the plan. I then translated these threshold maps into the three-dimensional threshold models, which reinterpreted the thresholds as lines which could negotiate movement on more than one plane.

The models created architectural spaces which served as a base for the application of narratives from the three fictions studied. These abstract images translate narrative into a spatial construct and 
remove the sequencing of narrative found in fiction. There are possibilities for audience interpretation within these images.

What has been revealed, through research and through the development of the design process, is that the application of narrative to architecture can be approached from a non-linear perspective which privileges the interpretation of the inhabitant. Reinterpretation of the narrative does not dilute the conceptual framework of the story. In fact, the ability of the user to reinterpret the work in new ways will strengthen the personal understanding of the spaces. The design phase of this research reinterpreted architectural representations to create new architectural understanding of narratives within space. By doing this, the design process reflected the storytelling process by creating new work out of reinterpreting existing stories.

Storytelling is a process whereby the conceptual framework of architecture gains legibility (through an improved personal understanding of space), durability (through a continuous cycle of preservation through change) and continued relevance (through adaptation to the changing fashions and sensibilities of society). This research has shown that architecture is capable of representing nonlinear narratives which allow for new interpretations of spatial concepts. By looking to the cycle of the story, which takes on new life as it is reinterpreted by the audience, I have seen that architecture can be enriched by applying narratives to be reinterpreted over time.

This use of narrative affords architecture with longevity in the face of a changing world, allowing every new inhabitant to add their own layer of meaning to the underlying story and in return gain a personal understanding of the spaces around them. The key benefit of the storytelling process is that by adapting concepts through new interpretations, the ideas within a work are constantly being refined. By applying storytelling processes to our architecture we not only improve upon our understanding of design but also our experiences of existing environments.
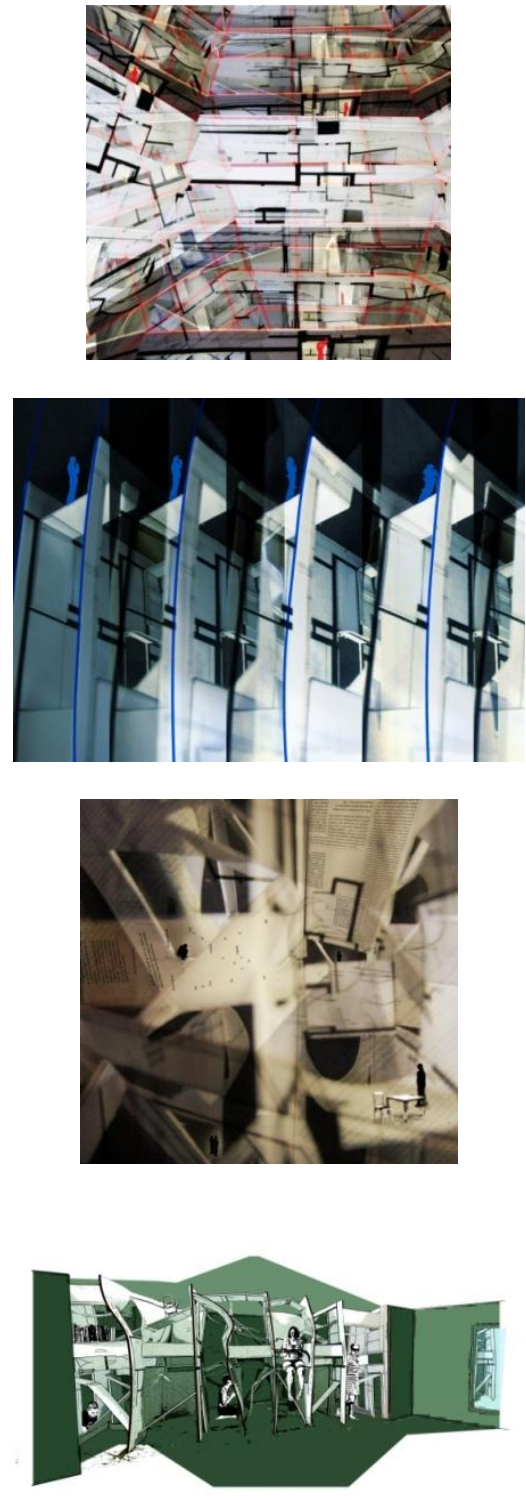

$P$ a g e $\mid 70$ 


\section{BIBI IOGRAPHY}

Alexander, Christopher. The Timeless Way of Building. New York: Oxford University Press, 1979.

Baldick, C. "The Oxford Dictionary of Literary Terms." Oxford: Oxford University Press, 2004.

Bemong, Nele. "Exploration\# 6: The Uncanny in Mark Z. Danielewski's House of Leaves." Image and Narrative. No.5 (2003).

Benjamin, Walter. "The Storyteller." Illuminations: Essays and Reflections. New York: Schocken Books, 1969. Print.

Bloch, William Goldblom. The Unimaginable Mathematics of Borges' Library of Babel. New York: Oxford University Press, 2008.

Borges, Jorge Luis. "The Library of Babel." Trans. Editores, Emece. Ficciones. New York: Grove Press, 1962. Print.

Chi, Lily. "Narration and the Architectural Program: The 'Mythical' Status of Architectural Fictions." Writing/History/Architecture/Myth. Ed. Linzey, Michael. Auckland, New Zealand: The University of Auckland, 1991. 79-86. Print.

Danielewski, MZ. Mark Z. Danielewski's House of Leaves. New York: Pantheon Books, 2000.

Doob, PR. The Idea of the Labyrinth from Classical Antiquity through the Middle Ages. Ithaca: Cornell University Press, 1990. 
Evanovich, J, Yalof, IL, and Evanovich, A. How I Write: Secrets of a Bestselling Author. New York: St. Martin's Griffin, 2006.

Frisch, Mark. You Might Be Able to Get There from Here: Reconsidering Borges and the Postmodern. Madison, N.J: Fairleigh Dickinson University Press, 2004.

G J Gardner New Zealand. "G.J. Gardner - New Zealand's Favourite Home Builders". 2010. Graphic Cafe. August 2010. <http://www.gjgardner.co.nz/cms/>.

Gill, Roma, ed. Romeo and Juliet. Oxford: Oxford University Press, 1998. Print.

Goldberger, Paul. Why Architecture Matters. New Haven: Yale University Press, 2009.

Hejduk, John. Mask of Medusa. New York: Rizzoli International Publications, 1985.

Hejduk, John. The Lancaster/Hanover Masque. London: Architectural Association, 1992.

Hejduk, John. Victims: A Work. London: Architectural Association, 1986.

Hill, J. Occupying Architecture: Between the Architect and the User. New York: Routledge, 1998.

Hollis, Edward. The Secret Lives of Buildings. New York: Metropolitan Books, 2009.

Hsu, Jeremy. "The Secrets of Good Storytelling: Why We Love a Good Yarn." Scientific American Mind. Vol 19, No 4 (2008): pp46-51.

Kafka, F, Bell, A, and Robertson, R. The Castle. Oxford: Oxford University Press, 2009.

Kafka, Franz. The Castle. 1926. Trans. Underwood, J. A. London: Penguin Books, 2000. 
Kern, Hermann. Through the Labyrinth: Designs and Meanings over 5,000 Years. New York: Prestel, 2000.

Knapp, Bettina L. Archetype, Architecture, and the Writer. Bloomington: Indiana University Press, 1986.

Krier, L, Thadani, DA, and Hetzel, PJ. The Architecture of Community. Washington, DC: Island Press, 2009.

Leslie, Alan M. "Pretense and Representation: The Origins Of "Theory of Mind"." Psychological Review. Vol 94, No 4 (1987): pp412-26.

Lillenfield, Scott O., Wood, James M., and Garb, Howard N. "What's Wrong with This Picture?" Scientific American Mind. Vol 284, No 5 (2005): pp80-88.

McGregor, James. "The Architect as Storyteller: Making Places in John Hejduk's Masques." Architectural Theory Review. Vol 7, No 2 (2002): pp59-69.

Mitrovic, Branko. "Architectural Formalism and the Demise of the Linguistic Turn." Log. No 17 (Fall 2009): pp17-25.

Olsen, Lance. "Diagnosing Fantastic Autism: Kafka, Borges, Robbe-Grillet." Modern Language Studies. Vol 16, No 3 (1986): 35-43.

Premack, David, and Woodruff, Guy. "Does the Chimpanzee Have a Theory of Mind?" Behavioral and Brain Sciences. Vol 1, No 4 (1978): 515-26.

Prose, F. Reading Like a Writer: A Guide for People Who Love Books and for Those Who Want to Write Them. New York: Harpercollins, 2006. 
Psarra, Sophia. Architecture and Narrative: The Formation of Space and Cultural Meaning. New York: Routledge, 2009.

Quine, WVO. Quiddities: An Intermittently Philosophical Dictionary. Cambridge, Mass: Belknap Press of Harvard University Press, 1987.

Rahmani, Ayad. "Rooms and the Question of Return in Kafka's Work." Built Environment. Vol 31, No 1 (1978): 70-78.

Reber, AS. The Penguin Dictionary of Psychology. New York: Penguin Books, 1985.

Rosen, Harold. Stories and Meanings. Sheffield, UK: National Association for the Teaching of English, 1985.

Rukeyser, Muriel. The Speed of Darkness. New York: Random House, 1968.

Thompson, Colin. How To Live Forever. London: Random House, 1996.

Tschumi, Bernard. Architecture and Disjunction. Cambridge, Mass: MIT Press, 1996.

Wigley, Mark. "The Translation of Architecture, the Production of Babel." Assemblage. Vol 8 (1989): pp6-21. 